\title{
In Business with God: \\ The Role of Religion in the Private Sector of Apia, Samoa
}

BY

\section{GABRIEL JANE THOMSON BUSH}

A thesis submitted to Victoria University of Wellington in partial fulfilment of requirements for the degree of Master of Development Studies

School of Geography, Environment and Earth Sciences

Victoria University of Wellington

2019 


\section{Contents}

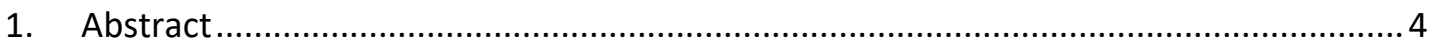

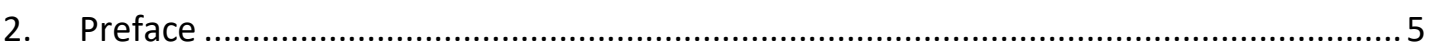

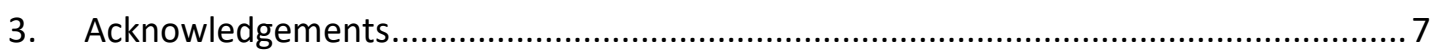

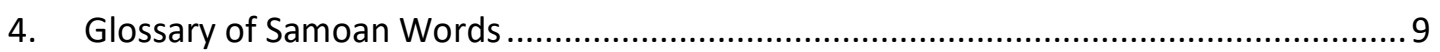

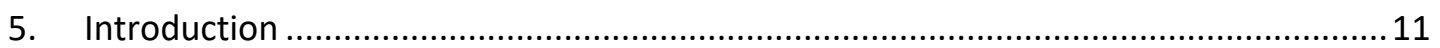

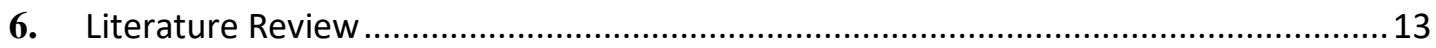

6.1 Capitalism, Globalisation and Economic Development in the Developing World....... 14

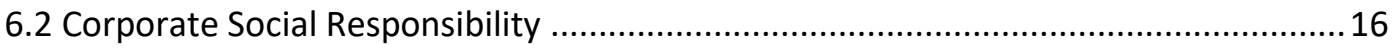

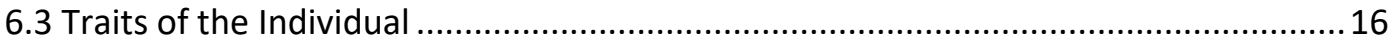

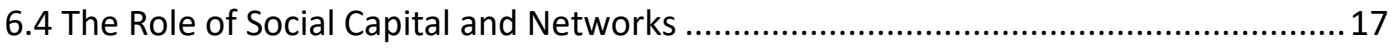

6.5 The Cultural Impact of Economic Drivers in Developing Countries ............................ 21

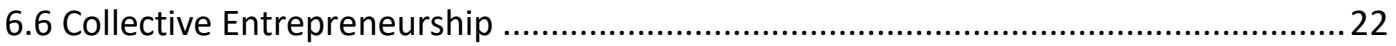

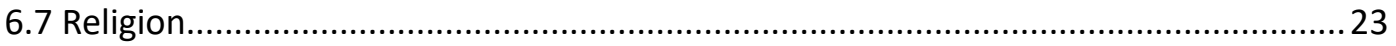

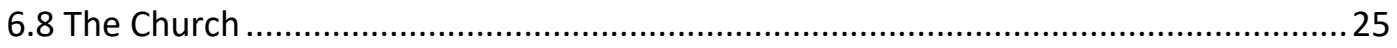

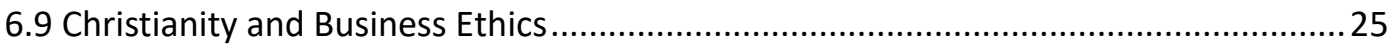

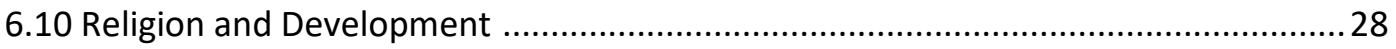

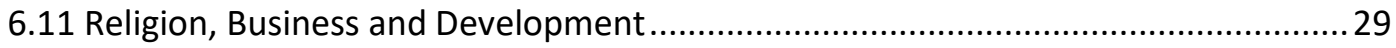

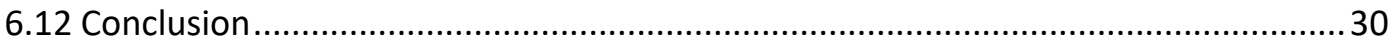

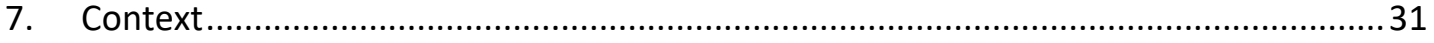

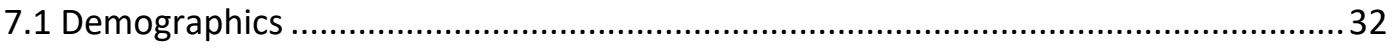

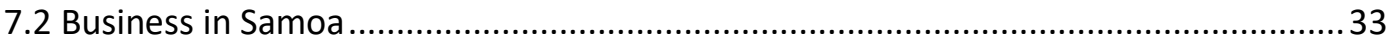

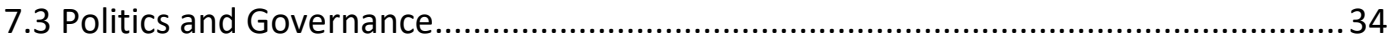

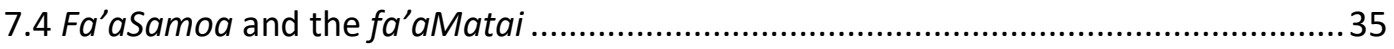

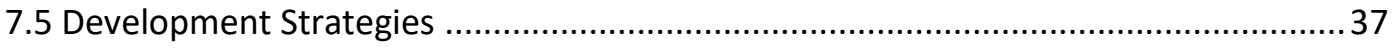

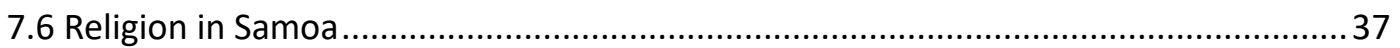

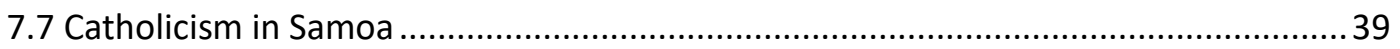

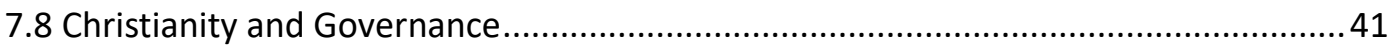

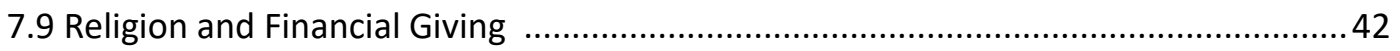

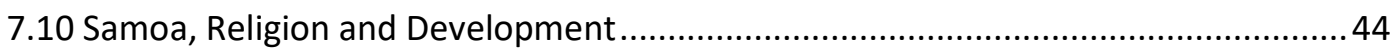

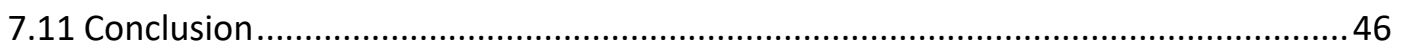

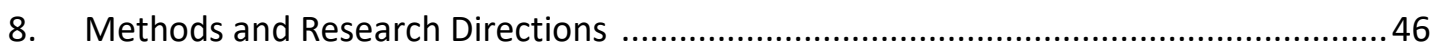

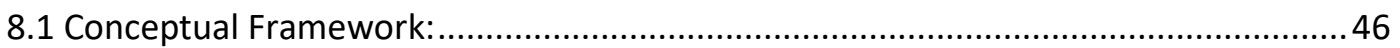

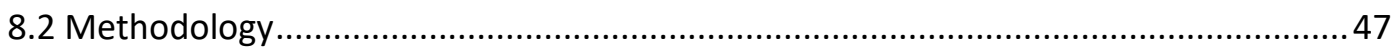

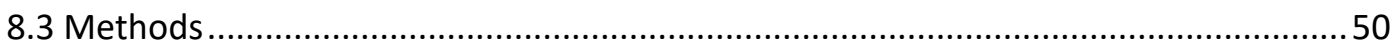




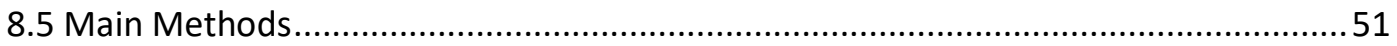

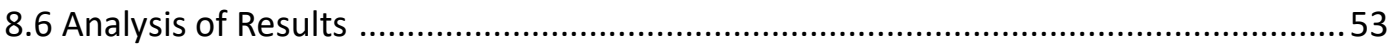

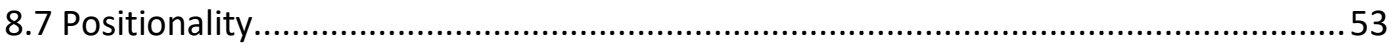

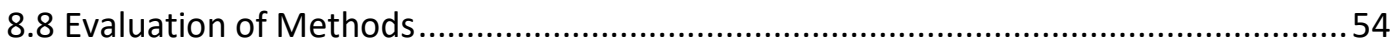

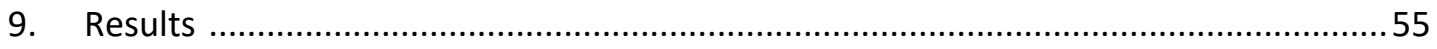

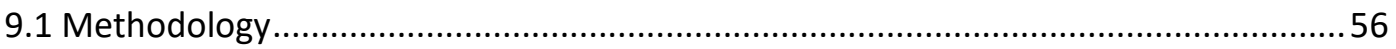

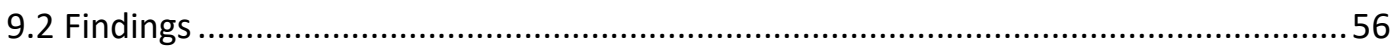

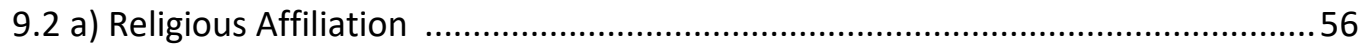

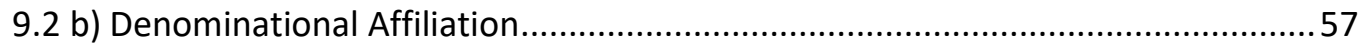

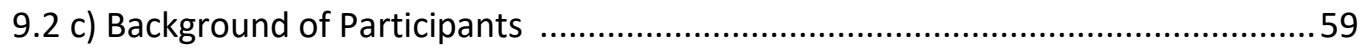

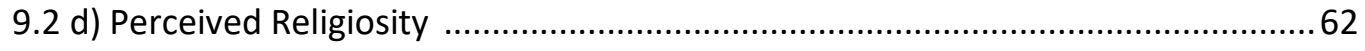

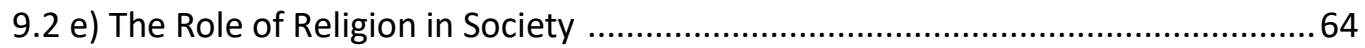

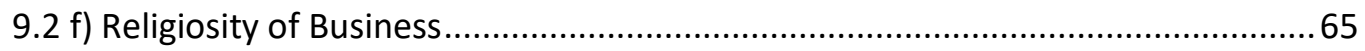

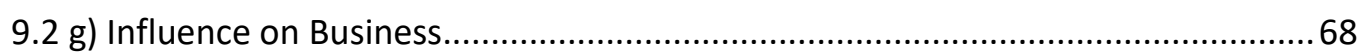

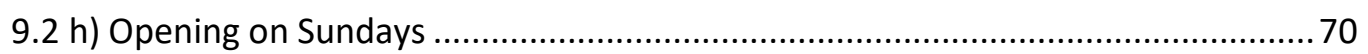

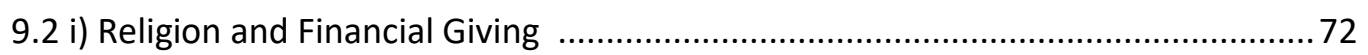

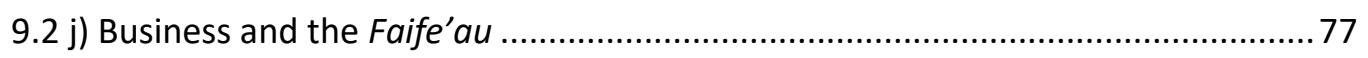

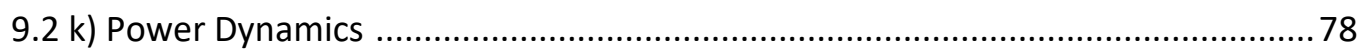

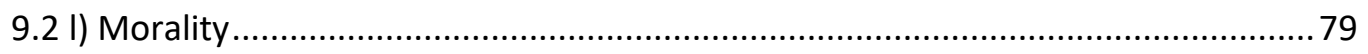

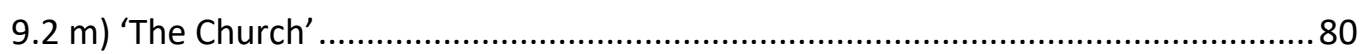

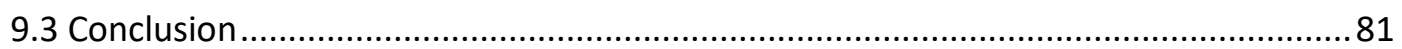

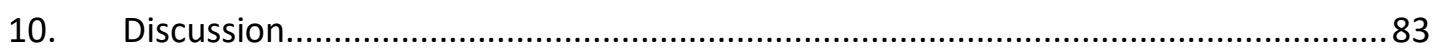

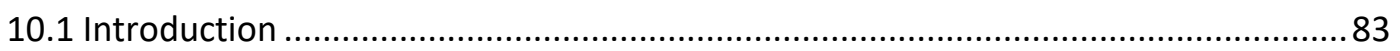

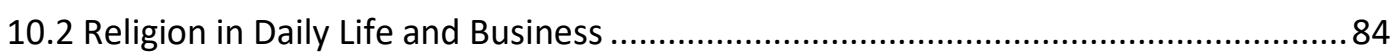

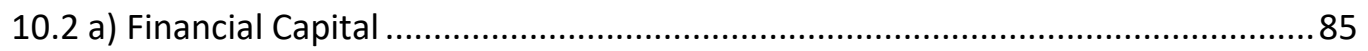

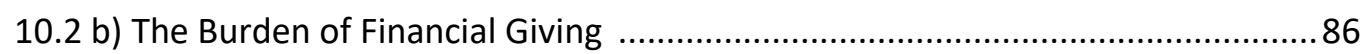

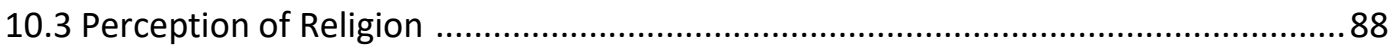

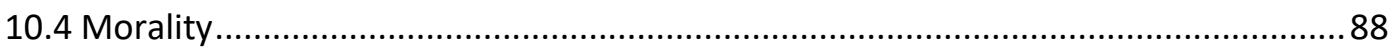

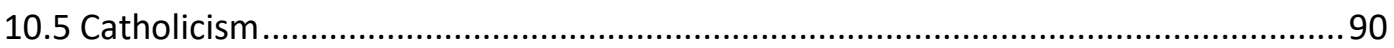

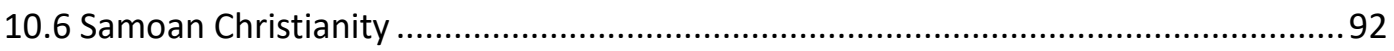

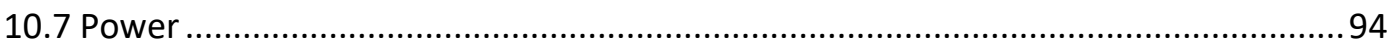

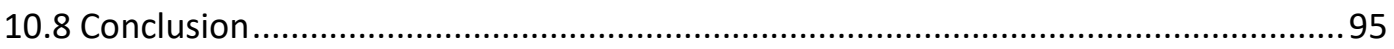

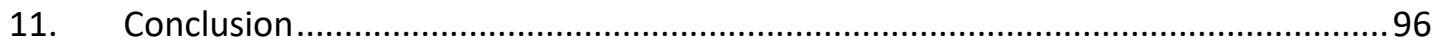

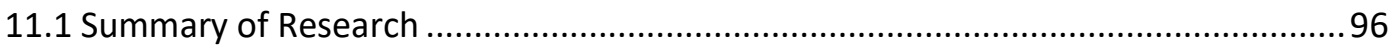

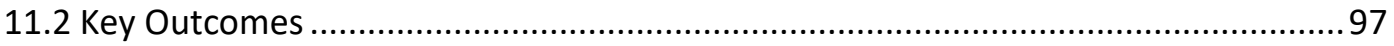




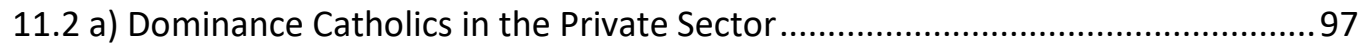

11.2 b) Low Religiosity and Dissent towards Organised Religion .................................. 98

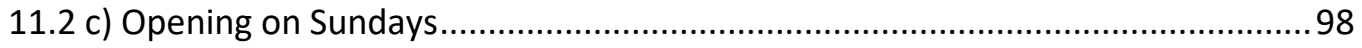

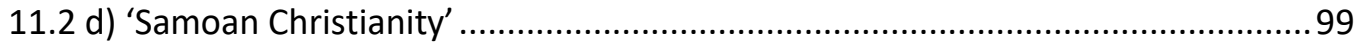

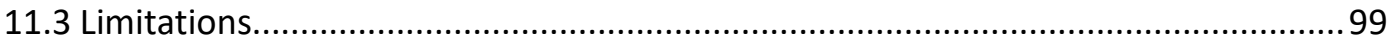

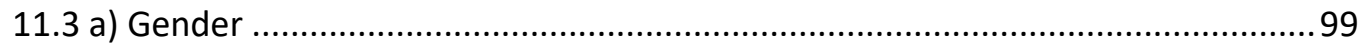

$11.3 \mathrm{~b}$ ) The Role of Chinese and Foreign Business Ownership in the Research ..........100

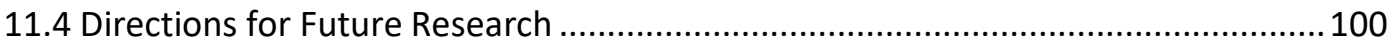

11.4 a) Further Power Dynamics and Cultural Hierarchies in Business ......................101

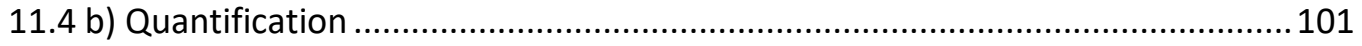

11.5 Development of Business in Apia ........................................................................ 102

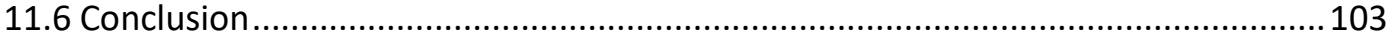

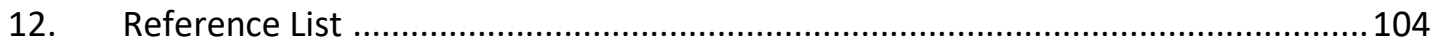

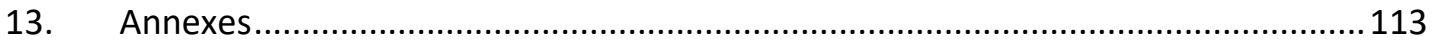

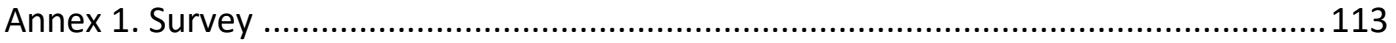

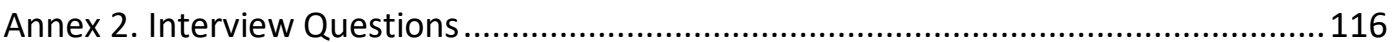

Annex 3. Samoa Bureau of Statistics Samoan Citizenship by Political District .................118

Annex 4. Samoa Bureau of Statistics 2016 State Census ...................................................119

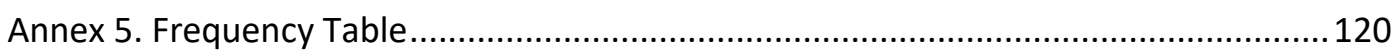




\section{Abstract}

Religion, in particular Christianity, has a large impact on Business in Samoa. Through surveys and interviews, this research was able to ascertain areas in which Christianity and business intersect to determine its daily function and the broader implications of doing business in a highly Christian nation. Christianity has taken on its own form of 'Samoan Christianity' through the merging of religion and fa' aSamoa which allows business owners facilitate the practice of religion, primarily for their staff members, while not being deeply religious themselves. This 'Samoan Christianity' is influenced by the disproportionate number of Catholics represented in the private sector who face fewer practical and financial demands than other denominations along with the assistance of historical privileges gained the status of the Catholic Marist Brothers. Businesses in Apia are heavily impacted by staff loans, theft and cultural demands, but owners maintain a positive outlook on the spiritual benefits that religion brings to their lives. Business owners are heavily critical of organised religion in Samoa, particularly the church and priests, believing fewer financial demands on staff members would ease the negative impacts of religion on business. However, interested in preserving the culture and religion of their unique homeland, business owners have opted to observe religiously motivated practises such as closing on Sundays as they believe this to be more important than financial gain. 


\section{Preface}

Every weekend, Apia starts to shut down on a Saturday afternoon. The town is bustling in the morning, but the first shops start to close around midday with everything bar a few supermarkets being shut by 3 p.m. Nothing opens again until Monday. During this time, Samoa withdraws from the outside world; consumerism and globalisation. Samoans retreat to their families and their villages to attend church and to spend time with their loved ones. Social media is showered with singing at church, laughing with cousins and sharing large meals of traditional Samoan food. I write this chapter on a Sunday, from the only café in Apia that is open. There is only one other table eating and very few cars on the road.

This day is special in Samoa, and my research suggests that this is for bigger reasons than just the church. And from being and knowing here, I would agree with that too. I have never met a people to whom family is so completely the be-all and end-all. And not just close family, here we value our third cousins twice removed and our godmother's sister's children. We sometimes joke about being Palagi related nuclear family and first cousins, or Samoan related - pretty much everyone. It's beautiful. In New Zealand, I would never go to bars and see friends there with their brothers and sisters and cousins and parents and grandparents. Everyone having a beer together. It is in these situations where I have learnt the most about my research. Where throw away comments have led me to research breakthroughs and where people share their opinions candidly, even if I am unable to put these in my work.

My positionality as a researcher has taken on a new context in a place I have lived and worked for over a year now. I have come to see Samoa as my home; this is where my bedroom is, full of things I have acquired over the last year and where many of my friends and loved ones are. I have been here long enough to see two Christmases, two New Years, three different contracts and a number of people leave and come back again. Samoa to me is no longer a place of research, but it has become my life, at least for now. I am using this opportunity to talk about my personal experience in Samoa. I feel I need to preclude this research with my feelings towards a place that has a special corner of my heart. 
For example, it is widely accepted that Afatasi people (a generally accepted term for half-caste) are often in places of privilege and that a number of wealthy Afatasi families are heavily involved in the private sector. I do not make these statements with any lens of judgement but simply from observation, conversation and from knowing a number of these lovely people. The converse is that many of the influential full Samoan families are involved in the private sector too and are also high up in Government and represented overseas. These family names, Samoan, Afatasi and Palagi, can be listed off by everyone and are names held by large families spanning across all sectors.

Within this, the stratification of society is evident to me, especially in the space which I live. As a Palagi on a good paycheck without a family to support, I am incredibly privileged to live among the wealthy and elite of Samoan society. I exist in a way that I might not otherwise, rubbing shoulders with those far more important than me or with their children and grandchildren.

Therefore, I live in a place that is not part of village life but instead part of Samoa that is not spoken of often. Often not seen as the 'real Samoa' despite the very realness of the way this group of people live their lives. It is a Samoa where people do eat brunch and have overseas holidays. Not those who live lives stereotypical of the developing world, but the developed. It is a group of people who live here intentionally. Despite Kiwi or Australian passports and their education in foreign universities, many of my dearest friends have chosen to stay in Samoa. They want to pursue a purposeful and meaningful life in their homeland. Some people talk about being 'stuck on the rock,' and there are families who apply for the New Zealand or Australian quota year after year. These people are of a different population, those who could leave but chose not to.

This is the population of people who are in my study. People who have stayed and invested in their country. Who are as proud of Samoa as anyone in the villages. While the real Samoa happens in the village, it also happens in Apia, differently. This research had the intention of speaking with this population of people. The ones who own the formal, private sector, not in the marketplace but the shops, cafes, bars and restaurants. The marketing companies and the hotels. This is the real Samoa, too. 
When you live in a place long enough, there are many things you come to know and understand. Often things that may not be proven through academic research and scientific fact. Things that may not even be scientifically true but are so generally accepted, it is important to recognise them regardless, perhaps in accordance with the 'ways of being and knowing' so integral to the fa'aSamoa.

The other thing that changes the context as a researcher is the emphasis and integration of oratory and oral histories in the fa'aSamoa. To this day, knowledge is passed around these islands through discussions and idea-sharing.

I recognised the place of my research on two levels. The first is that while I have been here over a year and very much feel at home in Samoa, I also know that I am still an outsider and that this is not a culture I have any claim over or even really a right to comment. I hope I can represent my findings fairly and with the deep respect I carry.

Secondly, I recognise that some of my findings and especially the interviews are heavily, heavily critical of the church and those that are part of the church. I hope to represent these views in a somewhat constructive way, from a place of love. I am creating space for this dissent while also knowing that dissent is frowned upon and sometimes unwanted, especially from an outsider.

I have faced many challenges here, and I know that this is another one. I want to do justice to my participants and the subject, but I also want to tread carefully, recognising my position and the arguments these discussions could cause.

\section{Acknowledgements}

I want to take this time to thank the wide, generous and wonderful family I have here in Samoa, at home and around the world. Thank you to everyone who listened to me talk about my research, who edited my horrible spelling and grammar, read and re-read my work when I needed it, those who supported me even though they were not quite sure what was going on. But most of all, I am sorry for all the times I said I could not hang out because I had to study only to be seen at the beach later that afternoon. 
Thank you to my supervisor John Overton, thank you for understanding that this research process was not as linear as it possibly could have been and supporting me regardless. Thank you to my Mum and Dad for helping me out from the home base. Thank you to Sapeer for the hours of editing and email cheerleading.

I want to thank you for reading this, and I also want to apologise, if any of the findings and discussion I present are hard to read or generally offensive to you. Please come and talk to me about it, and please recognise that I present one group of perspectives in a dialogue that is growing and changing and developing every day. I do not intend to harm but instead to "take peoples worldviews seriously." If I may be so bold, let this be the continuation of a discussion for the growth of Samoa.

Fa'afetai tele lava, alofa atu.

Gabby 


\section{Glossary of Samoan Words}

Afatasi - a person who is half Samoa and half Palagi

Agia - Family

Aitalafou - IOU or Loan

Fa'alavelave - Anything that interferes with normal life and calls for a special activity, but generally accepted to mean loan

Fa'alupega - Oral histories of the village

Fa'aMatai - The system of Chiefdom

Fa'aSamoa - The way of being and knowing in Samoa; Samoan Culture

Faife 'au- Pastor or Minister ${ }^{1}$

Faitaulaga - Priest

Fale- Traditional Samoan structure used for most functions such as a house or meeting room

Folefole - The practice of reading out the sum of family's church contributions

Fono - Village Council

Matai-Chief

$M e i$ - The month of May in which congregations are expected to provide gifts to their priests

Noa - nothing in particular

Palagi - Foreign person, generally, but not exclusively, referring to a white person

Pulenu'u - Village Mayor

Talanoa - Story telling

${ }^{1}$ Colloquially, and by the research participants, faife 'au is often used to describe the priest, minister or pastor of a church. 
Tala- to inform or tell

To'ona'i-Sunday Lunch 


\section{Introduction}

Religion is integral to life in Samoa. This research is a study of how religion intersects and impacts business in Apia, Samoa. The participants are business owners, and the study aims to understand their perception of religion and business to inform the existing research and development work in Samoa and other religious nations.

The growth of modern business and economics has been well researched, with scholars focusing on the impact this has had on the developing world. While the private sector does have the ability to elevate individuals and communities and provide successful development outcomes, researchers such as James (2011) and Adher (2003) have called for development research and practice that takes the worldview of the communities in question seriously. The neoliberal emphasis on capital accumulation and growth does not account for the priorities of cultures that do not exist in western frameworks. Research into collective entrepreneurship and corporate social responsibility is providing frameworks for more meaningful engagement with the private sector across the globe.

Religion can be highly influential in nature. Religious upbringings can equip individuals with traits that positively influence entrepreneurial success, making individuals less inclined to engage in harmful behaviours and Christian business ethics support meaningful engagement with the private sector (Pancorbo, 2012; Baker, 2015; Macpherson and Macpherson, 2011; Guiso et al., 2003). Social and spiritual capital allows for people to use their networks to improve their status, and often these networks can be found within religious institutions, especially those that are fully integrated into communities.

Samoa is a highly religious nation, boasting 98\% Christianity (Samoa Bureau of Statistics, 2016). There is broad denominational affiliation and Christian doctrine enshrined in the constitution. Samoa has a complex cultural structure with an ingrained hierarchy through the fa'aMatai (Chiefdom). However, religion has just as an important role in formal and informal life. Financial giving has a large part in Christianity in Samoa, which can sometimes be contentious (Macpherson and Macpherson, 2011; Thornton et al., 2010). 
The research was conducted through surveys and interviews in the Apia Urban Area. The participants were business owners in the formal sector. Talanoa methodology was used for the interviews to create knowledge-sharing discussions in which participants were able to cover whatever they felt comfortable sharing throughout the conversation. This research aims to understand the complex intersection of religion and business in Apia, Samoa. The research worked with business owners to understand the practical daily impact, the perception of religion and the possible way forward for their business and religion. Religion is now so tied into Samoan culture that business owners, despite complaints embraced religion and by extension their culture with a view to preserving Samoa. 


\section{Literature Review}

Business, religion and development are three complex and varied areas of the modern world. In the literature, they sometimes intersect, offering each theory and practice a different lens through which to view the idea of religion and its engagement with religion. To begin the literature review presents the move towards economic growth and the prioritisation of the private sector within the development and its general aims. Since the 1980s, these theories and priorities have changed. We can see the deviation from the prioritisation of individualist globalised capitalism, and movement towards corporate social responsibility and an understanding of the role which collective entrepreneurship plays in the developing world. We can especially see this in countries where community and family are paramount.

The literature uses theories such as social capital, to explain the socially enabling environment necessary for successful entrepreneurship. This writing assists in understanding business within society. These theories can include the role and traits of the individual but also networks and relationships necessary to help that individual.

As religion is one of the oldest theories and institutions in the world, there has always been literature that reflects on how business and religion interact with each other. These studies consist of denominational differences primarily between Catholics and Protestants. The literature includes studies that test the morality and ethics of religiously motivated business.

Development studies have also looked at the role religion plays in development, and studies have found that development is best teamed with religion when working with a population of faith. This literature is part of broader thinking that prioritises sensitive cultural approaches to development work.

The three broader ideas of this thesis are not widely written about in conjunction with each other, providing the gap for this thesis as well as a detailed case study. This literature provides a number of different perspectives and ideas from which to approach the topic, ones that can complement and conflict each other depending on emphasis and context. More work is needed to understand the religiosity of the private sector and its impact on development. Suppose the world is to move forward within culturally relevant and meaningful approaches to the development of the private sector 
and economic growth. In that case, we must work to gain an understanding of what this looks like and what those in question want.

\subsection{Capitalism, Globalisation and Economic Development in the Developing World}

It is difficult to talk about business without talking about global theories that surround the private sector. The developing world is not immune to these ideas. Globalisation can be defined as the integration of markets, goods, services and people which impacts on economies, politics and culture of entities, institutions and people that become ingrained in the system (Hopper et al. 2017). Globalisation can be seen as 'financialisation,' the prioritisation of financial actors, institutions and motives over almost everything else, allowing for banks to receive tax breaks. While, the rest of society makes up the difference (Antonio, 2013). Capitalism holds up the tenants of 'free choice, free competition and private property' with a view to prioritising the individual and the market over the state (Ali, 2016).

Liberalism came about in the 1920s in a post-war climate of growth. Liberalism, with capitalism at its core, believes in limited government and regulations with the core idea that the market will regulate itself and create growth. This premise allowed for the U.S.A to grow exponentially. The measure of success being capital accumulation and profit while explaining the failures of fair distribution through belief in meritocracies (Antonio, 2013).

Development as a practice was born out of President Harry Truman's speech in 1949 which urged the developed world, read, the U.S.A, to share with less developed countries the technologies and systems that allowed the western world to grow. These development principles included large scale lending, infrastructure and commercial capacity building with the principal of embedded liberalism, and is referred to as 'modernisation' theory (Bull and Boas, 2012).

Following a slowing of liberalism and modernisation theories during the cold war 'Neoliberalism' was reinvigorated in the 1980s and 1990s with reforms that followed a global trend towards privatisation and economic development (Antonio, 2013). American politics shaped this 'New Deal' with both Democrats and Republicans supporting neo-liberal economics and creating policy and legislation according. Even 
post the Global Financial Crisis of 2008/2009, neoliberalism was still the dominant ideology of global politics and economics.

Development policy also shifted in the 1980s and 1990s, partially as a reaction to the financial crisis that was being felt across Latin America (Gore, 2000; Babb, 2013). Development institutions such as the IMF and the World Bank encouraged these reforms, and in order to receive loans, developing countries liberalised accordingly. These reforms involved the championing of free-market capitalism and privatisation, therefore, the prioritisation of private sector growth. 'The Washington Consensus' was written and coined by John Williamson, consensus coming from Washington and its academics and technocrats, was a reengagement with the modernisation development policies that encouraged a small state that allowed the market to self-regulate therefore encouraging efficiency and economic growth (Scott, 2011).

The emphasis on growing the private sector in development has come from the lessons learnt of earlier development and government solutions, such as the redistribution of resources, which were no longer deemed to be long term solutions to poverty or a path to greater development (Hanushek, 2013). The growth of the private sector has the ability to provide greater employment opportunities and capacity building to populations, allowing for people to lift themselves out of poverty by providing for themselves and their families.

However, since the 1980s and 1990s, these reforms have been widely criticised, and the Washington Consensus has been abandoned. Ali writes that "the belief that capitalism is the only immediate solution to economic difficulties in developing nations is flawed and represents dogmatic rather than creative thinking" (Ali, 2016, p. 103). Khan (2015) described the neoliberalism of the development sector as 'growth at any cost' noting the compromising situation that privatisation and liberalisation caused in the social and environmental spheres. Hopper (2017), reinforcing Ali (2016), writes that "too often development policies implicitly assume that DCs should learn from rich countries, but the converse can be true" (p. 126). This notion is especially salient with the numerous examples of growing wealth divides and income disparity in the developed world (Khan, 2015). Allowing space for developing nations to pave their own economic development (while also acknowledging that opting out of Global 
capitalism is now near impossible) would allow for culturally specific models of engagement within the private sector and business.

\subsection{Corporate Social Responsibility}

In the wake of the Global Financial Crisis corporations and business came under heavy scrutiny, not just from development theorists in the academic world but across the globe. The idea of 'Corporate Social Responsibility' (CSR) is a growing expectation of businesses to mitigate the damage they may cause and prevent any further destruction to the communities where they operate. CSR can also look like outreach support to worthy causes in developing countries. CSR can be donating money to charities or Non-Governmental Organisations, corporations establishing their own charity arm, paying a living wage, providing free services to vulnerable groups or adopting environmentally friendly options like paper straws or using solar power. CSR moved the focus of business away from a shareholder, profit maximisation model towards encouraging stakeholders to take responsibility throughout their community. Research by Brik, Rettab and Mellahi (2011) published in the Journal of Business Ethics, showed corporations who adopted CSR practices did not see any change in their efficiency, performance or competitiveness, but did observe positive changes between the business and their customers. El-Bassiouny et al. (2015) in their study of CSR and Religiosity in developing countries noted that while many factors that contribute to CSR have been widely researched, very little literature exists regarding the role of religion.

\subsection{Traits of the Individual}

Studying business and entrepreneurship involves looking at the people who do business and their traits and reasons for working in the private sector. Described as "assets of change", entrepreneurs are well placed to pull countries and economies out of a crisis, or aid in their steady development, given the most enabling environment to do so (Isabel and Almeida, 2017). In much of the literature surrounding business and entrepreneurship, emphasis on the individual was prevalent. This is reflective of the western frameworks that encourage an individual's autonomy and hard work within an individualistic society. Throughout the literature, it was clear that business is primarily studied in western nations through a western lens and as such, the traits of 
an individual necessary for business success were widely discussed. For example, Halman and Muller (2006) found two 'orientations' for the way in which individuals approached work; intrinsic, prioritising the work itself through labour required and extrinsic, to achieve a goal outside of the work. They found that more prosperous societies had more intrinsic aims and were working to achieve the goals of work. Primarily due to the individualised nature of these societies.

Though developed and developing countries are distinctly different contexts for business, there are commonalities among individuals that aid business which cross developing/developed lines. The literature discussed traits such as an attitude and commitment toward 'hard work, originality and risk-taking' (Kirstiansen, 2004). It says the entrepreneur should be hardworking and put their work before their family and personal life. However, this is not reflected in the entrepreneurs of the developing world (Douglas and Shepard, 2002; Yan and Sorenson, 2003). The individual also needs to have well-honed social skills. Without them, they will be unable to convince buyers of the necessity of their product or service (Sangar and Stanosh, 2014).

Education has many benefits, and particularly in the field of business and entrepreneurship. Studies on the impact of 'human capital' on entrepreneurial and business success have shown a positive correlation between high levels of education and successful business owners (Cooper et al., 1994; Gnegy et al, 2011). Educational influence also increased the likelihood of traits such as determination and perseverance (Cooper et al., 1994). Zafar and Khan (2014) find that this can be as simple as the knowledge that you gain from reading, but found more concrete proof that one or more year of education equated to an increase of profits by $5.5 \%$. Therefore, as well as risk-taking and hardworking, the individual should be well educated in order to be a business success.

\subsection{The Role of Social Capital and Networks}

"Networks spanning multiple domains of social life apparently provide nascent entrepreneurs with greater access to multiple sources of information than do more homogenous networks and this enables them to make the transition between idea to action" (Renzulli et al., 2000, p. 541). 
Community and knowledge networks play a role in the way business and religion intersect. 'Social Capital' is a common measure of this intersection and is deemed necessary in many parts of life. Social Capital can be defined as "the relationships between individuals and organisations that facilitate action and create value" (Stokes et al. 2016, p. 38).

As social capital is something that you can gain and then grow, discussion of stakeholders generally refers to the 'accumulation' of social capital. Which involves working with the bonding, linking and bridging networks necessary to accumulate social capital. The literature emphasises the role of these networks and relationships increased production as well as linking them to social achievements such as better jobs and happier marriages. These traits also lead to economic success and business development (Baker, 2015; Rauf and Pervaiz, 2016).

Social capital is an often-used theory for describing interpersonal relations and their interactions with formal and informal institutions. The most common understanding is that social capital comes in three forms:

\section{Bonding Social Networks}

Bonding social networks are formed through meaningful interpersonal relationships, often with those closest to you, such as friends and family. These relationships often come from common backgrounds and shared characteristics, which are necessary for building strong ties (Elliot and Yusef, 2014). In the developing world, these ties are likely to be a strong foundation for businesses, especially SMEs, with extended families engaging in business together because of their bonding networks.

\section{Bridging Social Networks}

This form of capital is used to seek information or support from community centres such as religious organisations, places of worship or community centres (Larsen et al., 2004).

The literature emphasises the importance of 'knowledge networks' for business. Several studies reveal how entrepreneurs with diverse networks can access new information from several sources (Kirstiansen, 2002; Renzulli et al., 2000; Larsen et al. 2004). These networks provide information that keeps businesses engaged with different levels of society through continued flows of information. It was even found 
to reduce business costs. James (2011) describes religious organisations as 'horizontal and vertical networks' which are organised means of communication, human and financial resources.

Bridging networks, like those in churches, provide the perfect places for knowledge accumulation as people attending church, are likely to be from many different walks of life. Within a church, there are those from high socio-economic groups and low socio-economic groups. There are those from a variety of different professions, and children, elderly and people employed in the domestic realm. While it is possible that congregations are stratified by social-economic status, in principle, they should be open to all. These different knowledge links and perspectives are the bridging capital that business owners need to target their products effectively.

Kirstiansen (2004) finds that wide-reaching networks can have multiple benefits, such as reducing costs. However, this research emphasises that these networks are not equal; though the knowledge networks need to include members from all levels of society, in particular, wealthy individuals with high social status are of great benefit to the knowledge gaining of an entrepreneur. Kirstiansen (2004) emphasises the need for entrepreneurs to engage with 'communities of trust' and their ability to do this depends on their standing in society with primary concern for "wealth, social status and networks.'

The need for networks ties perfectly to the concept of collective entrepreneurship. This can be described as "the creation of something of economic value arising out of new, jointly created ideas that emerge from the sharing of information and knowledge" (Ratten, 2014, p. 299). Put more simply; networks provide customers, knowledge and visibility to any business, making them integral to success, especially when businesses are small or recently established.

\section{Linking Social Networks}

This social capital works as leverage within the political or social sphere. It can be defined as the "capacity to lever resources, ideas and informal from formal institutions beyond the community" (Ling and Dale, 2014, p. 6). Kirstiansen (2004) also emphasised the necessity for entrepreneurs and business owners to have the ability to navigate bureaucracy, rules and regulations. This linking of social capital is required so that business owners will fit within the policies and regulations of a nation-state. 
Dana (1993) has pointed towards the heavy influence that government policy can have on entrepreneurship and business. Research on business shows that several factors lead to the success of a business, and one of these factors is an enabling environment created through public policy. The enabling environment he describes includes the need for "understanding policies and socio-economic forces which do not unduly restrict entrepreneurship" (Dana, 1993, p. 85). Meaning, a policy should not only create the enabling environment through policy but also have the linking social capital to access the resources made available. Those lacking in linking social capital will find it difficult to harness these benefits. Those who cannot operate within government policies may be penalised, or those who are not aware of benefits or systems will miss out on opportunities.

These forms of capital can be applied almost universally and are interwoven with ideas of entrepreneurship and business development. In the developing world, bonding capital informs the communal business practices that provide collaboration and capital. Bridging social capital informs the necessary knowledge networks as emphasised by Kirstiansen (2004) and linking social capital allows successful business owners to engage on a political, governmental or policy level to establish their business in the formal sector.

\section{'Spiritual Capital'}

When researching social capital with reference to religion, another type of capital was discussed in the literature: Spiritual Capital. While this can be interpreted a number of ways, one common definition is:

"the set of personal, intangible, and transcendent resources that emanate from an individual's spiritual or religious beliefs and experiences and may be used in economic activity. These spiritual resources are personal in being unique to each individual, intangible in being mindsets and meanings associated with people and business, and transcendent in being associated with something beyond self and natural experience" (Neubert et al., 2017, p. 622).

It is also emphasised that while spiritual capital applies to the institutions and formalised religion, it is primarily concerned with the personal and spiritual aspect of religion. 
A study was conducted by Neubert, Bradley, Ardianti and Simiyu (2017) at Baylor University in which they researched the role of Spiritual Capital through an individual's Faith Maturity (FM) scale. In their study, they found that higher ranking on their FM scale positively correlated with entrepreneurial innovation. Their study found that, particularly in developing economies where entrepreneurs lack financial capital, strong spiritual beliefs can lead to more faith in the ability to innovate. The study also found that spiritual capital can positively impact relationship building due to the influence that it can have over perceptions of trust and reciprocity.

\section{Criticisms of Social Capital Theories}

Light and Dana (2013), while recognising social capital and its support to entrepreneurs, found that in countries with strong cultures, it was cultural capital and not social capital that was the most influential in the success of an entrepreneur. The research likens cultural capital to oxygen for athletes as it is so essential that it can sometimes be overlooked. In particular, Light and Dana (2013) found that when looking at research about social capital, only 2 of 114 articles related to ethnic or racial minorities. The research suggests that it is cultural capital that influences entrepreneurship more, noting that some cultures do not value entrepreneurship making cultural capital the determinate of entrepreneurial success.

\subsection{The Cultural Impact of Economic Drivers in Developing Countries}

While western economics has a number of accepted norms and principles such as privatisation and liberalisation, scholars have found that economic models can be modified to address questions of belief, norms and values. Dana (1993) also points to Weber's work which forms a 'causal link between entrepreneurship and cultural values.' Modifying these economic principles is necessary to make sure the development is successful.

Research into economic development in developing nations shows that often business is made of 'gap-fillers' determined primarily by holes in the market but also heavily influenced by personality and culture (Kirstiansen, 2002). To understand these influences, Kristiansen (2002), in their work on business development in Tanzania, 
encourages social scientists to work on understanding the entrepreneur's perception of the business environment in which they work.

\section{Economic Attitudes}

A growing body of research into the influence of 'economic attitudes' has found several traits that impact these views, such as the individual's attitude towards capitalism or the financial literacy of citizens in higher or lower socio-economic groups. The premise of this research is that "norms, politics, and everyday life reflect the values of a society" (Fedotova, 2017, p. 106) In order to understand economic growth or business we must understand the values of a society, which we can trace back to these groupings. Fedotova's (2017) study of the age-related differences of economic attitudes in Russia came with several conclusions surrounding the changes in Russian society. The research showed that participants were divided between the hangover of economic paternalism and the desire for economic autonomy. The broader conclusions of this research showed that "individualism was related to the readiness to invest energy in business but did not favour competition" (Fedotova, 2017, p. 115). This demonstrates a trait that gives business owners a positive attitude towards business ownership but perhaps an economic attitude that does not encourage general growth.

When discussing economic attitudes, the influence of morality and moral attitudes have been widely researched. A study conducted by Erceg et al. (2018) in Croatia found that economic attitudes were directly affected by moral concerns citing harm/care and purity/sanctity as two main drivers. These economic attitudes could be impacted by the cultural understandings of these drivers, 'care' taking on a different meaning according to the priorities of the society. The morality of the pure and the sacred is also widely explored throughout both religion and economics, informing consumers attitudes.

\subsection{Collective Entrepreneurship}

Researchers have pinpointed an important part of business and entrepreneurship in the developing world as being the collective and family aspect of building the private sector. Yan and Sorenson (2003) have criticised previous research on business and entrepreneurs for focusing only on the individual pursuit, which 
ignores the reality of the community and family-orientated cultures often found in the developing world. Chari and Dixit (2015) echoed this sentiment with research that found that family or collectively-owned businesses in developing countries were more successful as they were able to pool resources to create leverage in difficult markets. All these researchers point to the importance of family within these businesses, in particular the mother and father. Ratten (2014) emphasises that collective success is important in developing nations, as there is the need to pull the whole community up and not just the individual.

The nature of collective business and small to medium enterprise (SMEs) in the developing world is different from the businesses of the developed world. As Azmat and Samaratunge (2009) describe it, "the nature of doing businesses in SMEs is largely personal, the reputation of the business and the embeddedness of the firm within its stakeholder community" (p. 440). Because of this, the SMEs are likely to behave with an increased sense of 'corporate social responsibility.' The perception of who they are and how their business operates is under more scrutiny as an individual or a family in an interlinked community.

These scholars, particularly Ratten (2014), have called for further research into these areas. The research which does exist has proven that the success of family businesses and collective entrepreneurship in the developing world is far more common than in developed nations. Therefore, there is a greater need to understand the factors that contribute to this success and to discover potential entrepreneurs by facilitating these factors. Further research on collective entrepreneurship will also allow for the 'more creative solutions' Ali (2016) advocates for when discussing the engagement of the developing world with global capitalism.

\subsection{Religion}

"Religion is a complex social phenomenon, closely intertwined with and shaped by particular cultural, political and economic context" (Peterson and Le Moigne, 2016, p. 396).

In highly religious nations, the influence and role that religion plays in all parts of life are important to consider. The ingrained belief of a people is ultimately impossible to divorce from their actions. Therefore, considering the role of religion is integral to 
understanding a people. Guiso et al (2003) found that "a dominant religion often becomes enmeshed with the national culture and transmitted from generation to generation" (p. 250). As it has become integrated into society, ingrained in the culture, the religion will take on a new form as it works within its context and framework. McGuire (2012) wrote that "(since) in communities where religion plays a prominent role, the likelihood that social norms include components of religious beliefs is higher than in communities where religion plays a smaller role" (p. 645). This suggests that in countries with a heavily religious population, many social norms will be impacted by the dominant religion.

Religion often has a heavy influence on people. Studies have found that there are many traits associated with religion such as honesty, positive work ethic, discipline, responsibility, self-confidence, thrift, trust and wealth accumulation (Baker, 2015; Macpherson and Macpherson, 2011; Guiso et al. 2003). Those raised in religious households, according to Guiso et al.'s (2003) study, are more likely to believe market outcomes are fair and less likely to break the law. Traits such as a trust for other people as well as in the legal system and governments are often correlated with religious upbringings. As well as this, Autiero (2014) found that not only were these traits economically relevant but religious upbringings made people less likely to have drug and alcohol problems, to get divorced or even to have health issues.

These traits and the absence of damaging behaviour, such as alcoholism, show positive correlations towards economic success. Guiso et al. (2003) found that religion can be beneficial to business in the way religiosity fosters attitudes that help the free market and better institutions. Religion encourages the "transmission of values that promote education which in turn fosters physical capital accumulation and growth" (Autiero, 2014, p. 46). If the religious individual is predisposed towards positive economic attitudes, then fostering a relationship between religion and the private sector should have an impact on economic growth in developing nations.

Religions often fit into two common modes of behaviour - orthodoxy, which is the emphasis on belief, and orthopraxy, the emphasis on practice (Laurin and Plaks, 2014). In the Abrahamic faiths, there is a difference in this: Christianity is an orthodoxic religion, emphasising the belief in God and the holy trinity above all other tenants of the faith (Mele and Fontrodona, 2017). Islam, on the contrary, is an orthopraxic 
religion, emphasising the practices of the faith - praying five times a day and following other rituals. Of course, both practices encourage tenants of the other, but the primary mode of operation will have an impact on how business and religion intersect.

\title{
6.8 The Church
}

\begin{abstract}
"Arguably they are well positioned to influence public policy that seeks to address the material needs of poor communities in terms of both social welfare and infrastructure for economic development" (Thornton, Sakai and Hassall, 2012, p. 790).
\end{abstract}

With any organised religion, it is important to remember the institution through which the belief system is perpetuated. In the case of Christianity, obviously, the church is the biggest influence in the community. As Thornton et al. (2012) have found in their work, quoted above, the role of the church is not to be ignored, especially as it is wellpositioned to influence change through many spheres.

The church as an institution is widely researched, being described as a political institution, not purely spiritual. This is a continuation of the idea that they could be perfectly placed to inform policy - due to leaning politically already. Theriault (2014) points to history to demonstrate how they sensibly rationalise the idea that no church could have carried out the inquisition or the crusades without the political support and backing of the state. If the church is able to influence the state, then they are also able to influence development. In particularly religious nations and in rural areas the church has the ear of a people in a way the government may not, making collaboration for development, critical.

\subsection{Christianity and Business Ethics}

"I urge you to draw upon these great human and moral resources and to take up this challenge with determination and far-sightedness. Without ignoring, naturally, the specific scientific and professional requirements of every context. I ask you to ensure that humanity is served by wealth and not ruled by it."

Pope Francis, Letter to the Executive Chairman of the World Economic Forum, 2014. (Mele and Fontrodona, 2017, p. 671). 
Religion and its teachings on business have been studied thoroughly, though less so in a modern business setting (Mele and Fontrodona, 2017). As one of the primary focuses of religion is the dictation of behaviour, such as in the ten commandments, it is likely that practices in business and finance will also be covered. The most pointed Christian principle of economics and business is the use of wealth for a higher purpose. This principle can be mirrored throughout other religions and is reflected in the principles of Islamic Finance which have been doubling in growth in the last few years (Hussain, 2018; Mele and Fontrodona, 2017).

Christian business ethics primarily follow Thomas Aquinas' Moral Natural Law, accounting these basic principles with an applicable 'code of conduct' for business (Alford et al., 2008; Pancorbo, 2012). Though these teachings can be applied to economic behaviour and values, there is still the need to make sure the teachings of the church are 'economically feasible' (Pancorbo, 2012). Siker (1989) argued that 'business ethics' is an oxymoron in itself, asking: how can business be ethical when it is inherently tied to the corruptible capitalist institutions that are seemingly inherently devoid of morals? The pervasive question in the literature of Christianity and business ethics is how does one inform the other when modern economic theory falls, in the case of the Global Financial Crisis, but also when does the written scripture accurately explain the full extent of engaging in economics and business? Pancorbo (2012) describes the intersection as "the dignity of man, created with free will and a creative mind in the image and likeness of God" (p. 330) which influences business and the economy. As Christian ethics in business is still an emerging field, then creating an understanding in specific context provides some assistance to the intersection of Christianity and business.

The first scholar to write extensively on religion and economics was Max Weber, whose theory was that without Christianity and in particular the reformation, modern capitalism would never have been born (Hassan, 2017). Weber's work, 'The Protestant Ethic and the Spirit of Capitalism,' written in 1904 credited the protestant work ethic and the spirit of labour for capital accumulation as the primary means of the growing world order. This work has influenced work surrounding religion and business and has led to numerous studies on his theories. 
"One of the fundamental elements of the spirit of modern capitalism and not only of that but of all modern culture: rational conduct on the basis of the idea of the calling was born - that is what this discussion has sought to demonstrate - from the spirit of Christian asceticism." (Weber in Hassan, 2017, p. 180).

The influence of morality and virtuosity is ever-present in any discussion of religion and business ethics. Spiritual capital, as discussed above, is also credited as being an influence on 'good' or virtuous market behaviour; encouraging business owners to behave in trustworthy and truthful ways and supporting better business practices (Baker, 2015). Scholars tie these business ethics in a religious setting to the lessons that individuals were taught through their religious experiences. The intent is to demonstrate how ethical, virtuous and meaningful businesses are formed.

Guiso et al. (2003) also found that Christian religions foster economic growth more actively than other religions. While Weber credited the protestant work ethic for engagement in business, Guiso et al. (2003) suggested that Catholics "support private ownership twice as much as protestants" (p. 228). In the case of a Christian nation, you have the likelihood of a positive impact from the 'protestant work ethic,' but the society may also benefit from Catholic support for private ownership. A further study by Kirchmaier, Prufer and Trautmanna (2018) on religion, morality and economic attitudes found that religious people, while more likely to volunteer their time, are less in favour of income redistribution. The study also found, like Guiso et al.'s (2003) work, there are differences between the behaviour of Catholics and Protestants, where protestants might give more time to volunteering but are more likely than Catholics to betray others.

The influence of Christian ethics on business could impact a number of factors. The Christian values would hopefully allow for a business that prioritises trust and moral behaviour, but this business might not engage fully with the ideals of capitalism and market forces. Naughton and Cornwall (2006) negated the idea of risk and instead suggested business ethics and entrepreneurship require virtue and courage. Courage; the ability of an entrepreneur to draw on Aquinas' moral codes in order to overcome our inherently human vulnerability. It is this, the theory finds, to be the primary mode 
of Christian business ethics that steer entrepreneurs. In their conclusion, they state that:

"Economic systems, as important as they are, do not have the resources, nor do they possess the criteria, to provide a meaningful human life or to create the moral and spiritual conditions necessary for people to develop" (Naughton and Cornwall, 2006, p. 88).

\subsection{Religion and Development}

Development is primarily conducted through wealthy countries funding poorer nations, and there is a tendency to ignore or avoid religion within that process. There is a tendency for donors in development to ignore spirituality and religious practices, often due to their own secular leanings (Ver Beek, 2000). A growing body of work challenges and negates this practice. Thornton et al. (2012) advocate for creating social change through 'effective partnerships.' Such as, between communities, religious groups, governments, donors and development organisations.

Engagement with religion is incredibly important for engagement with a religious population. Community structures of the church can offer grassroots engagement as well as vertical and horizontal social capital that can ensure the success of development projects. Churches, with the embedded social trust they create, could become a central mechanism for grassroots development (James, 2011; Ahdar, 2013).

The United Nation's Sustainable Development Goals and the previous Millennium Development Goals encourage engagement with religion and faith-based organisations with the aim to "deliberately, systematically and strategically institutionalise a culturally sensitive approach to development" (Peterson and Le Moigne, 2016, p. 395). In order to avoid crossing the delicate line into patronising and paternalistic development work, overseas development aid must always consider the cultural and religious implications of any society. More importantly, in order for successful development to happen, agencies and development workers must start "taking peoples world view seriously" (James, 2011, p. 112). This mindset shift is particularly directed at increasingly secular donor countries and international 
organisations which often ignore religion and its benefits to development because of their own bias.

Although large numbers of faith-based organisations exist, there needs to be a general mainstreaming of the engagement with religious institutions throughout the development sector. Deneulin and Rakodi's (2011) 'Revisiting Religion: Development Studies 30 years on' champions two implications for changing development's engagement with religion. The first is a reinterpretation of secularisation and how it impacts society and culture, with the understanding that secularisation is not necessarily relevant in many religious parts of the world. The second is to change development mindsets to "recognize that religion is dynamic and heterogeneous" (p. 45). Allowing for a revaluation of the role of religion in development allows for a more centralised place in the discourse and practice. These academics credit the original move away from religion to the belief that governments, and subsequently, economic systems, could become primarily responsible for the health and wellbeing of their constituents.

\title{
6.11 Religion, Business and Development
}

\begin{abstract}
"Although people may use religion to gain financial capital, social capital and cultural capital many also seek something uniquely spiritual, something that cannot be reduced to money or sex or power" (Baker, 2015, p. 29).
\end{abstract}

As demonstrated throughout the literature, religion intersects with business in many ways. The spiritual capital, the influence of economic attitudes as well as Christian business ethics show the ways scholars have used the two principles to understanding the workings of religious peoples and societies. In development, it is important to consider the core attitudes and values of communities. In many cases, religion and the church are the central tenets of societal, cultural, economic and political governance. Thornton et al. (2013) state that "Kinship and Christianity traditionally form the foundation for all political, economic and social organisation and are inextricably linked" (p. 357). The literature shows many ways in which religion and business are messy, complicated and sometimes contradictory but will ultimately point to 
conditions that help to grow the business and the private sector and subsequently help to grow the economy and foster sustainable development outcomes.

The literature has shown many factors, including collective entrepreneurship, trust and knowledge networks, affect successful businesses. These factors are all present through religious communities and networks. As scholars such as Ratten (2014) have suggested, there is a need to further research and identify the factors that impact successful business and entrepreneurship as a means of understanding how to support successful growth for sustainable development. A number of factors that were present through the literature alluded to the traits of religion - such as the successes of community-led and collective entrepreneurship in developing countries (Yan and Sorenson, 2003; Ratten, 2014).

The complex interconnectivity of religion, business, and a religious population reveals the many ways in which these factors clash with and complement each other. It is important to note that religion is spiritual in nature and may be practised regardless of its business benefits. James (2011) points to the "complex world of faith" (p. 116) and the inherent difficulty in pinpointing the role that religion plays in the life of any individual. In highly religious countries, the literature suggests that decisions surrounding religion are considered more important than business and that these decisions will be made without considerations of the impact they might have on business.

The amalgamation of these theories and research point towards a need for studies that encompass a number of interrelated factors that address business as a multi-faceted practice; changing and adapting according to the local culture and the belief systems of a society and a people. For the development sector and its workers to understand this, and the ways that enabling environments can be fostered for religion to work at its most complimentary to economic growth, we have to deeply understand the

uniquely spiritual aspect of people's lives to move forward on the practical in a respectful and meaningful way.

\subsection{Conclusion}

The literature shows that on a global scale, religion, development and business are all significantly affected by norms and principles championed by various actors. 
Global economic theories and principles have been championed for business throughout the world with both successes and failures. Development had a shift towards prioritising business and economic growth, but that has been criticised for being culturally insensitive in its approach. While there are tangible benefits of economic growth, there is a growing need for this to be catered towards the population that is engaging with religion at the outset.

Business in the developing world is still under-researched. Conducting a case study at this point allows for the research generated, to begin through a culturally sensitive approach directing further work towards relevant and meaningful outcomes.

Further research demonstrates that religion, in many cases, can be deeply positive for business, through the knowledge networks, the benefits of spiritual capital, the denominational work ethic and prioritisation of private ownership that research suggests are bound up in religion. The benefits of religion appear to be underutilised when considering priorities and approaches to economic growth and further research can influence how these take shape, with a view of prioritising and creating space for people to use those benefits.

This literature review provides the basis for a case study which focuses on the religiosity and perceptions of business owners regarding the role religion plays in their business; on a spiritual level and in daily life. The literature considers many factors which will influence the business owners in their understanding of business and religion separately but suggests that ultimately, they may view it through the lens of spirituality and community engagement.

\section{Context}

The following chapter will provide the Samoan context of which to centre the discussion of religion, business and development. This chapter details the three main areas of study, including the intersection between religion and financial giving in Samoa and the relationship between the church and state. Also included in this section: a description and summary of the fa'aSamoa and the fa'aMatai (chiefdom) and the role they play in Samoan society. The reason for this is that you cannot, especially not 
respectfully, talk about Samoa without talking about the fa' 'aSamoa and the fa' aMatai. As well as this, the interview participants discussed these two aspects of Samoan culture through their interviews. This chapter is structured to give an overview of the nation before engaging in some of the literature surrounding Samoa and the academia that exists surrounding religion, business and development.

\subsection{Demographics}

Samoa is a cluster of nine islands in the South Pacific. The population is approximately 195,979 (Samoa Bureau of Statistics, 2016), which is divided unevenly between the two main islands - Savai'i and Upolu. Manono and Apolima are also inhabited with the other five islands being deserted, save for a few overnight fale (traditional-hut like structure) businesses primarily aimed at tourism. Approximately $76 \%$ of the population live on Upolu with around 36,000 people living in the capital, Apia (Thornton et al., 2013; U.S Central Intelligence Agency, 2018). The population is around 98\% Samoan, and this cultural and ethnic homogeneity has a strong influence on life in Samoa (Thornton et al., 2013; U.S Central Intelligence Agency, 2018). As of 2011, the country moved the international dateline, aligning themselves with important trading and donor-partners in Australia and New Zealand, making Samoa among the first nations in the world to see the new day.

\section{Ethnicity}

Though Samoa is highly ethnically homogenous; Fairbain (1988) wrote that Samoa's population was 90\% pure Polynesian, but the U.S Central Intelligence Agency (2018) estimate was 96\% Samoan in 2011. A further 2\% was Samoan New Zealanders and the last $2 \%$ being 'other.' Samoa has a large diaspora, primarily in New Zealand and Australia, and a population of very transient people with seasonal worker schemes, schooling, university and scholarships.

\section{Afatasi People}

A notable population in Samoa, especially in business, are the Afatasi, meaning 'halfcaste'. The title does not necessarily contain any derogatory meaning (Meleisea, 1987). Afatasi are generally half Samoan half Palagi, which refers to a foreigner. The term is generally, but not limited to, a white foreigner. Under colonial administration, both German and New Zealand, Afatasi were originally prevented from holding matai 
titles or acquiring land. As they were legally European, the paternalistic protection of full Samoan people legally alienated the Afatasi people. (Meleisea, 1987). Following independence, they were able to improve their status, especially through business growth. Meleisea (1987) estimates that, since independence, more than half the parliamentarians would once have been classified as 'Europeans,' generally referring to the Afatasi population. Gershon (1999) wrote that the Afatasi population were able to easily transition into the newly formed parliament, as they were familiar with both European and Samoan culture. He also writes that the Afatasi population are stereotypically elitist often only marrying each other or palagi.

\subsection{Business in Samoa}

In a 2017 estimate, Samoa has a GDP of USD 844 million (U.S Central Intelligence Agency, 2017). By sector, GDP comprises of $10.4 \%$ agriculture (coconuts, nonu, bananas, taro, yams, coffee, cocoa,) 23.4\% industry (food processing, building materials, auto parts) and 66\% services (U.S Central Intelligence Agency, 2017). However, the economy is not grounded in the formal sector. A large part of the population exists through subsistence agriculture, or selling their products and produce in the market place (Chan, 2012). The relative lack of agricultural representation in GDP is because a large number of people make a very small amount of money. A large proportion of GDP is made up of Overseas Development Aid (ODA) or remittances, coming from New Zealand, Australia or China. The private sector is somewhat limited, and the largest formal employer is the Government of Samoa (Chan, 2012). The largest private-sector employer was previously the Yazaki Factory, who employed up to 3000 people before they closed their operation in August of 2017 (Feagaimaali'i-Luamanu, 2017).

\section{Business owners according to Fairbain}

Fairbain's 'Island Entrepreneurs' (1988) details the outcomes of the Pacific Islands Development Programme research project. This project defined the characteristics of a typical business owner and business, which would include the following:

- In a higher age bracket

- Ethnically Samoan, however, it states "if he or she is part European, success and growth are more likely" (Fairbain, 1988, pp. 80) 
- Has nine dependents

- The business will be based close to, or in Apia

- Has no more than five employees

- Has more education than the average Samoan

- Is a Matai (Chief)

These defined characteristics may have changed since this research was published in 1988, but it provides grounding with which to understand business owners in Samoa.

\subsection{Politics and Governance}

Samoa adopted a Westminster parliamentary system in 1962 which involved democratic principles, but the system remained tied to the fa'aMatai (chiefdom). Under the new system, the matai (chiefs) continued having both candidacy and suffrage as they remained the primary source of authority and valid political representation (Huffer and So'o, 2003; Taua'a, 2014). So'o (2006) describes how this system was established with a mandate; those holding the four paramount matai titles or 'king titles' were to be represented in the role of 'Head of State,' elected by family consensus. In 1962, 55 of the 57 seats in parliament, had to be held by matai. ${ }^{2}$ Before 1991, no system of universal suffrage existed in Samoa. Primarily, representation came from the matai, and officials were elected through village voting systems. More conservative populations argue that universal suffrage was contrary to traditional Samoan culture - the matai are tasked with taking care of the population and therefore vote in the interests of their constituents (So'o, 2006).

In the villages, the General Fono Act of 1990 delegates the power over law and order, health and social issues to the village council known as the General Fono. Following this act, every village has a mayor called the Pulenu' $u$, who receives a stipend from the Government of Samoa and is the central authority for the village (Sawrey et al., 2011). The Pulenu'u is always a matai. According to the traditional structure of Samoan governance, it is the family that bestows the power upon the matai in exchange for service and protection (Thornton et al., 2013; Thornton et al., 2010). After withholding the power from the community, it then trickles up. Thus, upholding

\footnotetext{
${ }^{2}$ Samoan Parliament now contains 50 seats.
} 
a system that works within it, to justify the western parliamentary system. According to some scholars, this act 'more or less defined the social responsibilities' of the matai. However, these responsibilities were already known to the village and practised by the matai (Taua'a, 2014).

Since 1982, the Human Rights Protection Party (HRPP) has governed Samoa, with only one coalition government in the mid-1980s. This party has been led for the last 20 years by the Honourable Prime Minister Tuilaepa Dr Sailele Malielegaoi. The longterm governance of the HRPP and PM Tuilaepa has led consideration that Samoa is one of the most stable nations in the Pacific, avoiding coup d'etat and political turmoil experienced in countries like Fiji and the Solomon Islands (So’o, 2006).

\subsection{Fa'aSamoa and the fa'aMatai}

In Samoa, the indigenous principle of $f a$ 'aSamoa is the primary understanding of being and knowing. For Samoan people, it is a "tool for understanding the world, and the way relationships Samoan people have with each other, the church, outsiders and the environment" (Cahn, 2008, p. 4). Fa'aSamoa and the fa 'aMatai are massively influential in all parts of life, especially on governance and political structures, although they are rarely ever discussed. Huffer and So'o (2003) have found that the pervasive influence of these values and the corresponding lack of dialogue has resulted in the easy manipulation of fa'aSamoa principles by the elite. The deeply ingrained notion that fa'aSamoa should not be criticised. Many Samoan people believe it to be so inherent to their nation and culture that it not only cannot but should not be questioned.

The importance of fa'aSamoa and its emphasis on family and kin ties means that dissent movements and questioning voices are silenced. Huffer and So'o (2003) describe them as being 'passive and individualised.' The notion of fa'aSamoa is ingrained in the way Samoan people view themselves. As Ravulo (2016) said: "the Samoan understanding of self is not understood in the individualistic sense; rather it is comprised of integrated aspects that deeply impact each other" (p. 193). Huffer and So'o (2003) emphasise the importance of social cohesion and consensus to Samoan society. Building consensus, especially within governance structures, is seen as a 
symbol of strength and an important continuation of the fa' aSamoa. The opposite of this is the disregard and contempt held for dissenting opinions viewed as "decisiveness, egocentrism, selfishness, ambition and considered devoid of dignity" (Huffer and So'o, 2003, p.281).

The fa'aMatai is a system based on a hierarchical lineage that serves as regular political administration (Taua'a, 2014). The traditions and salutations of the fa'aMatai manifest in the fa'alupega. The fa'alupega is, in its primary form, an oral history. The primary understanding is that it describes the history of the village matai titles, but it can also be described as the description of the village constitution. Taua'a (2014) writes that "one only has to hear the fa'alupega of a village being recited to be able to deduce immediately which matai(s) and title(s) make up the core authority (pule) in the village" (p. 60). This meeting in which the fa'alupega is given can be seen as a manifestation of the village as an autonomous, self-governing entity.

As well as the emphasis on consensus, Samoan society has a strong focus on hierarchies. The Samoan Government classifies youth as being from the ages of 18 to 35. Following this, in traditional council fonos, only the elders and matai are allowed to speak. According to Huffer and So'o (2003), the traditional Samoan emphasis on hierarchy and consensus was reinforced by the colonial experience, which united Samoans against the common colonial enemy.

Though fa' 'aSamoa and fa' aMatai are not the main research focus, they are necessary concepts for understanding how religion and business interact. They are essential to the identities and lives of all Samoans. This idea will reflect on business practices in the way Samoans engage in the spirit of fa' 'aSamoa with both business and government alike (Cahn, 2008). In such a small population, church and fa'aSamoa are inherently tied to each other: as there are two ways of thinking, informing, and working together.

It is generally accepted that "religious organisations are the oldest social service networks known to mankind" (Thornton et al., 2012, p. 780). Religion is an inherently social act, and most religious practices are communal in nature (Baker, 2015, Guiso et al., 2003). Fa'aSamoa is incredibly collaborative, and therefore the combination of religion and traditional culture makes Samoan society completely socially and community-minded. Cahn (2008) found that the fa'aSamoa businesses she encountered were more concerned with family fulfilment than economic pursuit. In 
her research, Cahn also found that the influence of fa' aSamoa played a larger role in business in the villages than in Urban Apia, due to the stronghold matai have in the rural villages and their ability to enforce church and agia (family) commitments. Western business models prioritise cash flow and investment, but this is not the concern of fa'aSamoa.

\subsection{Development Strategies}

The Government of Samoa produced the 'Strategy for the Development of Samoa 2016/17-2020/21' (SDS) in 2015. This strategic document outlines the goals of development for Samoa and provides a roadmap for progress. Key outcome five centres around business development. It focuses on enhancing the participation of the private sector in development, aiming to harness business to provide jobs and opportunities for Samoa's development. The prioritisation of the private sector marks a move towards a more globalised economy in Samoa. Outcome three of the Small Island Developing States Accelerated Modalities Of Action Pathway (S.A.M.O.A Pathway) (2014) focuses on 'Sustainable and Inclusive Economic Empowerment.' the outcome expresses an aim; by 2022, "people in the Pacific, in particular youth, women, and vulnerable groups, benefit from inclusive and sustainable economic development that creates decent jobs, reduces multi-dimensional poverty and inequalities and promotes economic empowerment" (p. 17). The detailed description includes the need to foster 'entrepreneurial culture' and prioritise business. The outcome also highlights the need to align the private sector and development aims with regional frameworks and culturally sensitive and relevant approaches.

\subsection{Religion in Samoa}

Christianity is the dominant religion of Samoa, with most figures sitting around 98\% (U.S Central Intelligence Agency, 2018; Thornton et al., 2010, Samoa Bureau of Statistics, 2016). Thornton et al. (2010) found that $70 \%$ of this population adhere to one of three mainline churches: Congregational Christian commonly referred to as EFKS (pronounced eh fa ka sa,) Catholic and Methodist in order of size. The other $30 \%$ belonging to newer denominations: Latter Day Saints, Assemblies of God, Seventh Day Adventist. The U.S Central Intelligence Agency (2018) estimates the denominational breakdown as the following: protestant $52.6 \%$ (Congregationalist 
29\%, Methodist 12.4\%, Assembly of God 6.8\%, Seventh Day Adventist 4.4\%), Roman Catholic 18.8\%, Mormon 16.9\%, Worship Centre 2.8\%, Other Christian 6.3\%, Other Protestant 2.4\% and other 2.4\% (includes Baha'i, Muslim), none 0.2\%. These two data sources show that religious affiliation is majority Christian, with the total of those belonging to a faith outside Christianity or with no faith existing at around 2$3 \%$.

The Samoa Bureau of Statistics (SBS) published the 2016 census results without a full description of all denominations in Samoa. The survey instead included 6 of the mainline denominations as represented in each political district. Below is an excerpt from the table. The complete table is in the annexes.

\begin{tabular}{|c|c|c|c|c|c|c|c|c|}
\hline Total & $\begin{array}{c}\text { EFKS/ } \\
\text { Congregation CCS }\end{array}$ & ist & $\begin{array}{l}\text { Roman Catholic } \\
\text { Church }\end{array}$ & $\begin{array}{l}\text { Latter Day } \\
\text { Saints }\end{array}$ & $\begin{array}{l}\text { Assembly of } \\
\text { God }\end{array}$ & $\begin{array}{l}\text { Seventh Day Adventist } \\
\text { (SDA \& SISDAC) }\end{array}$ & $\begin{array}{c}\text { Total of } 6 \\
\text { denomination }\end{array}$ & tion \\
\hline 195979 & 56818 & 24228 & 36766 & 33077 & 13399 & 8534 & 172822 & 88 \\
\hline
\end{tabular}

From this table, we can see that the adherence to the mainline denominations represented is only $88 \%$, and SBS had noted this was down from 92\% in the 2011 census. There is no data to show if the other denominations make up the additional $10 \%$ to support the $98 \%$ rating from the alternative sources. The denominational outline from the U.S Central Intelligence Agency (2018) lists the further denominations with the following percentages - "Worship Centre 2.8\%, Other Christian 6.3\%, Other Protestant 2.4\%," which does provide insight into the further $10 \%$ missing from this data. SBS has also measured this through 'attendance' to one of the above churches throughout Samoa, so perhaps this primarily measures those who attend church but does not count those who identify with a denomination while not regularly attending services. SBS does describe Samoans as being "devout Christians," which suggests other populations could make up a further $10 \%$.

As Christians make up the majority, there is very little tension between Christian denominations, and in some cases, families and individuals move between churches throughout their lifetimes. Hardin describes how "interdenominational coexistence is an everyday activity that crosscuts other meaningful social forms of difference: family titles, geopolitical location, occupation, age and gender" (Hardin, 2016, p.381). Thornton et al. (2013) has found that the movement between denominations can be tied to the increasing financial expectations of the traditional churches. These expectations led to people moving from the more traditional mainline churches such 
as the London Missionary Society or 'EFKS' to the newer, more evangelical churches such as the Assembly of God or the Church of the Latter Day Saints.

Although no religious affiliation rivals that of Samoa's Christian faith, another notable religion present is the Baha'i faith. Samoa boasts one of only eight Baha'i mother temples in the world and is home to the only reigning Baha'i Monarch of modern times, his highness Maleitoa Tanumafili II. Maleitoa is one of the most paramount chief titles from the four king families of Samoa. These titles are ingrained in the Samoan political system as the 'Head of State' who governs the country next to the democratically elected Prime Minister. The reign of his highness Maleitoa Tanumafili II was viewed as very important in the Baha' $i$ faith, as he was the only reigning Baha' $i$ monarch in modern times. Despite this, the Baha'i faith, as shown above, is still relatively small.

\subsection{Catholicism in Samoa}

In the spirit of academic guidelines, this section will detail some literature surrounding the Catholic Church in Samoa. Although this feels like a spoiler in the narrative thread of these findings, Catholicism must be discussed. There is an overrepresentation of Catholic business owners in the research. The following literature will inform the findings and discussion section.

Very little published work exists on Catholicism in Samoa. The only accessible piece of work is "A history of the Roman Catholic Church in Samoa 1845-1995," written by Reverend Joseph Heslin and published in 1995. Cardinal Pio Taofinu'u, the Archbishop of Samoa, wrote the forward and noted that this work was:

"A Marist story from the standpoint of the priests who came. It is a story of spreading faith for those who accept what it means to be catholic. It is also a story of the Samoan Culture being merged with the culture of the West, both in government and social life as well as a movement of faith" (Heslin, 1995, p. 4).

Catholicism arrived in Samoa in 1845, primarily through the French Marist Brothers under the direction of the Vatican. They were sent under "propagation of the faith" on a mission intended for New Holland (Australia) and the surrounding islands, including 
Polynesia. They landed first in Leatatele, Savai'i. They were not the first missionaries to arrive as Tongan Methodists had entered in 1828, and the London Missionary Society sent their first mission in 1836.

The Marist Brothers successfully converted the villages in which they landed, but arguably their best success was in providing education in Samoa. The Marist Brothers opened the first Catholic school in Saleufi, Apia, in 1871. However, this school collapsed in 1877 because of the civil war. In 1888, they opened the first school for Europeans in Mulivai, the site of the current Catholic Cathedral. Reverend Heslin (1995) wrote, "If a Marist brother called for all past pupils to raise their hands, more [sic] than $30 \%$ of all the men and boys in Samoa would have their hands in the air" (p. 91). As the Marist education system was so vast, the government understood they were shouldering the cost of education in the nation. Throughout the 1900s, the generations of Marist educated children also grew. As Heslin described it: "[the government] in their turn they supported the Marist brothers in every way possible" (p. 99).

The first described involvement of the Catholic Church in business-related activity was in the Catechists' credit union scheme, supported by the Catholic Mission (Heslin, 1995). The Catechists were members of the church who supported the priests, gaining an education, and their families being given land to establish a plantation.

A further excerpt from this work is essential to the ideas of this thesis. Heslin has described in this chapter, the intersection of Catholicism and the fa' 'aSamoa:

\footnotetext{
"As we set out to tell the story of the growth of Catholicism within the fa' aSamoa, we can only narrate its historical beginning amidst a culture which was beginning to change colours under the influence of outside forces. Some of these outside forces were beginning to affect the traditional culture... Gradually the customs, habits and ways of life would disappear and be forgotten and be replaced by a Samoan interpretation of the "papalagi culture" for now by other cultures were being integrated by marriage, family influence and occupational opportunities, but most of all, by the influence of religion which entered into the very core of their way of life" (p. 1).
} 


\subsection{Christianity and Governance}

Christianity, deeply enshrined in the constitution of Samoa. The declaration of the constitution reads:

"In the Holy name of God, the Almighty, the ever loving,

Whereas sovereignty over the Universe belongs to the Omnipresent God alone, and the authority to be exercised by the people of Western Samoa within the limits prescribed by His commandments is a sacred heritage;

Whereas the Leaders of Western Samoa have declared that Western Samoa should be an Independent State based on Christian principles and Samoan custom and tradition..." (Constitution of the Independent State of Samoa, 1960).

This excerpt describes a state deeply engaged with Christian principles, listing them before the Samoan culture. While Samoa's legislation is less explicit, several laws are heavily based on Christian principles, including sodomy laws. Informally it is often stated that "Samoa was founded on God," which can be seen throughout the nations on buses and street signs and will sometimes be stated in opening prayers of official ceremonies. 


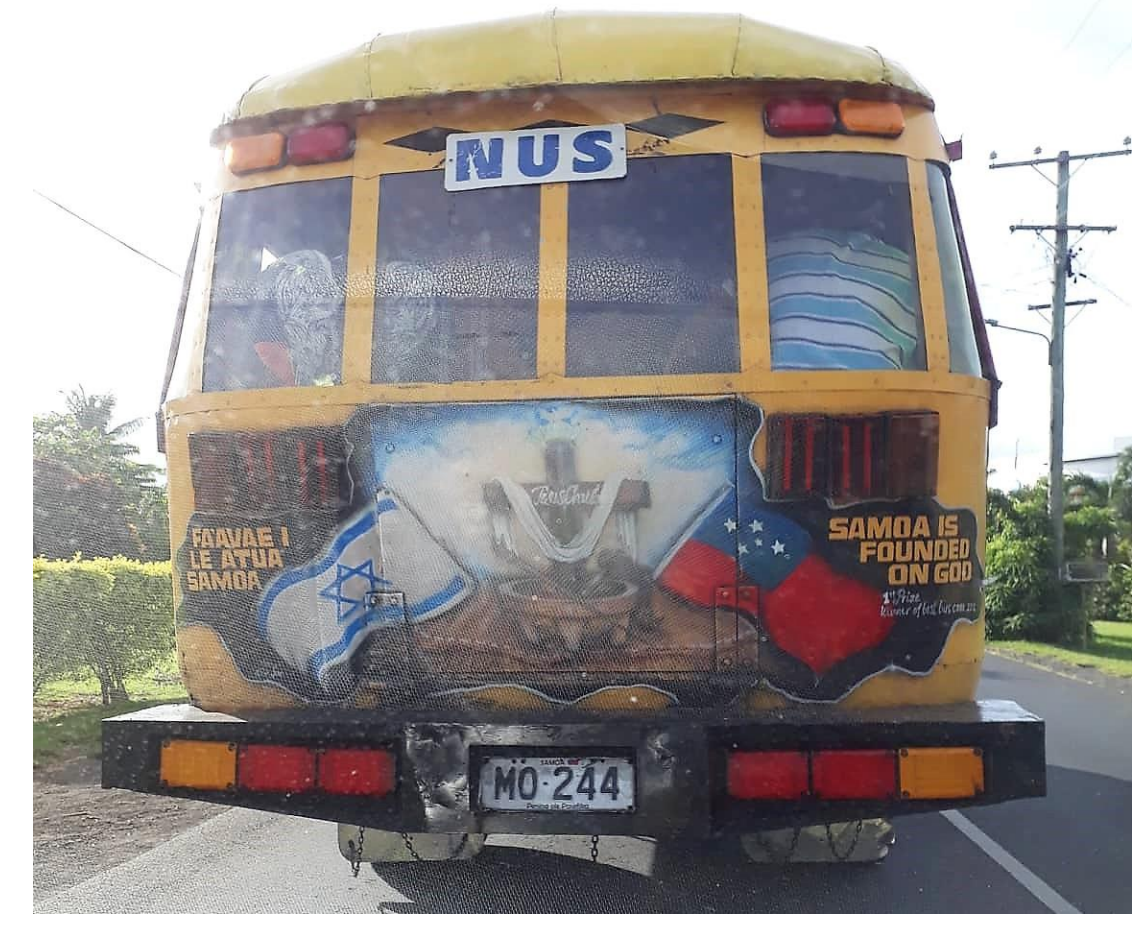

'Samoa is Founded on God,' Bus, Malifa, Apia, Samoa. 23 ${ }^{\text {rd }}$ November 2018.

While in legislative practice the Christianity is not enshrined, the intersection of church and state is inevitable due to the nature of a religious society. The most recent and controversial example of political conflict between church and state was the Government of Samoa's decision to tax church Ministers, effective January 2018 (Feagaimaali'i-Luamanu, 2017, Radio New Zealand, 2018). This controversial law has resulted in the Government of Samoa taking Ministers to court in November and December of 2018 as they refused to pay the required tax (Radio New Zealand, 2018). In this specific case, the actions of the government were widely criticised as the public did not agree with charging the Church Ministers. However, those who agreed censured the Ministers of demanding support for their dissent from their congregations.

\subsection{Religion and Financial Giving}

In Samoa, large amounts of money are given to the church regularly. Somewhere between $20-50 \%$ of a family's income will be given to the church or the pastor in the form of tithing and compulsory donations (Thornton et al., 2010). 
Macpherson and Macpherson (2011) found that around 52 million Western Samoa Tala (WST) (USD 19.6 million $^{3}$ ) is spent on church and cultural obligations, therefore removed from the formal economy. This financial decision could be refuted as it is often put back into the economy through construction contracts or buying food and gifts. However, a large portion of this money is likely to be kept by the church and faife'au. These records are not published, nor are they likely to be if this is the case. Nevertheless, these obligations can be crippling to some families, often remittances are required, or large and unforgiving loans are taken out to make payments.

Although families are only supposed to give the excess money that they have to the church, families from particularly religious villages will prioritise church payments over school fees, food, and electricity (Macpherson and Macpherson, 2011; Thornton et al., 2010). These payments are a source of pride; no family wants to be seen to be giving the least. Especially in rural villages, some churches practice folefole, which is when the amount of donations given by each family is read out at the end of the Sunday service. This practice may be intended to inspire shame in the congregation and encourage further giving.

Thornton, Kerslake and Binns (2010) found the move to the newer denominations as the costs associated with the mainline churches grow. The newer denominations, such as Assembly of God, claim to be the 'Church of the Poor' requiring fewer donations. Internationally, the Mormon church structure is that everyone tithes $10 \%$ of their income, which goes into a pool of money that is distributed across the global Mormon church. This amount of tithing can be seen as a large input in countries without widespread compulsory giving and higher wages. However, the opposite is true in Samoa, where the usual contribution is much higher than the expected 10\% (McBride, 2007; Thornton et al., 2010). Fairbain (1988) wrote that the Congregational Christian Church of Samoa (EFKS) expects a more considerable amount of money compared to other churches, particularly the Catholic Church.

Though there is movement between denominations, it can be risky, as leaving your church can result in isolation from your village and community. Apia's westernisation has been enabling this option, but those who chose to leave their rural villages face an uncertain future. A common punishment for wrongdoings in villages is to be exiled

${ }^{3}$ XE Currency Converter. 26/01/2019 Exchange rate. 
from it. Those thrown out of their villages are most likely to suffer in the capital. Thornton et al. (2010) found that urban landlessness and poverty are among the fastestgrowing issues in Samoa. Leaving the village and church community for Apia results in people without the traditional familial support systems, and currently, the state does not provide support to those in vulnerable situations. Communities such as those of people who are no longer part of their traditional villages or non-traditional villages on free-hold land are providing new challenges to the nation's religious and social structure.

Another widespread practice of financial obligation are fa'alavelaves. Fa'alavelave describes any exceptional activity that disrupts the usual routine of daily life. The call for a fa'alavelave often means large payments required for events such as weddings, funerals, medical care, and other extraneous circumstances. Though they are not specifically church-related payments, these obligations involve donations given to every priest, politician and matai who attends any funeral or wedding service. As family demands bigger weddings or larger tombstones, the costs for a fa'alavelave are sometimes exorbitant.. This custom is deeply ingrained in modern church practices. Samoa receives a large number of remittances every year - 186 million USD - (Central Bank of Samoa, 2018). While there is currently no way of tracking what this money is spent on, it is likely to be partially used to make church and fa'alavelave contributions.

\subsection{Samoa, Religion and Development}

Developing nations tend to be highly religious, and Samoa is no exception. In development, it is vital to consider the core attitudes and values of communities. In many cases, religion and the church are the central tenets of societal, cultural, economic, and political governance (Peterson and Le Moigne, 2016). Thornton et al. (2013) state that "Kinship and Christianity traditionally form the foundation for all political, economic and social organisation and are inextricably linked” (p. 357).

Development is primarily conducted through wealthy countries funding poorer nations, and there is a tendency to ignore or avoid religion within the process of development. The wealthier nations champion the separation of church and state, believing it enables the development process and, therefore, excludes the church from 
projects, programmes, and aid (Ver Beek, 2000). A growing body of work negates this practice. In much of their work, Thornton et al. $(2012 ; 2010)$ advocate for 'effective partnerships' to create social change.

Participating in religion is incredibly important for engaging with a religious population. Community structures of the church can offer grassroots engagement and vertical and horizontal social capital that can ensure the success of development projects (James, 2011). Ahdar (2013), in 'Samoa and the Christian State Ideal' expresses how the social trust religion has created could become a central mechanism for grassroots development.

The literature has shown that many factors, such as collective entrepreneurship and trust and knowledge networks, play a factor in successful businesses. These factors are all present throughout religious communities and networks. As scholars such as Ratten (2014) have suggested, there is a need to research and identify the factors that impact successful business and entrepreneurship as a means of understanding how to support successful growth for sustainable development. Several factors present through the literature alluded to the traits of religion - such as the successes of community-led and collective entrepreneurship in developing countries (Ratten, 2014; Yan and Sorenson, 2003).

The complex interconnectedness of a religious population and business suggests that there are many ways in which these factors clash and complement each other. It is important to note that religion is spiritual in nature and may be practiced regardless of its business benefits. James (2011) points to the "complex world of faith" (p. 116) and the inherent difficulty in pinpointing the role that religion plays in the life of any individual. In a country with the rate of religion and saturation of faith present, the literature suggests that in some cases, decisions made regarding religion may be viewed as more important than businesses, despite the potential consequences of these decisions.

As Samoa has directly outlined in the SDS, business development and the private sector are a key focus for Samoa's future. These focal points should create Dana's (1993) enabling environment and Ratten's (2014) prediction of sustainable growth through business success. 


\subsection{Conclusion}

The literature shows that religion in Samoa provides a complex and messy ground on which to do further research. The various intersections of Samoan society help and hinder the ability of those in the private sector to conduct business in the uninhibited way they might in other countries. Overwhelmingly, cultural and religious practices form the basis of life in Samoa, which creates an ethnically and religiously hegemonic population that is incredibly proud of its nation of origin. The literature has pointed to some areas where religion and its intersection with business may be flawed or problematic. This is especially prevalent in the case of fa'alavelave contributions and tithings, and the great expectations on the congregation to give. More broadly, the literature suggests that Samoa may begin to face some further societal issues, with landlessness and urban poverty.

\section{Methods and Research Directions}

Statement of Situation: Samoa is a highly religious country. Organised religion greatly affects the population and all aspects of society, including the private sector. Purpose: The purpose of the study is to understand what kind of impact organised religion has on the private sector, from the perspective of business owners.

\section{Research Questions:}

What is the role of religion in business in Apia, Samoa?

In what ways does religion directly affect the daily running of a business?

How do business owners perceive the role of religion in their businesses?

What do business owners think is the way forward for the relationship between religion and business?

\subsection{Conceptual Framework:}


For the research, I will use a religion and development framework. This framework is based on the idea that "embracing human development requires taking peoples' world view seriously" (James, 2011, p. 112). This framework acknowledges religion as a complex phenomenon that influences various behaviours, including cultural, institutional and economic (Peterson and Le Moigne, 2016). The church in Samoa is so meaningful to the people, governance, and institutions of the nation that it seems impossible to research Samoa without considering Christianity at its core (Macpherson and Macpherson, 2011; Thornton, Binns and Kerslake, 2013).

The conceptual framework provides the lens through which to view the research and how the data was analysed. In this case, this means the research is framed around how business owners perceive religion in their businesses and viewing this as an influential factor and acknowledging its impact. The framework suggests that without understanding religion's role, we cannot truly understand business. Therefore, we cannot aid the development and growth of business and Samoa as a whole. The framework has been chosen as scholars such as Thornton, Sakai and Hassall (2012), Peterson and Le Moigne (2016) have advocated for a more serious approach to religion and religious communities in development work.

\subsection{Methodology}

Talanoa Methodology came from Maori and Pacific fatigue of western research methods that did not represent them or the traditional pacific ways of creating knowledge (Vaioleti, 2006; Tecun et al. 2018; Farrelly and Nabobo-baba, 2014). The methodology aims to counteract the disdain for methods that produced research that was not helpful to the participants and the community or holistically failed to understand place and culture. Viaoleti had found that "even Pacific researchers, endeavouring to create Pacific knowledge with their own people, must strictly adhere to research methods that are foreign to them" (Vaioleti, 2006, p. 23). Tala means to inform or tell while noa means nothing in particular, which embodies a less rigid, western process discussing and researching, recognising that purpose is not the main reason for conversation and knowledge exchange (Tecun et al. 2018; Farrelly and Nabobo-baba, 2014). In Samoa "Talanoa was also described as the method by which business and agency leaders receive information from the community, that they use to make decisions about civil, church and national matters" (Vaioleti, 2014, pp. 193). 
This methodology is about using discussion to share information in an unstructured manner, without a rigid framework. Ravulo (2016), describes the talanoa methodology as an endeavour to use Pacific ways of knowing and belief systems as a foundation for conducting academic research. Historically, this has failed to account for the cultural context in research design using the Pacific understanding of self, not individual but collective. The idea is to create knowledge sharing through conversations that do not hold a defined research framework but instead are about empathy and the sharing of self. This notion is integral to the methodology, creating knowledge is central to the Pacific understanding of being and knowing, and not the western framework of science. The idea is that "research [is] for the knowledge sharing of our participants not the other way around" (Farrelly and Nabobo-baba, 2014, p. 328). The framework is about reversing the purpose; research participants are not subjects for observation but instead an integral part of a process that informs outcomes that benefit the participants and not the researchers. The intention is for the research process to be less exploitative. It aims to balance out the power relationship that can exist between the researcher and the participant.

Talanoa methodology is conducted with several aspects. The first is that it requires an extended presence, usually requiring residence in the place of research (Farrelly and Nabobo-baba, 2014; Vaioleti, 2006). This is because a talanoa framework accommodates multiple truths. Ravulo (2016) writes that this is because there is no single version of the truth; the pacific framework relies on intuition rather than rationalisation. Therefore, multiple truths cannot be uncovered merely through research. They must be experienced and lived for the research to be in a talanoa framework.

The second is that any interviews or discussions conducted as part of research require an empathetic and collective knowledge sharing. This process allows the participant to freely to choose the conversation's direction, and the topics covered during the informal chat (Vaka et al., 2016). The conversation needs to have an aspect of sharing between researcher and participant, as the conversation should create closeness and not objectivity like the western framework requires (Farrelly and Nabobo-baba, 2014). These research practices are centred around decolonisation of knowledge and recentring the power of narrative and storytelling in the indigenous peoples' hands. 


\section{Embodying Talanoa Methodologies}

My research writing was conducted from Apia, Samoa, to truly engage in talanoa research practices. I moved to Samoa in November 2017 before beginning the research process. Thus, I designed my study while developing an understanding of being and knowing in Samoa and how business works. This direct experience informed the questions of my survey and the way my interviews have been conducted. It has also meant that the process of information collection has been long and, at times, slow, embodying 'island time' or pacific frameworks of time and being.

My research participants are people that I spent time around and came to know personally and through my research. It is in the spirit of multiple truths and seeing people not as only individuals or business owners, but as collective spirits with families and communities that inform who they are and the narratives they have to tell. It has also meant that within the general research process, I shared aspects of myself with the participants in my work. I contributed to their businesses daily, using their services, buying their products and forming trusting relationships. Recruiting participants was a more straightforward process than if I had asked them to share information without having already established those relationships. The collective feeling of shared trust and the Pacific, Samoan spirit of helping out the people around you meant that the business owners I know were happy to help and participate in a research process to which they felt they could contribute. Those who were unsure about the subject matter trusted me enough to engage in the research, despite being apprehensive.

\section{Working with the Conceptual Framework and the Methodology}

I have presented here, two lenses through which to view the research. The two interact importantly: the religion and development framework provides the basis for research on two global issues - religion and business, with the view of making sure they are understood and represented in development work and growth. The talanoa methodology provides the grounding for taking these ideas seriously. Through talanoa research processes we begin by being mindful of the culture, centering it in the research and creating a baseline for understanding before discussing religion and business ideas. 


\subsection{Methods}

This research will involve both qualitative and quantitative methods. I chose to use mixed methods to gain a multi-faceted understanding of the situation, through numbers and data that represent the business aspect combined with personal and situational accounts of how religion interacts with businesses. This blended research offers a deeper understanding of how religion, its practices and obligations, affect businesses. The aim is to use the conceptual framework to address development, especially economic development, through the worldview of those participating. As previously discussed, my interviews were informed by talanoa. The participant directs the discussion to inform how the knowledge and information was shared.

The interviews took place usually in the location of the owner's business. We either sat down for a general discussion or shared a coffee during the conversation. Two interviews took place in a café where I regularly saw these business owners, and in these cases, we shared a coffee and some food during the interview.

\subsection{Participants}

The participants are business owners in the Apia Urban Area. During this process, some business owners requested that I go through the survey with them, and asked for explanations of some questions. Many of these business owners became known to me during the time that I spent in Samoa. In the case where those whom I worked with on my research were not already friends or acquaintances, many became friends, especially those who found the study interesting or meaningful. In many cases, I was approached again after a survey or interview. Often, I was asked about how the research process was going. These participants were actively interested in the process, hoping to gain further insight into the topic, after the research.

In Apia, businesses are generally recognised as falling into one of two categories - the formal and informal sectors. My measure of what constituted the formal sector was that the business would have windows and doors. The informal sector was market vendors and small side shops, which would have provided different outcomes in this research. This study was conducted within the formal sector. Therefore, participants were all owners of businesses within this sector. 
As stipulated in Victoria University Ethics Approval guidelines, all participants gave written consent or selected 'yes' to consent in the online survey before participating in the research. This consent was renegotiated throughout the research process. Participants were given the option to opt-out of the study before September 30 ${ }^{\text {th }}, 2018$. All participants were given an information sheet or read the information section before participating in the survey or interview. In some cases, a discussion took place surrounding the nature of, the reason for, and the intended outcomes of the research. This act of information sharing was also part of the research, sharing knowledge and informing consent. 'Informally chatting' with the participants I did not previously know was also a way of building trust.

\subsection{Main Methods}

This research involved semi-structured interviews and surveys. The semistructured interviews contained questions that addressed how business owners incorporate religion into their own lives and business practices. Questions also addressed the impact that their church and religious beliefs had on how they conduct their business practices and view economic development. The interviews were less structured, and the questions were only prepared as a general guide (See Annex 2). The questions reflected the survey regarding similar topics. However, through a talanoa framework, discussions were led primarily by the participants, with them sharing stories and examples of their own experiences with religion and business.

Interviews lasted from twenty minutes to an hour, accounting for the time available to business owners. A total of 7 interviews took place. According to the talanoa framework, the interviews varied in substance and emphasis according to the specific topics that business owners felt the most compelled to discuss. Only one recorded interview took place with each interview participant. However, over the thesis duration, I have had multiple conversations with interview participants about the research, which has informed the ideas and themes presented in the discussion and conclusion. 
The surveys were conducted through snowball sampling ${ }^{4}$, known networks, and cold calling businesses; this involved visiting businesses in the Apia Urban Area with paper copies of the information sheet, consent form and survey. Sometimes this was unsuccessful, as the business owner was not present. However, the nature of small businesses in Apia is such that many business owners were present and working. Some businesses requested an online version of the survey; I gave them a link to a Google survey, which included the information sheet and the consent form at the beginning. These businesses were already known to me, or the link was sent to the business owner through a mutual friend, utilising snowball sampling. Surveys were conducted primarily in person, often with myself present. Some participants requested to complete the survey with the researcher, as they wanted to ask questions throughout the process. No leading answers were given, and participants were encouraged to answer independently and were told there were no possible wrong answers

The survey had two sections. The first section was yes/no answer questions, such as, 'are you religious?', or 'are you Christian?'. This section also collected details such as the opening hours, where the owner was born, if they or their business gives money to the church, and if staff members were given IOUs for religiously affiliated activities. This section aimed to collect data on the demographics of the business owners and answers to specific questions regarding the direct impact religion has on their business (See Annex 1).

The second section was a series of questions answered with a scale from 1 to 5 , the first part from 'very religious' to 'not religious' with questions on how religious they/their family/their community or business is. The second part went from 'a lot' to 'a little' and asked questions about the influence of religion, family, and community in their business. The final three questions were scales from positive to negative. These asked about the role of religion, family, and community in their business. The questions aimed to provide data on impressions of how religion works for the individual business owner. No personal details were asked in the survey, with the only possible identifier being the church or denomination with which each participant was affiliated.

\footnotetext{
${ }^{4}$ Snowball sampling involves identifying a small group of accessible participants, and utilising their connections to include less immediately accessible network members (Sedgewick, 2013).
} 


\subsection{Analysis of Results}

The survey data was compiled in a spreadsheet and presented through tables and graphs. Some of the data, displayed in the same graph, to show the correlation between the different questions and results.

The interview results were manually coded into related themes such as closing on Sundays, loans, theft, power, and morality. Often these themes correlated with and supported the survey data. Quotes have been included in the results section to show the raw data stories and include voices in the results.

The quotes have been used to create a narrative behind the raw data of the surveys. Allowing the participant voices to be included in with the data can provide the context and explanation for the data. The interviews also offer further insight through analysis, not just through what the participants said but by demonstrating the unconscious bias of speech patterns and emphasis on particular words and concepts. Analysis of multiple interviews can also demonstrate trends that appear through those patterns.

I also used the transcriptions of the interviews to analyse the text and reveal themes. The first way was to pull out important words like 'god,' 'church,' or 'religion' to count how many times these words were used. This analysis shows what can be gleaned from how people speak and the importance of their use of words. The themes are presented in the discussion section with sub-sections of related topics that provide a more detailed analysis.

\subsection{Positionality}

As a palagi New Zealander, I am incredibly mindful of my position as an outsider. While I have lived here for over a year and feel very much at home here, as I have described in my prologue, I am still aware that I am not Samoan, and this is not a culture of which I have the right to comment. I have been conscientious in presenting my findings; they do not represent my views, but that of the participants. Had I not been living in Samoa for a significant amount of time before my positionality as a researcher, I would have had less expansive conversations and could not have utilised my existing knowledge and established relationships. This immersion was at a basic 
level, such as knowing businesses, events or villages and having an in-depth and working knowledge of both the cultural practices, the language, and the religion.

During the research process, I approached all conversations and discussions mindfully, with neutrality. If anything, I tried to lean towards a positive approach to the discourse, which I felt allowed space for the participants to present their feelings towards the topic, which were often positive.

Living in Samoa and having a reasonably extensive network meant that, upon reflection, I may have been unnecessarily timid about approaching participants. Knowing that there could be broader implications of my research and that this would carry into my life meant that, in some cases, especially with larger businesses whose owners are incredibly crucial to the Samoan society. I did not approach them when I probably could have and should have. While this hindered me in a few cases, I utilised my existing networks while building relationships and connections throughout the research process.

\subsection{Evaluation of Methods}

The combination of surveys and semi-structured interviews allowed for wellrounded results, with data that was supported by human stories and perceptions. If I were to conduct the research again, I would spend more time formally presenting the initial findings to the participants and conducting further rounds of interviews or interviews with those who only did surveys to gain a deeper understanding of the themes that presented themselves. This adjustment would create a richer dialogue and a more participatory talanoa research process.

In the research process, the main change was putting the survey online for completion without face-to-face interaction. While this did not present any issues, many face-toface, survey participants had questions or wanted reassurance that they were filling it out correctly. This support might have been useful to the participants if they knew that they could have had this if they wished. 


\section{Results}

This chapter explores field research findings conducted between March and September of 2018, aiding understanding of the role that religion plays in business in Apia. This chapter explores the salient themes of the research that tie into the theories of religion, business, social capital, morals, and ethics while remaining uniquely Samoan. This chapter aims to present statistical findings in a raw form, with graphs, percentages and numerical representation, and weave these with the stories of the business owners and their thoughts, feelings and frustrations.

As described in the methods chapter, most of the seven business owners interviewed were known to me before the research, and some of them were friends. Thus, the stories and descriptions presented in the findings come in a sometimes uncensored form. In the talanoa way of sharing narratives with the people around you, these words 
come right from the participants' true feelings, and I was privileged to hear them and add them to my findings. This open dialogue also means that these opinions are not just those speaking about their businesses as professionals but of the actual people behind Samoa's businesses and how they fit within their society.

These informal discussions marry the data with the feelings of the business owners. As shown in the literature, the discussion of religion and business can be a profoundly personal experience, both emotionally and spiritually. The findings display this, with the description of staff members as family, or the challenges of power struggles. Although all names have been redacted, the participants described those around them, other businesses, and those in power. Thus, it truly reflects the ties across all parts of the small island nation.

\subsection{Methodology}

The results are presented through wide thematic areas with smaller related subsections. The data from the surveys is combined and supported by the themes and discussions from the interviews. In most cases, the survey questions were expanded upon by the interviews, enabling further explanation of the survey data. In the appendix, interview and survey questions can be found along with graphs that were not included.

\subsection{Findings}

\section{2 a) Religious Affiliation}

\section{Figure 1.}




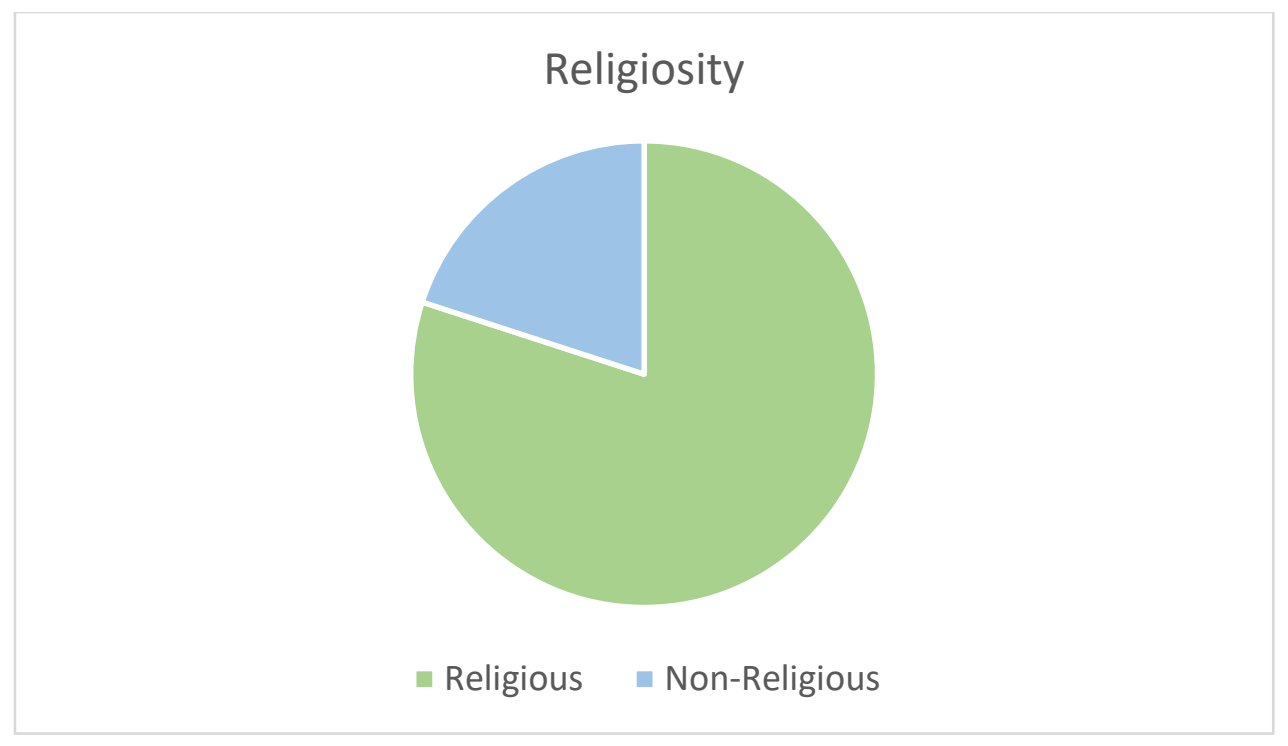

Figure 2.

\begin{tabular}{|l|r|}
\hline Religiosity \\
\hline & \\
\hline Religious & $80 \%$ \\
\hline Non-Religious & $20 \%$ \\
\hline Total & $100 \%$ \\
\hline
\end{tabular}

Figure 1. and Figure 2. demonstrate the religiosity of the participants, showing $80 \%$ of participants identifying as being religious and $20 \%$ who do not identify as being religious. All of whom identify as Christian of some denomination.

While the sample of business owners is still very religious, this is not reflective of the general population's religiosity. If $98 \%$ of Samoans identify as religious, but only $80 \%$ of business owners surveyed are religious, the $18 \%$ drop in religiosity is notable (Samoa Bureau of Statistics Census 2012; CIA World Factbook 2016; Thornton, Sakai and Hassall, 2012). The decline in religiosity amongst the business community is also reflected in the results demonstrated in Figure 5. and Figure 7. These statistics come from the CIA World Factbook (2016) and studies conducted by Thornton et al. (2012) as well as from the data collected from the Samoa Bureau of Statistics (2012). Samoa is also generally regarded as a 'Christian nation' as described throughout the constitution. The business community is somewhat of an anomaly within Samoan society, with this high $20 \%$ non-religiosity rate.

\section{2 b) Denominational Affiliation}


Figure 3 .

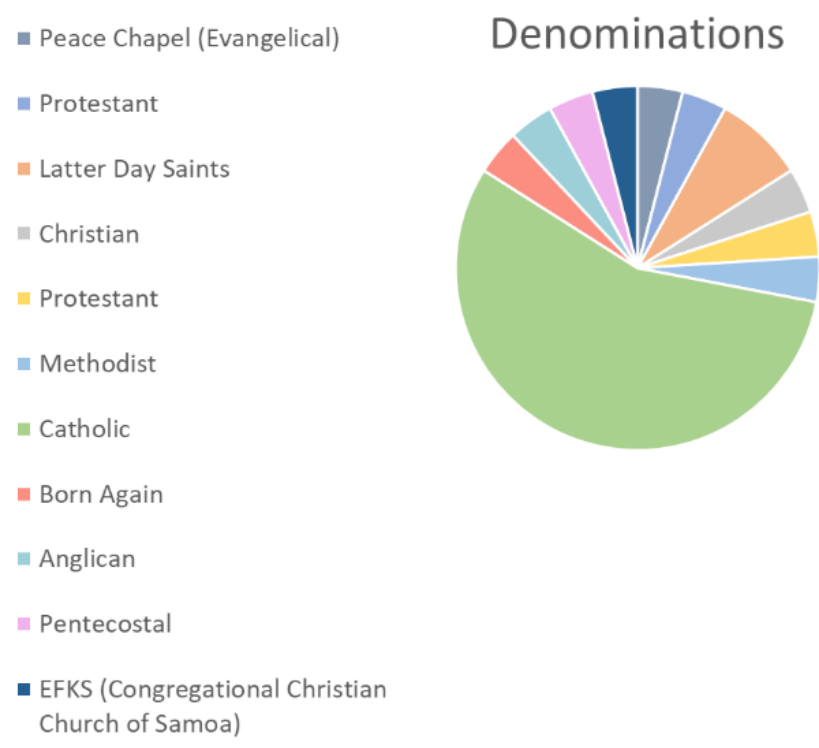

Figure 4.

\begin{tabular}{|l|r|}
\hline Demoninations \\
\hline Catholic & $56 \%$ \\
\hline Latter Day Saints & $8 \%$ \\
\hline $\begin{array}{l}\text { Peace Chapel } \\
\text { (Evangelical) }\end{array}$ & $4 \%$ \\
\hline Protestant & $4 \%$ \\
\hline Christian & $4 \%$ \\
\hline Protestant & $4 \%$ \\
\hline Methodist & $4 \%$ \\
\hline Born Again & $4 \%$ \\
\hline Anglican & $4 \%$ \\
\hline Pentecostal & $4 \%$ \\
\hline EFKS (Congregational \\
Christian Church of \\
Samoa)
\end{tabular}

Figure 3. and Figure 4. provide the breakdown of the denominational affiliation of those who identified as religious. The results show that over half of religious participants identify as Catholic, with all other participants citing a different protestant denomination, except two people, who identified as Latter Day Saints (Mormon). In Figure 5., twenty-five responses to the question about which denomination they adhere to, but only 24 respondents identified as being religious. This participant likely cited 
a Christian denomination to which their family belongs, in the nature of being culturally and circumstantially religious while not actively practicing.

$56 \%$ of participants responded Catholic. Catholics only make up $18.8 \%$ of Samoa as a whole (Central Intelligence Agency, 2018).

\section{Figure 5.}

\begin{tabular}{cccccccc|c|}
\hline Total & $\begin{array}{c}\text { EFKS/ } \\
\text { Congregation CCS }\end{array}$ & Methodist & $\begin{array}{c}\text { Roman Catholic } \\
\text { Church }\end{array}$ & $\begin{array}{c}\text { Latter Day } \\
\text { Saints }\end{array}$ & $\begin{array}{c}\text { Assembly of } \\
\text { God }\end{array}$ & $\begin{array}{c}\text { Seventh Day Adventist } \\
\text { (SDA \& SISDAC) }\end{array}$ & $\begin{array}{c}\text { Total of 6 } \\
\text { denomination }\end{array}$ & $\begin{array}{c}\text { \% 6 denomination } \\
\text { (SDAn }\end{array}$ \\
\hline 195979 & 56818 & 24228 & 36766 & 33077 & 13399 & 8534 & 172822 & 18 \\
\hline
\end{tabular}

Figure 5. shows the SBS (2016) percentage of Catholics $(36,766)$ of the total population $(195,979)$ is $18.76 \%$, again confirming the number of Catholics in Samoa.

The overrepresentation of Catholics could be due to several factors. Anecdotally, the Catholic church requires fewer financial payments. This data is not readily available as churches are not required to report donations, especially as they are often considered ad hoc contributions and not formal payments. It is generally understood that the protestant churches that are more widely represented in the villages have higher tithing and financial expectations. Therefore, Catholics would have more capital with which to invest in businesses. This study was conducted in the Apia Urban Area within the formal private sector. Thus, it involves businesses that needed capital investments to be established. The denominal representation may have been different; had this study been conducted regarding the marketplace, like in Cahn's (2008) research on indigenous marketplace entrepreneurship.

\section{2 c) Background of Participants}

\section{Figure 6.}




\section{Were you born in Samoa?}

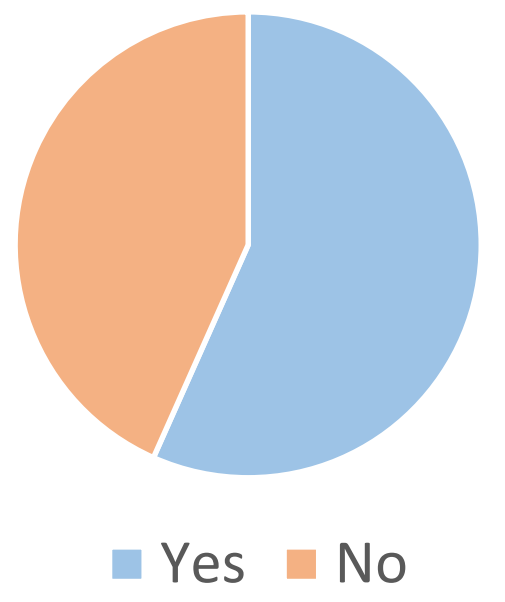

Figure 6. shows the numerical and visual breakdown of business owners born in Samoa. The figure shows that just over half the business owners surveyed were born in Samoa, and the other half were born outside the nation.

\section{Figure 7.}

\begin{tabular}{|ccc|}
\hline Total & Samoa & \% Samoa citizens \\
\hline 195979 & 189035 & 96.5 \\
\hline
\end{tabular}

Figure 7. shows the total number of Samoans with citizenship according to the 2016 census. This statistic is for the number of people holding Samoan passports. However, this number does not represent those born outside the country and still have citizenship according to their parental lineage. This discrepancy does not necessarily support the claim that most Samoans are born in Samoa; it shows that the country is mostly ethnically homogenous, especially since most foreigners do not get passports but instead permanent resident status.

Having $43 \%$ of participants being born outside of Samoa is incredibly high. This percentage does not necessarily mean those born outside of Samoa are not Samoan. However, it is likely that a number of them are not Samoan, and expected to be more than $2 \%$ representative of the rest of the population. This indicates an overrepresentation of foreigners or foreign-born Samoans owning businesses in the Apia Urban Area. Figure 7. includes participants who were born outside of Samoa and are not Samoan. 
What can be deduced is that many participants, significantly higher than represented by the SBS (2016) or by the Central Intelligence Agency (2018), were not born and bred Samoan in the truest sense.

\section{Figure 8.}

\section{Have you spent more than 5 years of your life} outside of Samoa?

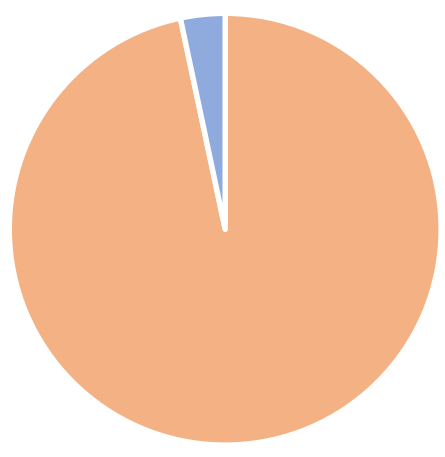

Yes - No

Figure 8. shows the visual representation of the number of business owners that have spent more than five years of their life outside of Samoa. In numbers, only 1 of the 30 business owners surveyed had not spent more than five years outside of Samoa. Of the $57 \%$, or 17 participants, who were not born in Samoa, only one had not left the country for longer than five years during their lifetime.

The vast majority of participants spent some time out of the country. There is a correlation between business ownership and time spent in a foreign nation, which suggests that owners of businesses with windows and doors may be influenced by time spent overseas. One could also assume that this would create a more worldly experience and broaden any person's view on life, ultimately impacting business.

Figure 7. and Figure 8. could also explain the lower rate of religiosity amongst the participants. As only $80 \%$ identify as religious, the $20 \%$ who do not may have come from backgrounds where religion is less important than in Samoa and its culture. It is also very likely that these participants were born and raised in New Zealand or Australia. Both countries are very secular; in 2016 censuses, 35\% of New Zealand (Statistics New Zealand, 2013) and 30\% of Australia declared having no religion (Australian Bureau of Statistics, 2016). 


\section{Figure 9.}

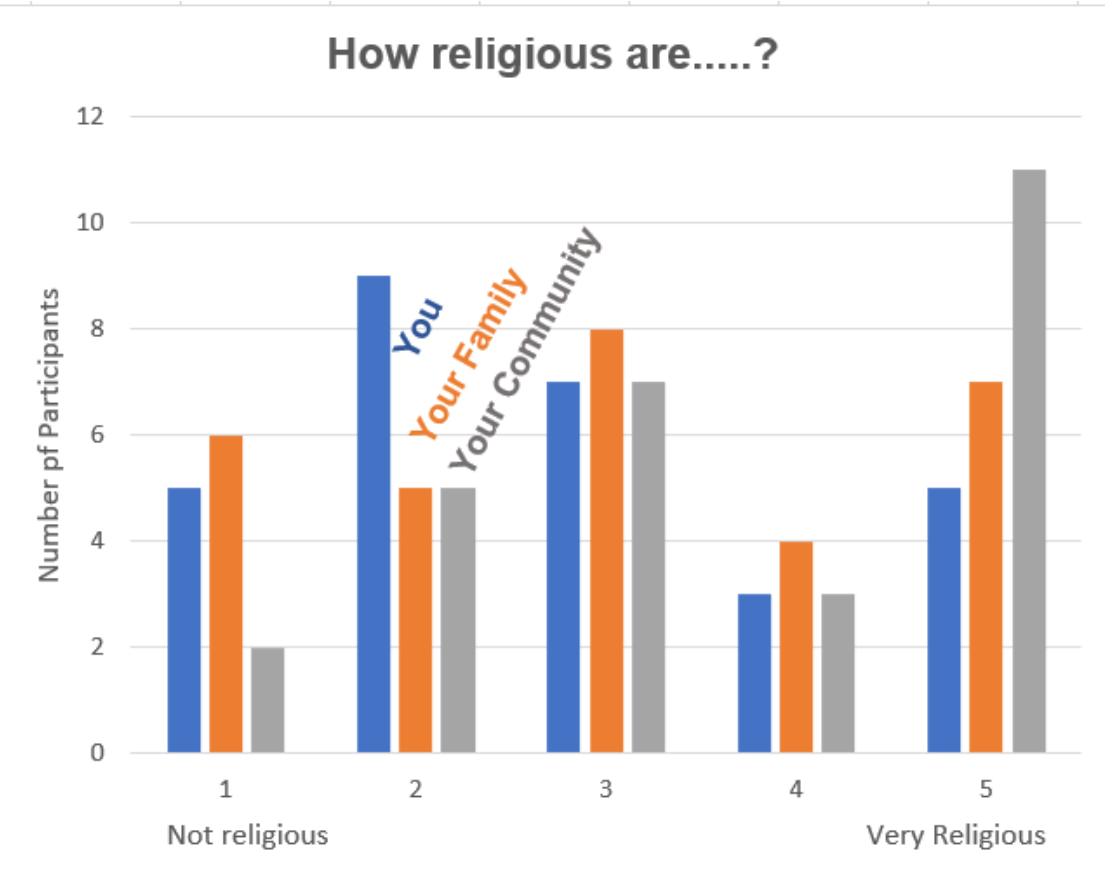

Figure 9. shows the responses for questions regarding the religiosity of yourself, your family, and your community. The graph shows some consensus within the answers. A similar number of people voted '4' on all three, and another similar number of people voted ' 3 ' for all three. The first unexpected outcome of the findings from this question was that the majority felt their community was very religious while not reflecting the same religiosity in themselves or within their families. The other unexpected was the number of people who voted ' 2 ', that felt they were not very religious. The graph shows that business people did not feel religious but feel their families and communities are. The perception appears to be that everyone else is more religious than you are.

This graph provides a contrary snapshot into the religiosity of the participants. As $80 \%$ identified as religious, the expectation would be that the average rating for individual religiosity would be higher than is represented in these findings. This figure could indicate the cultural practices of Samoa - that being religious is a cultural expectation. However, when asked about one's direct personal belief, people are not as outwardly religious as society suggests. 
The contrast between the individual rating of religiosity and the perception of the community's rating as being high could be related to the $56 \%$ majority of Catholics. Supposing the generally accepted standard is that the Catholic Church places fewer demands on their congregation than other denominations in Samoa, then this could explain why the Catholic majority of participants perceive the rest of the community to be more religious than them. This analysis would depend on how the participants measure 'community.' However, due to the lack of denominational segregation, especially demonstrated by Thornton et al. (2010), it is likely their understanding of 'community' includes those of other, more demanding denominations.

\section{Other Business Owners}

In a few of the interviews, the topic of other business owners was discussed. Only one business owner said he would actively talk about religion and business with other business owners, but this was amongst close friends and was not discussed outside this small, private circle. The general perception of other business owners reflected the findings of Figure 9., where business owners perceive their community to be more religious than they are. In this case, the community is the other business owners.

Outside of this one example, the business owners did not talk with each other about religion, some of them describing the topic as "taboo" (Participant B, 2018).

Another business owner described it further: "It's like sort of, going along and saying, talking about sex... it's not taboo; it's just that... it's always assumed that you're gonna [sic] be so enthusiastic about religion that um, they just assume that. They don't even think that you would not be" (Participant $C$, 2018).

While this business owner does not think it is taboo, they liken it to the discussion of sex but then describe it in a more banal way - it is not that you are not allowed to discuss it. Rather, it is assumed there is nothing to discuss because everyone agrees. The above findings disprove this, showing that approximately half the business owners view their business as being not religious or not very religious. However, $80 \%$ are religious themselves - meaning that about $30-40 \%$ are religious but their business is not. Would the study's findings be different if the business owners did discuss the impact of religion on their business with each other? Figure 5. might show different 
results if they knew how their community felt about religion, with a more inter-owner conversation about it?

\section{2 e) The Role of Religion in Society}

Figure 10.

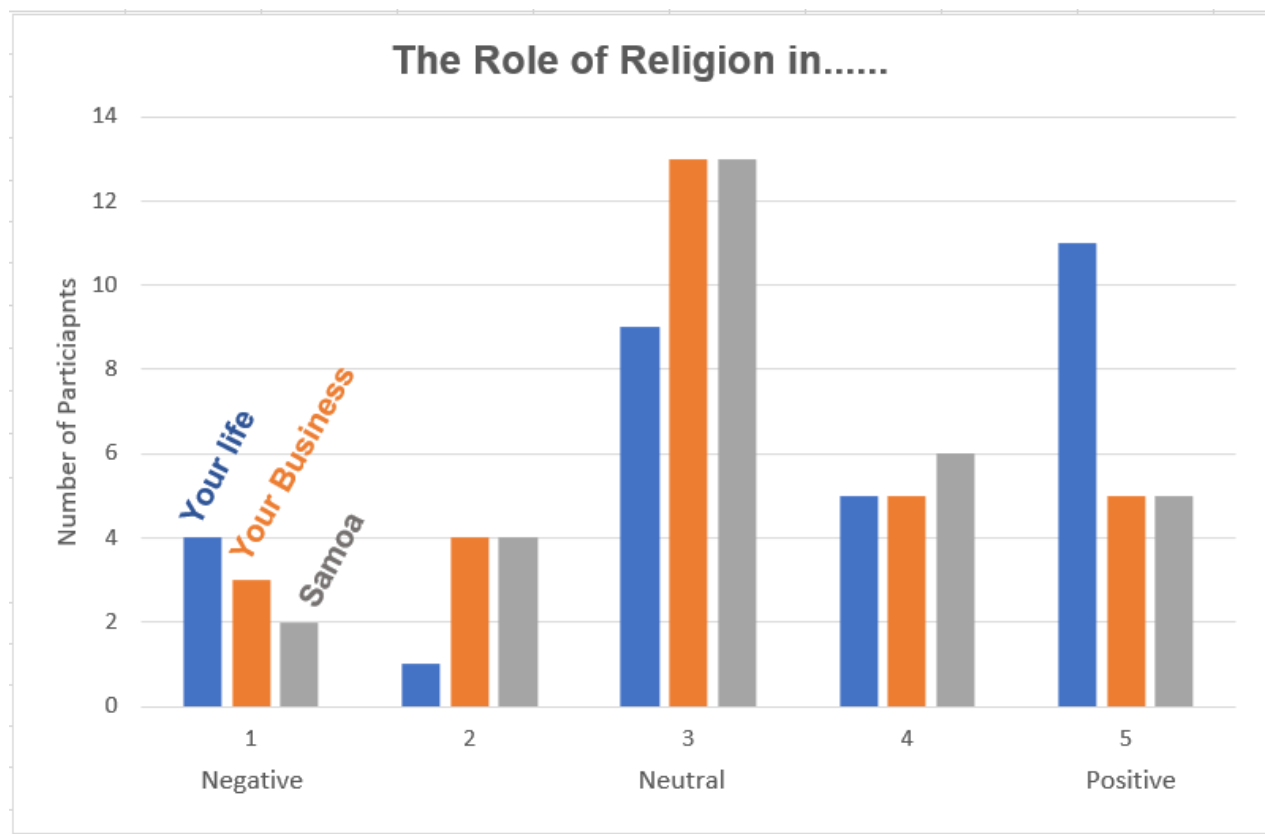

Figure 10. compares the positive and negative rating of religion on your life, business, and business in Samoa in general. The majority felt that religion's the influence was neutral across their life, business, and Samoa in general. The main outlier is those who felt that religion was a positive influence in their lives. Suppose most participants felt that religion had a positive effect on their lives. In that case, this contradicts the majority, who thought that they were only 'two' or 'not very religious,' on the scale of religiosity. If this many participants felt that religion was overwhelmingly positive in their lives, why are they not more religious?

The other interesting comparison between Figure 5. and Figure 7. is that the participants who felt their community are very religious and that they are "not very religious' thought the role of religion in the community is mostly 'neutral' but in their own life, 'positive.'

A common theme in the interviews when describing their religiosity was the idea that one could be spiritual, Christian, or generally religious without needing to be part of a formalised religious practice. The general eschewing of institutional religion was due 
to the many issues faced in Samoa that will be discussed further in the findings excessive financial demands from churches, with subsequent loans or theft demands. This deliberate deviation from the norm allowed business owners to distance themselves from the more negative aspects of both religion and their staff members' behaviour.

The pervasive influence of religion was also looked upon kindly by most business owners, explaining the overall 'positive' rating seen in Figure 6. However, many were more subtle about this appreciation in the interviews, than when they were given a scale to rank themselves. One business owner put it:

"We are very fortunate that we live in a place where religion and belief can be a large part of your lifestyle. Um, I think that in more developed countries sometimes there's less of an allowance for that, you know, it's relegated to Sunday, Sunday you can maybe have some time to do these things, but for us, it's very much of a daily attitude and approach to life", (Participant F, 2018).

This notion was reflected in my interviews with business owners and their discussions of opening hours and the principles of Christianity. There was a consensus that 'done right,' the influence of Christianity would be overwhelmingly positive. Those who were spiritual and did not adhere to the formalised religious practices in Samoa supported religious integration in everyday life. 
Figure 11.

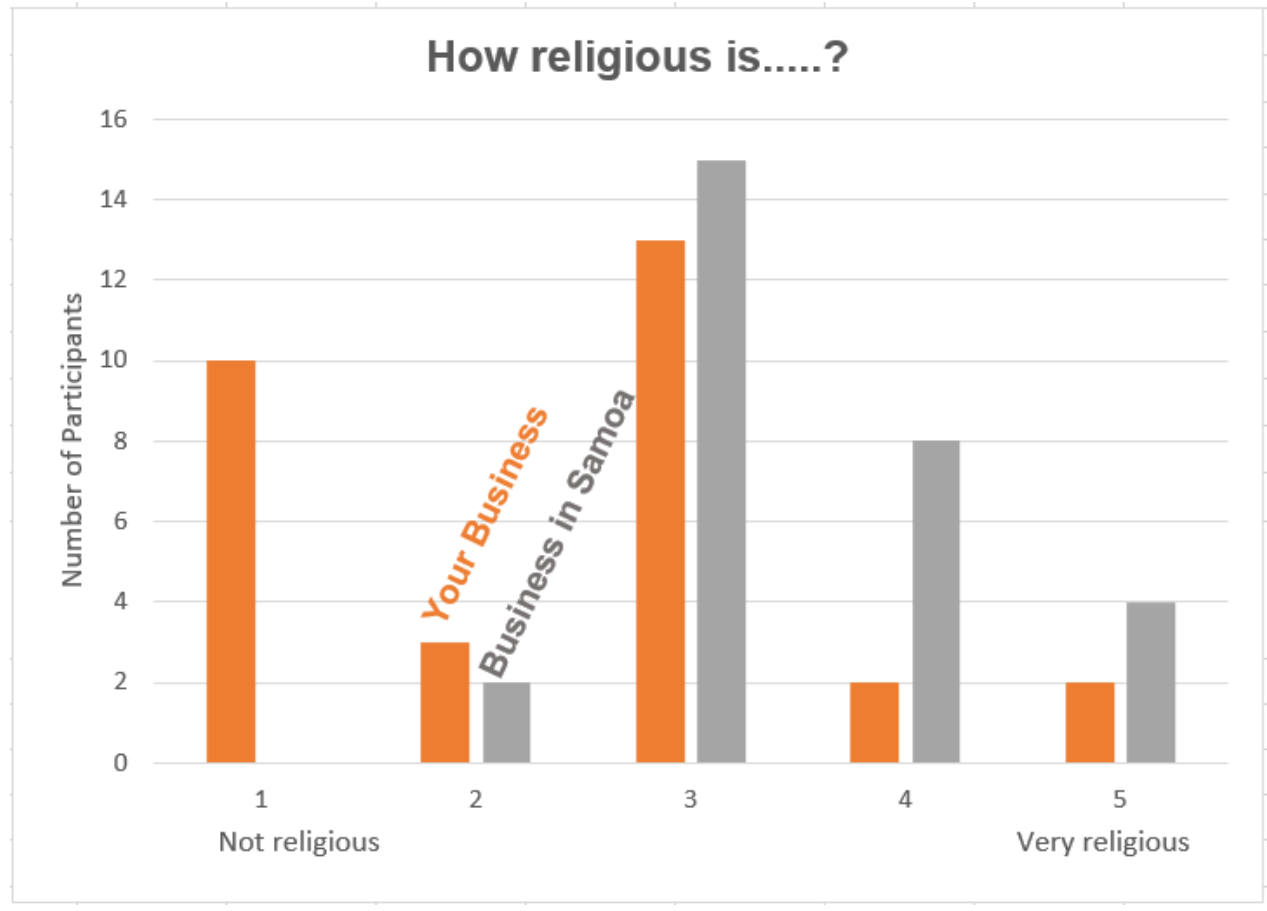

Figure 11. shows the ranking of how religious their business is in comparison to how religious business in Samoa is generally. This graph shows a similar trend towards ranking others as being more religious than yourself. Contrary to Figure 10., when it came to other businesses, respondents did not feel they were as religious as the community that they saw as being very religious. This graph also shows that several owners felt their business was 'not religious' $-33 \%$ of respondents. This group of participants are likely represented in the $20 \%$ of those who are not religious, and all those who responded with ' 1 ' or ' 2 ' when ranking their religiosity. However, those who rated their business at ' 1 ' could be related to the type of business they own. For example, the owner of a bar may be very religious, but the nature of the work means the company itself is not religious. Other work environments such as offices or shops may allow for more dedicated time to religious practices and affiliations.

In the interviews, religiosity was widely discussed, and many participants described the practice of religion in the workplace as a given or apparent activity. A number of business owners, including those who were not religious themselves, described praying before meetings or meals with their staff members. 
"I try and get them to do that prayer. It's something they are comfortable doing, and it builds their confidence which I don't mind, that's good, but we don't really incorporate any religious stuff in our business per se"

(Participant D, 2018).

Another owner described a similar practise of morning prayers in the workplace and disengagement from this on a personal level:

"Every day at 8 a.m., we have a staff meeting for the general factory staff, and they do a prayer; opening prayer and ending prayer. Those are the only things that are really religious. Aside from that, um, the general manager and myself tend to shy away from anything to do with religious [sic]" (Participant B, 2018).

This continued engagement in practice was not seen to reflect the religiosity of their business, even though in a different context, praying before a meeting would be considered heavily religious. It was not necessarily seen as being either positive or negative but simply what was expected. The business owner who describes praying at the beginning of the day as being good precludes this with pointing out that she 'doesn't mind.' The only business owners to comment on these practices in a negative light said they would make sure the prayer didn't go on too long and interrupt working hours.

"We leave it to them to do their own practices, in saying that we tell them that if it does affect their work, then we will need to look at what they're doing... if you're gonna [sic] be spending like 55 minutes doing a prayer we're gonna [sic] have to look at what you're doing" (Participant B, 2018).

This graph also highlights the discussion of what the ranking of number ' 3 ' signifies. The discussion in the interviews which highlight religious practices that are deemed normal suggests that the ranking of number ' 3 ' means neither religious nor not religious. The ' 3 ' could be characterised as 'neutral' as opposed to 'somewhat religious' which might be the interpretation in a secular country.

The interview discussions highlighted religious practices that are deemed normal, which suggests that to the respondents that the ranking, ' 3 ,' does not mean neutral but 
rather 'somewhat religious.' For example, businesses which ranked themselves at '3,' or neutral, reported they prayed during work time. From the interviews, I understand the respondents see their ranking of ' 3 ' as 'neither religious nor not religious,' a description which is apt in a deeply religious country like Samoa, where, simply praying is considered neutral. For this graph, and possibly others, ' 3 ' could be interpreted as 'somewhat religious' despite participants feeling it was a 'neither religious nor not religious' ranking.

\section{$9.2 \mathrm{~g}$ Influence on Business}

\section{Figure 12.}

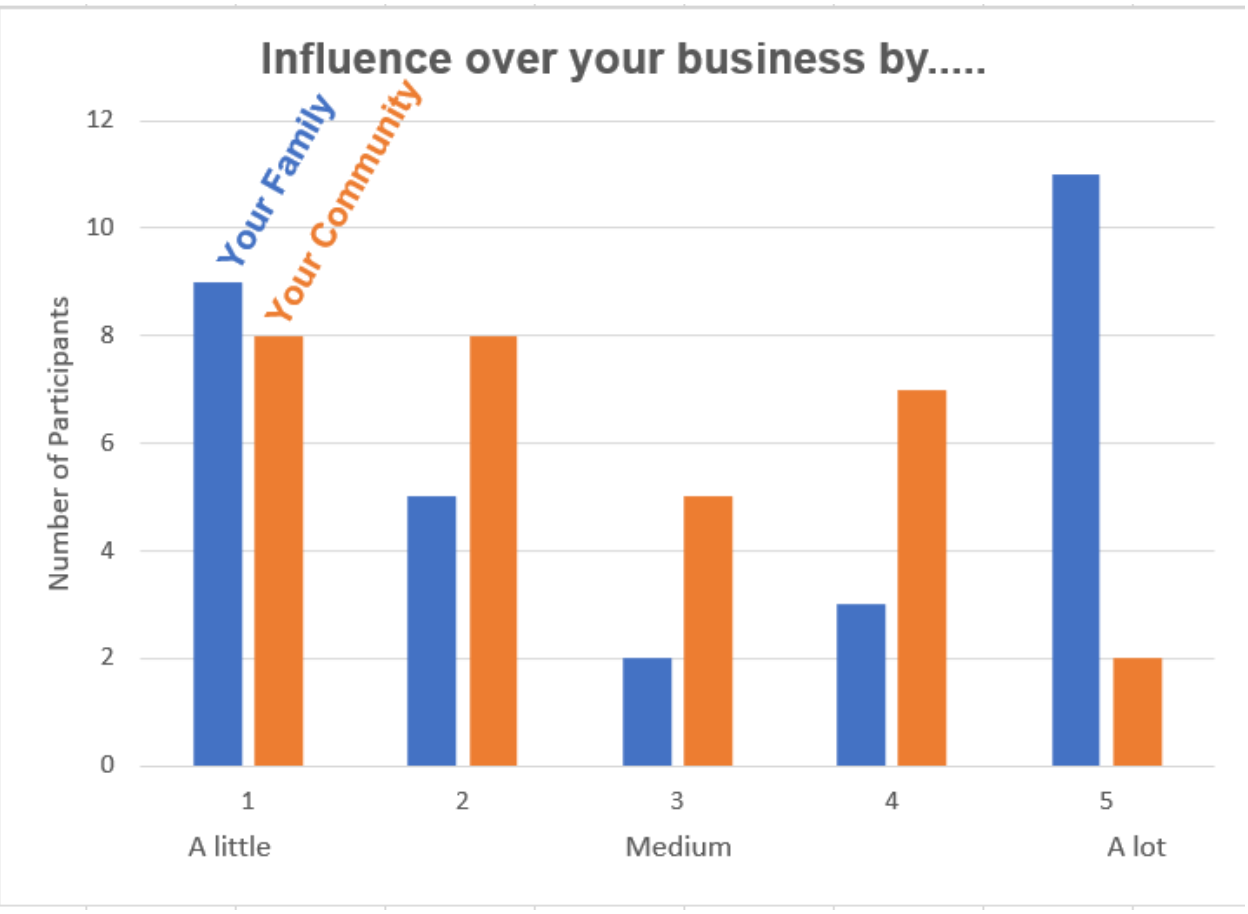

Figure 12. shows the rating of the influence that family and community have over your business. As shown in Figure 10. business owners perceive their communities to be very religious, but Figure 12. shows they do not perceive their communities to have much influence over their business. By contrast, many business owners felt that their family either had considerable power over their business, or very little influence. This comparison is an interesting reflection as, according to the fa' aSamoa, family is very important. The perception that family would have very little influence over your business shows huge deviance from accepted and practised norms in Samoa. In contrast to the influence of family, the influence of the community appears to be much 
more neutral; most people felt it had less of an influence, while still populating mostly around the medium to a little mark.

The reason for the polarisation of results for the family ranking could be that the businesses rating their influence as 'a lot' are probably family-run businesses, with parents, siblings, grown-up children and cousins being involved directly in the daily running of the business. Those who have ranked the involvement of their family as being 'a little' are most likely not family-run businesses.

Another impact on the results could be that the perception of what family influence means is different according to the cultural context of Samoa. Perceiving family to have 'an influence' is from a context in which family involvement is not a given. The participants answering that there was only a little influence may have been considering what the influence means differently or considering the bounds of one's family with different parameters. Of course, their siblings and parents are involved, but their third cousins and a wide variety of aunties and uncles are not, meaning the overall family influence is small. This understanding can be seen in interviews where participants ran their businesses with direct family members.

The interview participants also discussed the role of their family members regarding matters such as needing to discuss loans with their husband and son before giving them out to staff members, wives running part of the business or siblings running offshoot companies.

"My son is a soft touch... These things really need to be talked out. You know, as a group" (Participant C, 2018).

There were many ways in which the participants worked with their families, both inside and outside the businesses in question.

"Their main role is support [sic]. And yeah, I get a lot of support from them. And they don't expect me to do all other family stuff because the business contributes to the family as well. So, they support me and the business. And the business pays for what we need" (Participant E, 2018.

This business owner may have been one of the owners that did not feel their family played a large role in the business, just a large role in their life. This position was 
varied, but every business owner mentioned a family member or their family as a whole without being prompted.

\section{2 h) Opening on Sundays}

In this section, I will outline the findings surrounding opening on Sundays in Samoa, a key issue I identified throughout the research. While this is not necessarily contentious, and opening in on Sunday is not illegal, opening on Sundays provided a vital stepping stone in each interview and created space to start the discussion in a somewhat neutral way.

Opening on Sundays, or not, as shown below is something that can be easily compared and contrasted to direct trading partners for Samoa - New Zealand, Australia and the United States have private sectors which regularly open on Sundays. Other Pacific Nations reflect Samoa's opening hours, and most do close businesses on Sundays.

\section{Figure 14.}

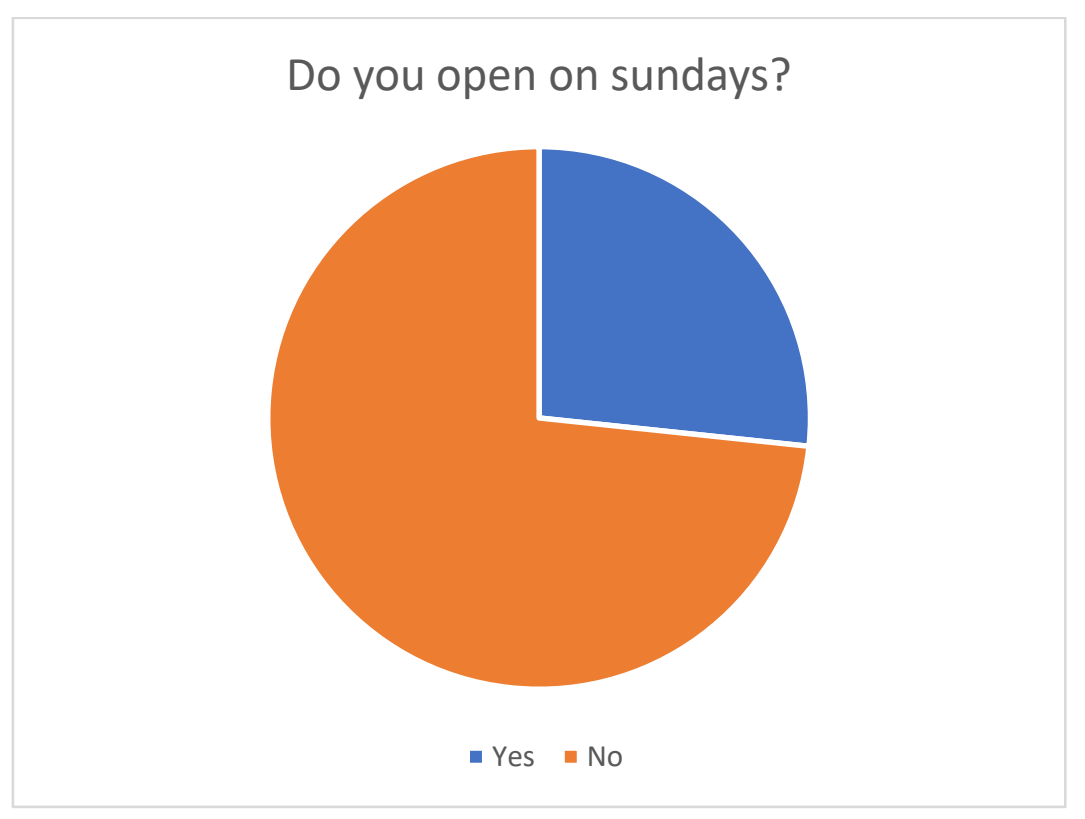

Figure 14. shows that $73 \%$ of businesses do not open on Sundays. Drawing on the interview discussions, it is likely that the eight businesses that do open on Sundays are in the tourism sector. As one participant described it, "tourism does not stop" (Participant A, 2018), and this appears to come from both government and the private sector pushing to expand the tourism industry. Resorts and hotels especially cannot close on Sundays. Businesses are legally allowed to open on Sundays. The main 
restriction is regarding alcohol; shops and restaurants not being allowed to sell alcohol, and hotels only being allowed to sell between 10 a.m. and 12 a.m. on Sundays (Radio New Zealand, 2018).

In the discussion of opening on Sundays, this was where business and religion most directly intersected-. At the beginning of most interviews, this was brought up as an easy way to demonstrate the intersection, especially for those who felt somewhat uncomfortable engaging in the interviews on their religiosity and business life. Sometimes, this was brought up as an interview question or was drawn upon as an example when broadly questioned about religion's role in their business.

All business owners generally expressed that staying closed on Sundays was acceptable to do. The overall understanding was that while some did not go to church themselves, they respected and appreciated the time given to themselves to relax and spend time with their families. To them, this was more important than making money. As one respondent said:

"Because of my staff, 'cause they need to have a break as well. And Sundays, if I can avoid it, not opening. I think it's a good thing, give them a break, and they can go to church and spend time with their families and stuff... it hurts a lot of businesses that you can't open on Sunday... it does financially hurt, but I guess you gotta [sic] have a day off as well”, (Participant A, 2018).

The recognition of the impact this has on business is a meaningful finding. It is unique to Samoa, that religion, family and culture come before business and financial gain. The business owners who discussed this directly did so with an aspect of pride. These business owners had the benefit of running successful businesses within an enabling environment of a guaranteed day off every week and which, by extension, purposefully or not, gives staff time off too.

For those who did open on Sundays, they described different ways of rostering staff members to enable this. The Baha'i business owners primarily employed Baha'i staff members who are not generally required to go to church on a Sunday (Baha'i often reflecting their day of worship according to the dominant religion of the country of residence.) Those with Christian staff members had shifts that allowed for church attendance in the morning or evening, or they were only rostered on Sundays every 
second week. These religious practice allowances show the influence religion has on business for these respondents, and how they are expected to act, according to the beliefs of their staff members.

\section{2 i) Religion and Financial Giving}

Figure 15.

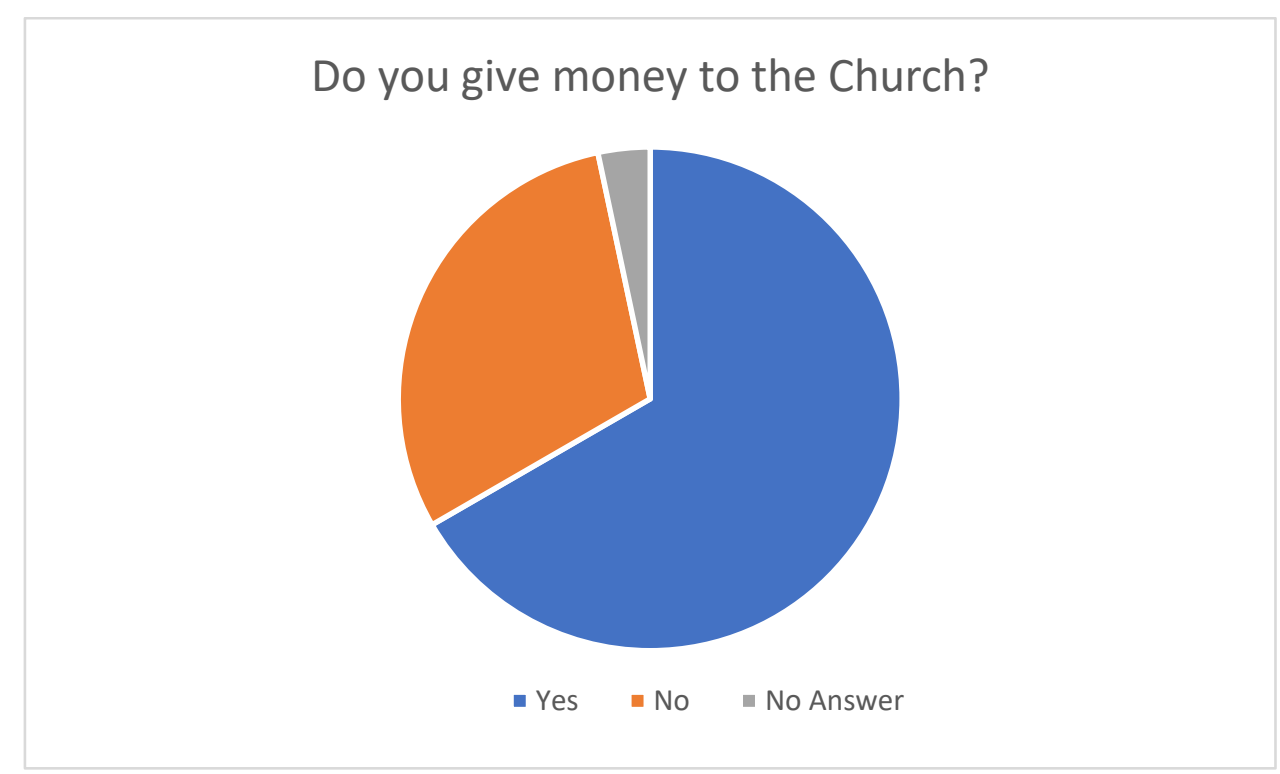

Figure 15. shows the number of participants who said they give money to their church, which makes up almost three-quarters of respondents, $66 \%$, or 20 participants, said they gave their own money to their church. This figure does not reflect $80 \%$ of respondents who identify as religious. The numeral is an anomaly, as financial giving to the church is a large part of religious practice in Samoa. This figure could be tied to $56 \%$ of the participants who identify as being Catholic and therefore, have lower expectations placed on them for financial giving. A lower amount of pressure could result in some not giving any money at all.

This explanation could be the reason for the lower number of participants financially donating to the church. If they are not attending formal church services, they will not be giving money during the service and therefore, identify as religious but do not give money to the church.

Alternatively, given that most respondents are Catholic and therefore likely to give less or not at all, $66 \%$ might be considered quite a lot of church giving respondents in comparison to other countries. They may be the same respondents who, in Figure 10., 
perceived their community to be more religious than themselves, and therefore feel compelled to compensate for their lack of belief, with financial giving.

Figure 16.

\section{Does your business give money to the church?}

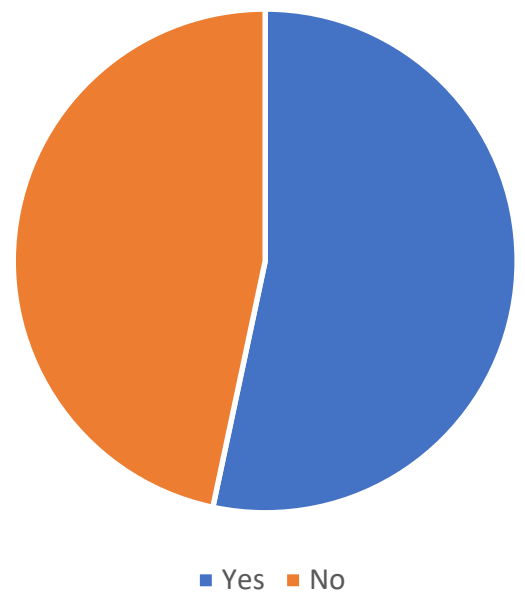

Figure 16. shows the proportion of business owners that give money to the church through their business. The figure shows a marginal majority of business owners, 53\%, giving money from their business. This proportion is smaller than those who give their own money to the church $-66 \%$. The decrease in rates of financial giving could be credited to the data in Figure 5. and Figure 9. that show the business owners who identify themselves as being religious but do not think their business is. These figures would explain those who did not donate from their businesses directly but did donate from their own pockets.

"I do, I do give. You know, when the church needs money to improve our rugby field in the village, you know, okay. I'm in. You know the church needs money here for you know, things along that line with the community you know, uh, or they're travelling. The choir's travelling, they need money to buy uniforms, I'll help with that, you know? I'm in with that stuff" (Participant A, 2018).

As shown by this participant, interview respondents described how they preferred to give for a specific event or activity, so they would know exactly where their donation was going. Many of the participants favoured in-kind donations over financial giving. The idea behind this was always to understand that the money or donation was going 
to the community. Not the faife'au, or to church practices that the business owner might disagree with inherently.

\section{Figure 17.}

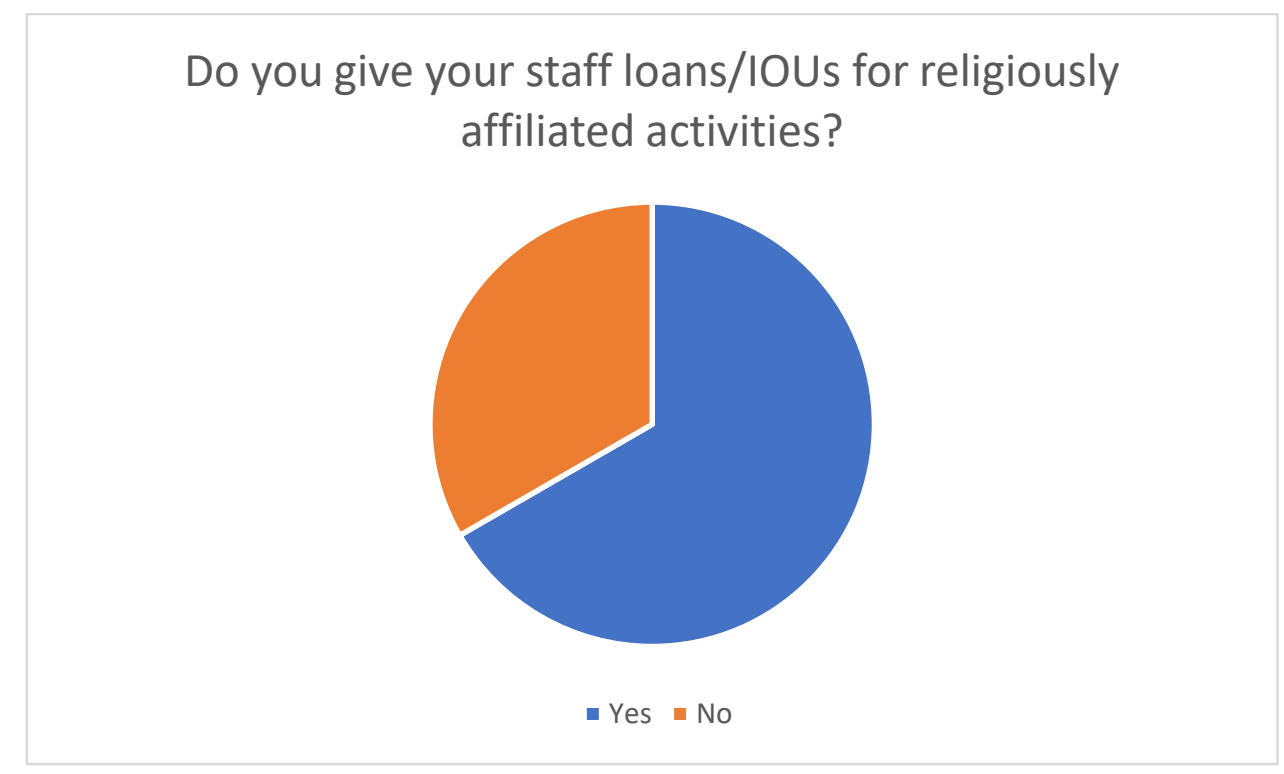

Figure 17. shows two-thirds, $66 \%$ of business owners, give their staff members loans for religiously affiliated activities, which shows more business owners give to their staff members than give from themselves for religion-related activities.

Loans or aitalafous were widely discussed in all interviews as they were a significant point of contention where religion intersects business. Business owners described receiving daily loan requests, especially those with large companies.

Many respondents expressed frustration towards the expectations of financial giving, knowing how much pressure it puts on their staff members. As the minimum wage is meagre (WST \$2.30 per hour), in many cases, staff members were giving away all their income. As one business owner put it:

"The church just takes money off our staff all the time, and basically they come to work because we feed them. Basically, that's the only reason why they come to work because all their pay goes straight to the church, straight to the family" (Participant D, 2018).

This expression of frustration showed a wider discontentment with the system and with how it affects their business. Other business owners described the direct effects 
that this had on their staff members, noting how their attitudes changed once it came time to pay back the loan. One of the business owners described the "shitty attitude;" explaining that when loans were taken out of their paycheck, the staff members felt they were not being paid correctly.

"[Giving an IOU] won't[sic]be helping us because when the IOU kicks in; like when the pay comes and we have to cut the IOU, then they give us the shitty attitude, that when they're at work, they don't feel like working because now their pay is cut in half and they've been working really hard. Like, that's not my fault, that's your fault for asking for an IOU for Church" (Participant E, 2018).

\section{Strategies for Dealing with Loans}

To address these issues the business owners described either refusing to give loans at all, or having processes in place to limit the number of loans; those given, the frequency, and the amount. One business would only give erratic loans for special circumstances, but frowned upon constant loan requests, denying them if they became regular requests.

“We discourage aitalafous... if someone looks like it's becoming a pattern

[sic]. I don't mind out of the blue, you know, if it's white Monday come up [sic], children's day..." (Participant G, 2018).

Another said they only gave loans every second week so the loan could be taken out of two paychecks and not one, to avoid the negative attitude of the staff members that they often experienced. A third business described requiring full payment of the first loan before another loan could be given. Another family business had a different perspective where the mother encouraged loan giving, believing that it keeps staff tied to the business when loans need to be repaid.

\section{Impact on Business}

The smaller businesses approached loans differently as their cash flow did not allow for large amounts of money to be lent to staff. The business owners felt that everyone was strapped for cash and therefore felt the pressure of expected financial giving more keenly than other businesses. One family business required discussion and financial 
planning before loans could be provided, often denying loan requests due to financial strain.

Even for businesses with better cash flow, consistently giving loans incurs costs to the business, especially if loans are not paid back by staff members who leave. The use of cash for loans would also impinge on the capital of the business and would affect their abilities to invest in additional business development.

Theft

Theft tied heavily into the discussion of giving money to the church. The participants moved quickly from conversations about giving, to ones about loans, then to theft. Stealing was a huge issue for all businesses, emphasised by one owner who said: "everyone has a universal problem with stealing" (Participant B, 2018). Business owners often linked the theft to financial expectations from the church and family. They noted it happened most often after a loan request had been denied or at expensive times of the year like White Sunday, Mother's Day, Easter and Christmas. These holidays are linked with higher expectations from the church and the community. The business owners went as far as blaming this directly on the church, believing that it wouldn't happen without the pressure.

"The church I see putting tonnes of pressure on people, on their businesses and on individuals, to contribute often way more than they can, and so this leads to theft and leads to dishonesty and all kinds of things that might not happen otherwise" (Participant F, 2018).

The theft was spoken about with some anger, but many respondents seemed resigned to the fact that it constantly happens, with a couple of business owners even being able to laugh about it. Others, with smaller businesses, felt personally betrayed by the theft, especially when they felt close with their staff members.

"My staff, I treat them like really part of my family, I'm so good to them, and I adore them, and yet many of them have been fired for stealing over and over, and you just don't understand how they can do that" (Participant D, 2018).

This betrayal of trust, as well as the loss of income, was a massive problem for the business owners and often led grim discussion of the role of the church and religion 
in Samoan society. In some cases, they seemed to think that staff members used church giving to justify stealing, with the emphasis they put on family.

\section{2 j) Business and the Faife'au}

This frustration was targeted at the faife'au, whom they believed to be the cause of the financial expectations and pressure placed on staff members. The business owners were heavily critical of the priests, one owner calling them "scumbags" (Participant A, 2018) and others lamenting how the role of the priests had changed over time. Business owners discussed how priests used to be humble and the "shepherds" of the village, guiding behaviour such as making sure people are getting married before cohabitating and discouraging premarital sex. Business owners described how it was now rare to find a "good" priest, and when they did, they made sure to support that priest.

One manifestation of this is the month of May called 'Mei' where the congregation is expected to provide gifts for the priests. One business owner described how this month intended to make sure that the priest had adequate household supplies to host the community during the year. It used to be cups, plates and fine mats for the floors of their houses but is now house renovations, plasma screen TVs and new cars. This change in expectation was believed to be driven by the faife'au themselves, and the business owners expressed their "disgust" at these new practices. A few of the business owners referenced how the priest's house would always be the nicest in the village and the growing costs of the churches, driven by the priests playing on the pride of the villagers is forcing people to pay for bigger and better.

"The church was not so... arrogant and full of avarice back in those days when my husband's father was a church minister... he comes from a long line of faife'au in the family. But he's disgusted. I'm disgusted" (Participant C, 2018).

The month of $\mathrm{Mei}$ as also described as being part of decisions made by businesses. One restaurant owner talked about how "all the other businesses keep putting on ads (advertisements) for this month and so do car places" (Participant C, 2018) pointing out how businesses also profit off the growing expectations of Mei and the faife 'au. However, there was some sympathy for this as "I think that there is a lot of opportunity 
[sic] for people to use the church to make money and they do do that, but I guess that business isn't it? You see the opportunity, and you use it" (Participant D, 2018). The business owners, while critical, did understand this approach, again laying the responsibility on the faife'au and not on the other businesses that take advantage of this practice.

"I think that yes, that does spring from the ministers, they will say that people were only showing us with their love and think there is an awful lot of auto-suggestion there, and I think the businesses jump on board" (Participant C, 2018).

This participant was describing how the faife 'au are suggesting practices or gifts that should be given to them, placing expectations on their communities. This business owner believes that other businesses are supporting the faife 'au in this by advertising expensive gifts and suggesting that people should be buying them for their faife 'au.

\section{2 k) Power Dynamics}

What was widely demonstrated in the discussion of the faife'au, is the role of power in business and money. The business owners discussed the complexity of this, especially when it intersects with the matai system, which came up in several interviews. Until recently, businesses were required ten matai signatures to get a liquor licence. One business owner described in detail the issues they had getting a liquor licence, because of the control the paramount matai has over the village. This matai was financially motivated to protect the interests of a nearby resort. The business owner described how the matai cut down the sign for the business on a number of occasions and brought in other matai from the village to support his actions. The business owner had paid the required 500 talas and had permission from the government to display her sign on the road. When she complained to the relevant government ministry, she was told that the matai had the right to enforce their rules on the rest of the village.

"The main paramount chief of the village... rules with an iron fist, he is the liaison officer... he gets a stipend every week which goes not to the village for amenities and assistance, but it just goes straight to him" (Participant C, 2018). 
These frustrations with the matai who directly impacted the advertising for the business was particularly problematic due to the somewhat hidden location of the restaurant. Other business owners talked about how being a matai themselves would help their business, as they could be part of the decision-making processes in the relevant area. Being a matai would mean more control over their business and how they worked in the area.

Other business owners described problems between the matai and the faife'au. One business owner talked about his matai title and that in a bid to take control over the area the faife 'au attempted to throw himself and the other matai out of their village. The case was taken to court, and the matai were not kicked out of the village, but the business owner expressed their concern for the power of the faife'au even just in the attempt to override traditional Samoan power structures.

This complex interconnection of power was relevant in every interview. The business owners were either describing the power that the faife' au had over their staff members or the power the matai had over their business. In both cases, the control of government was lesser than that of the matai or faife'au, or non-existent. When asked what role the government played in business, none of the participants had much to say, simply feeling that government and corresponding legislation was enabling to business and never caused them any trouble. While this is overwhelmingly positive for business and the growth of the private sector, this meant that when it came to local village law or religion, there was less input or regulation through formal channels.

\subsection{I) Morality}

A theme that was carried throughout the interviews was the discussion of morality. This discussion stemmed from the huge problems detailed above that all interview businesses had with staff stealing from them, often due to the financial expectations of the church and family. The business owners, especially those who are not religious, heavily questioned how staff could justify their own religious beliefs when their religion directly condemned stealing. Put bluntly, one of the owners questioned the outcome of the theft: "Okay, so are you buying your golden ticket to heaven with this company's money? Does that make your ticket golden? Like, I don't understand!" (Participant D, 2018). The business owner obviously felts exasperated with the contradiction of stealing to give to the church. 
However, despite business owners feeling betrayed by their staff who were stealing, they felt positive about their own intersecting religious and business values. They felt that religion encouraged them to act in the best way possible, embodying principals of trustworthiness and truthfulness in all their practices including practical actions like paying their taxes and refusing to bribe or sell faulty products. This discussion can be reflected in Figure 10., where the participants felt that religion had a positive impact on their lives as business people.

The business owners were hoping that their staff members would embody the practices of Christian doctrine, suggesting that if they were 'proper' Christians, there would be no theft in their business. Some felt that this worked well, as it encouraged them to be good people, while others lamented on the lack of morality such as the issues with stealing, described previously.

“They don't see it as theft because they're serving a greater good. In most cases they're giving to the church, they're giving to their community, they're giving to something else - they're passing the buck of responsibility by saying but my people need this" (Participant B, 2018).

The idea of 'the greater good' weighs heavily with discussions of religion as it gives normal tasks a greater purpose. The business owners are struggling with the idea that their staff members can justify theft from their businesses using the divine. The business owners passionately vocalised their frustration, especially when evaluating their own religious beliefs. The business owners hoped that religion would be used for good, to be good employees and good people but found that most of the time, this was not the case.

\section{$9.2 \mathrm{~m})$ 'The Church'}

As shown throughout the results, the discourse of religion often turned into discussions of the church. It appeared to be more than just a descriptor of formalised religion, but of the church as a source of power and authority.

\section{Figure 17.}

\begin{tabular}{|l|l|l|l|l|l|l|l|l|}
\hline Word & A & B & C & D & E & F & G & Total \\
\hline God & 2 & 17 & 3 & 6 & 0 & 5 & 1 & 34 \\
\hline
\end{tabular}




\begin{tabular}{|l|l|l|l|l|l|l|l|l|}
\hline Religion & 5 & 13 & 5 & 6 & 6 & 27 & 6 & 68 \\
\hline Church & 12 & 30 & 40 & 27 & 26 & 11 & 8 & 154 \\
\hline
\end{tabular}

This analysis demonstrates the frequency with which the participants discussed the church by directly mentioning it. Overall, the participants said 'church' almost three times more than they said 'god' or 'religion'. Recognising this linguistic element is vital to understand that the church, not religion, "just takes money off our staff" (Participant D, 2018). It is "the church" that leaves families "struggling" (Participant D, 2018). When pressed on this topic, the business owners did not appear to feel this reflected on spirituality, God or religion in its actuality. But, on the formal, organised institution that is churches in Samoa.

The interview discussions showed that the church had more impact than the families and the communities of the participants on their businesses. The study may have come out differently if the questions were about the role of the church and not of religion. It was clear that these two could be divorced in the minds of the participants. In the interviews the business owners, while using this specific language, discussed how spirituality and religion were ultimately a good thing. However, the formalised institution was no longer representing what they felt were Christian values and principles.

\subsection{Conclusion}

The results firstly describe a business community which is less religious than the statistics for the general population. The participants had a higher rate of nonreligiosity, and Catholics are over-represented in the sample. These participants also had much experience living overseas, and many of them were not born in Samoa. The participants also voiced opinions that are contrary to the accepted beliefs and norms of Samoan society with regards to their level of religiosity and their negative attitude towards the faife 'au and organised religion generally.

The results point to a population of people that feel somewhat at odds with the practices and behaviours of the society they belong to, and where they live and work. As the business owners perceive themselves to be less religious than their staff 
members, families and communities, they feel required to make concessions for people around them. While they have some ability to limit the scope and influence of religion through denying loans or monitoring prayer time, the saturation of religion on society is so great, that to some extent even the business owners who try to avoid it are unable to do so.

There is a schism between the church, the matai and the businesses which at times directly impacts business and makes the business owners feel somewhat powerless. In many cases, the business owners are also at the mercy of their staff members when it comes to giving loans and not requiring staff to work on Sundays. They feel compelled to do these things due to the expected norms of their society.

The question of morality was pervasive. The business owners referenced their ideas of good behaviours and practices and were highly critical of their staff members, the faife 'au and matai. Namely, when it came to any interference in their businesses. The idea of 'good and bad' and 'right and wrong' was salient throughout the reactions of business owners towards the actions of their staff members. In particular, the business owners criticised the theft they all experienced, especially in the name of religion.

The results presented in this chapter demonstrate that religion is very present in business in Apia, but it is contested and challenging for those operating businesses. The business owners voiced discontent towards some practices while also praising the environment that allows and encourages cultural activities and time for participation in family and community, especially on Sundays. 


\section{Discussion}

\subsection{Introduction}

This section delves into the implications and more significant ideas presented in the results section. Here, the aim is to tie the literature to the results and show how they support the research findings then expand on the ideas that are already published. Discussions of the findings pull in other factors in Samoan culture that influence the intersection of religion and business. It is because the results demonstrate the total interconnectedness of all aspects of Samoan society. There is no one concept that you can have without the other; religion, business, fa'aSamoa, fa'aMatai. This chapter discusses the integration of religion, Catholicism, money, power, morality, capitalism and globalisation. 


\subsection{Religion in Daily Life and Business}

This research demonstrates that Christian practices have become fully integrated into Samoan life, often regarded as a form of cultural protocol. Business owners showed this in the low rankings of their religiosity, while still making time to pray before work or giving money from their businesses to their churches. Christianity, as a cultural practise, is further emphasised by the number of identifying, practising, tithing-giving Christians in the survey who did not view themselves as being 'highly religious.' Religion was viewed as not only being about god and church but also about family and practice, regarded as a way of life.

An example that emphasises this idea is the closing of businesses on Sunday. As discussed earlier, it was not simply a practice of church-going but about making time for family. Yan and Sorenson (2003), Chari and Dixit (2015), and Ratten (2014) all highlight the importance of family in entrepreneurship in the developing world. In Samoan culture, one's family is paramount, and Sundays exist not only to attend church but for to'ona'i (Sunday lunch), where everyone prepares food for the family. This part of a Sunday ritual is often more emphasised; the sharing of food together after church, the day spent playing music and napping together. Azmat (2009) found that in developing world entrepreneurship, the social standing of the business owner is very important. As Sundays are so important to one's family, business owners avoid requiring their staff members to work during this time, investing in their business through social and cultural capital rather than prioritising financial capital.

This idea was more than just the benefits it would bring to their business through capital accumulation but embodied the concept of the "uniquely spiritual" discussed by Baker (2015). As demonstrated in the results, the religious business owners expressed their appreciation for being able to practice their religion and more broadly everyone liked the space they were given to spend time with their family and engage in their culture. It was the articulation of the need for things that are more than "money or sex or power" but also the manifestation of cultural capital (Baker, 2015, pp. 29.; Light and Dana, 2013).

The business owners generally harnessed the 'spiritual capital' that comes from religion. It was utilised by allowing their staff members to pray before work, in the 
hopes that it would keep them honest, prevent them from stealing or feeling angry about small paychecks after taking out loans. However, 'spiritual capital' did not prevent business owners from experiencing theft in their business. Contrary to the study conducted by Neubert et al. (2015) at Baylor University, there is less correlation with faith fuelled innovation as this population does not identify as being very religious. Their entrepreneurship is more likely to be due to the bonding, linking and bridging capital they have in Samoan society.

\section{2 a) Financial Capital}

Business needs capital to function properly. Often starting a business requires a large investment of capital at its establishment, but then continues to need capital in order to reinvest, expand and do necessary upkeep. The development reforms described by Gore (2000), Babb (2013), and Hannushek (2013), express the prioritisation of financial reforms and support to the free market through deregulation and privatisation, as the previous development model of redistribution had been unsuccessful. Critics of these reforms felt they were contextually and culturally blind. The research aligns more with these critics of the neoliberal development reforms; the business owners prioritised other things, such as Sundays off over capital gains for their businesses (Ali, 2016; Khan, 2015; Hopper, 2017). More directly, the majority of business owners gave loans to their staff members and gave money to the church from their own pockets. A slightly smaller majority also gave money from their businesses to the church. This prevalence of loans and donations proves that prevalent neoliberal economic priorities do not take in to account the local context.

The participants widely discussed the IOUs and loans requested by their staff members. The impact of these loans can be crippling to small business. Which, may mean that due to capital constraints, only the larger businesses or owners with multiple businesses can grow, as after loans are given they have remaining capital to invest. This indirect expense (which can be hard to measure) puts small businesses in a difficult position, especially if staff members delay repayments or default on the loans they are given. Furthermore, business owners described the personal effect these loans have on their businesses, where they lose money from their own pockets or face the repercussions of denying their staff members loans: poor attitudes and theft. 
The behaviour of business owners supports the theories of Brik, Rettab and Mellahi (2011) on corporate social responsibility. Suppose we see these business owners as practising a form of Samoan CSR, without detrimental impacts on business (theft aside). In that case, it supports the idea that socially responsible business practices benefit everyone. However, within a western framework, CSR is more of an elected practise, at least currently. In Samoa, giving loans and closing on Sundays is more of a societal expectation, and therefore business owners display a certain amount of social responsibility, while the framework of CSR may not correctly represent the forces that are at play in this research.

A better explanation for this giving is through the fa'aSamoa and the emphasis expected through this. I repeat here, Ravulo (2016), from the context chapter: "the Samoan understanding of self is not understood in the individualistic sense; rather it is comprised of integrated aspects that deeply impact each other" (p. 193). Cahn (2008) found this too, writing that western business models do not work in the marketplace of Samoa as the fa'aSamoa is completely different to a western way of being. Emphasis on capital accumulation and growth are not the main drivers of the business owners in Samoa, who make time for their religious and family commitments.

\section{2 b) The Burden of Financial Giving}

As discussed in the results, the majority of business owners expressed that financial giving put an enormous strain on the businesses. Macpherson (2015), Thornton, Kerslake and Binns (2010), have written about the excessive financial giving in Samoa from a development perspective, with research that shows large amounts of money being given from families to the church, between $30 \%-50 \%$ of their income. The business owners were directly impacted by this, especially those with large numbers of staff members who needed regular financial assistance.

The respondents voiced desires for the financial expectations placed on their staff members to be lessened, some being heavily critical of the faife'au, who were encouraging these practices. There was also criticism of other business owners who supported this financial giving with encouragement through advertising. As reflecting the work of Macpherson and Macpherson (2015), Thornton, Kerslake and Binns 
(2010), the development of Samoa is compromised by the churches that continue to expect more than the families are able to give.

From a different perspective, the business owners were given a platform in this research to share unchallenged opinions. The minimum wage in Samoa is 2.30 WST an hour. ${ }^{5}$ While several factors inform staff member wages and it is the prerogative of business owners only, to meet the requirement set by the government, if staff are paid this much, their take-home pay is very, very little. Thornton, Kerslake and Binns (2010) found that many families were meeting church demands before meeting basic needs. If the church is criticised for keeping the people poor, it is also important to turn that question back to the private sector. Many families would still struggle to live off minimum wage, especially in large families with few people working.

The hope would be that a rise in the minimum wage or financial literacy training would create a population of people that are more equipped to deal with how they interact finically to address their religious and spiritual needs. Or, it provides those who do not wish to contribute the financial autonomy to step back and say no. Perhaps the money they start to put aside for financial giving and fa'alavelave payments runs out, and in that instance, they feel confident to say that there is no additional money to give.

However, as previously discussed, a deeply religious person may find giving to the church is an important and meaningful part of their faith. It may be a way to feel closer to God or to feel absolved from sin. People may feel the money they donate to the church, and the faife' $a u$, does get reinvested in the community through more than just material means.

A more financially literate population, with a higher minimum wage, might be more empowered to choose how to use their money when it comes to religion and spirituality. Additionally, perhaps people may feel empowered to stop making

\footnotetext{
${ }^{5}$ Websites such as the Numbeo or Expatistan which are informal measures of the cost of living through food, rent and beer prices list the following for comparison to the minimum wage - 15 tala for a meal in an inexpensive restaurant, 5 talas for a beer, or 17 talas for a McDonald's combo. At the same time, rent is not comparative as many families do not pay rent due to traditional land ownership. The costs that are often accrued would be approximately 300 talas per child to attend most schools, 2.30 talas for a can of mackerel and around 5 talas for a $3 \mathrm{~kg}$ bag of rice.
} 
financial contributions when they cannot afford it, or if they are saving to develop their home, business or family, without worrying about the social ramifications of doing so.

\subsection{Perception of Religion}

The business owners expressed significant anger towards the faife 'au and the church. However, there was a distinction made between religion and spirituality. No business owner expressed hatred or distrust towards religion or God, with a number of them sharing their own beliefs. This notion is supported by the high number of those who rated religion as being positive in their lives. This emphasis on spirituality or at least positive feelings towards the idea of God and religion shows how the discontentment lies with the institution of religion, not the tenets of it. No business owner interviewed, wanted to do away with religion entirely, but there were many questions raised about how religion should be practised or what form it should take.

Whether the dissociation from formal religious institutions came from the impact of religion on their business was unclear. Many questions surrounding the validity and actions of organised religion in Samoa started because of the problems with loans and theft. But, this led to a bigger discussion over the direction that religion has taken in Samoa. These business owners looked more towards the orthodox side of religion (Mele, 2017), emphasising their own beliefs, such as the idea that you do not need to be part of a church, go through the practices of a Samoan Christianity to believe in God or to be a good person.

The dissent against the church and organised religion was only given on an anonymous platform, reinforcing Huffer and So'o's (2005) description of the fa' aSamoa emphasis on consensus which may continue to prevent these voices and ideas from taking root. The respondents in my research may have felt freer to voice their dissenting opinions, knowing they were speaking anonymously, and to a New Zealand born, non-Samoan, which should be remembered when thinking about these questions.

\subsection{Morality}

Throughout the interviews, the question of church and its impact on business morphed into a broader issue of supposedly 'competing moralities' in the business community and among the faife' $a u$. The anonymous platform allows business owners 
to use arguments and criticise the faife'au in a way that positions them as morally superior. Erceg, Galić and Bubić (2018), and Fetodova (2017), describe these economic attitudes. Suppose business owners engage in economics with the attitudes and outlook of pure/impure or moral/immoral. In that case, this should impact their business positively, but it most likely makes them look negatively on those requiring donations towards a cause of which they disagree.

The discussion of morality also supported the literature showing the perceived importance of the outside perception of the business owner working in communal culture, as demonstrated by Azmat's (2009) study. The business owners seemed keenly aware of the persona or behaviour they needed to display to make sure their business thrived. However, perhaps this, in turn, makes them more critical of others who are not watching their behaviour for fear of repercussions. The criticism was mostly positively motivated, where the business owners wanted the best for the people of Samoa. However, a small part could also be the unfairness of a people doing perceived ill, such as requesting loans, while the business owner is trying hard to be moral and fair with their business practices. The feeling expressed was almost that in the quest to run an honest business; they felt that the staff members were not engaged in this attempt, especially when they were stealing.

The economic attitudes that show concern for morality also reveal how the Samoan business community is disengaged from capitalism and globalisation. They emphasise making allowances for church and family, which shows they support upholding Samoan culture, and wish to curb the impact of outside influences. While it could be expected that the general population might eschew the growth of globalisation and capitalism, it is interesting that so do those who are the most engaged in it. It could be for many reasons: perhaps business owners are successful enough in the domestic market that there is less need to encourage the growth of trade and promote foreign investment. Foreign investment could also involve direct competition for these locally owned businesses.

There also appears to be the deep and underlying understanding or unspoken agreement that what makes Samoa, Samoa, is more important than any money or growth. Even in the face of profit loss, the business owners chose the preservation of Samoa, its culture and customs, over the growth of business and profit. The direct 
example of this was the business owners who discussed closing on Sundays while acknowledging that they would make a profit if they opened. Some dissenting views were presented, but when it came down to it, the appreciation of Samoa seemed greater than the desire to change.

\subsection{Catholicism}

A finding that was simultaneously unsurprising and surprising was the overrepresentation of Catholics in the private sector. It is generally accepted that many of the Afatasi population are Catholic. While Meleisea (1987) and Gershon (1999) did not write this in their works, they did describe the Afatasi population becoming very successful in the private sector and government, following independence in the 1960s. This possible correlation aids the explanation for this research finding.

Heslin (1995) reveals a series of intentional and unintentional historical events that would have led overrepresentation of Catholics in the private sector. Firstly, the success of Catholics in the private sector was due to government thankfulness, for the education provided by the Marist Brothers. As he writes, they "supported the Marist brothers in every way possible," suggesting that the government also provided an enabling environment for the Marist Brothers that wished to do business in Samoa.

The second factor was that the Marist Brothers started the first Credit Trade Union in Samoa. Unfortunately, this trade union was only accessible to the Europeans and the Afatasi. If we accept the anecdotal generalisation that many Catholics are Afatasi, this can help to explain the overrepresentation of Catholics in the private sector. If their ancestors had access to credit, they would also have been able to start businesses and build capital for their families. While a Credit Trade Union was created later for full Samoan people, the extra years that the Catholic population had to amass capital and start businesses would put them ahead of other groups in the private sector. According to Meleisea (1987), the Afatasi population were also incredibly successful in business after independence.

Fairbain (1988) also wrote that in comparison to other denominations, Catholics gave fewer financial contributions to the church and that the number of tithings would affect the ability of business owners to use their capital for investments such as businesses. The results of this research support Fairbain's work, demonstrating that Catholics, 
with fewer tithing requirements, do represent a higher percentage of the business community.

Further literature on Catholicism, such as that of Guiso (2003), showed that Catholics prioritise private ownership more than other denominations. While the protestant work ethic is still viewed as the catalyst for modern capitalism, this must come with private ownership. In this society, the prioritisation of private ownership was the trait that overtook the private sector. As argued above, this trait was well-matched with the capital and the necessary support to succeed.

Additional pieces of anecdotal evidence support this theory; the first is the sale of land from the Catholic church to its congregation. Radio New Zealand (2002) reported on the sale of land from the Catholic Church in Samoa, it is the biggest owner of private land in the country, but it is more anecdotal that the land is sold to the congregation. If this is correct, it means Catholic church members had the privilege of land ownership in central Apia on which to start their businesses. It would be interesting to do this same survey in other parts of Samoa to see if land ownership impacts private sector ownership in places where the Catholic Church did not own the land. For example, the village of Vaitele is a growing hub of the private sector. It is possible that there are fewer Catholic business owners, and it could be interesting to understand how denominational affiliation is represented there. However, as many business owners own multiple businesses, and Vaitele is an area where businesses from Apia are starting to open their second store. The results of the survey from Apia could be similarly reflected in Vaitele.

All these factors play into social capital and the bonding, linking and bridging networks that are described by Elliot and Yusuf (2014), Larsen et al. (2004), and Kirstiansen (2002). The Marist Brothers have all these forms of capital. They have strong familial ties (as does everyone in this society) and they have the bridging capital through the Catholic Church and the access to the knowledge networks, a result of $30 \%$ of the population having attended Marist schools. They also have the linking networks necessary as they are government-supported. Much of their Marist cohort are represented in government and other positions of power. Fairbain (1988) wrote that business owners are usually matai and while Helsin does not detail that, it is that likely many of these Marist alumni are widely represented in the fa'aMatai. 
When discussed in this context, the Catholics have a multitude of powers within Samoan Society. The factors such as access to capital, government, land and the chiefly system have made it easy to participate and integrate themselves within the private sector.

\subsection{Samoan Christianity}

As Laurin and Plax (2014) described, religions can fit within two general forms - 'orthodoxic' and 'orthopraxic'. These two categories refer to the action considered most important to the form. Christianity, in principle, is generally regarded as orthodoxic, prioritising one's personal beliefs and relationship with God. Suppose you apply this logic to the fa'aSamoa. In that case, you have a belief system that is othropraxic $-f a$ 'aSamoa is considered the manifestation of the time, care and attention you give to your family and your culture.

As Samoan culture focuses on practice, it has heavily influenced Christianity which, as described by Laurin and Plax (2014), and Mele and Fontrodona (2017), is an orthodoxic religion. This influence shows how deeply Christianity was absorbed into the culture. Is Christianity practised because of its teachings, or are these things practiced due to the fa'aSamoa? Christianity has taken a unique Samoan or at least Pacific direction.

From the research, Samoan Christianity was represented by the interview participants in a way that was primarily orthodoxic. It was also backed up indirectly by survey participants with their identification as Christian but their low belief ranking. As the business owners described the practices that they went through with their business and their staff members while carrying a low level of belief themselves, shows that Christianity in Samoa has become primarily orthodoxic. My hypothesis from these findings is that Christianity in Samoa has taken on a uniquely spiritual form because of the influence that orthopraxic fa'aSamoa has had on religion.

This hypothesis can be backed up with two research findings:

1. The business owners go through the motions expected of them by Christianity without this practice necessarily being supported by their own strong beliefs.

2. Sundays are described as a day in which you have to go to church, followed by time spent with family, cooking and eating, which is the fa'aSamoa. 
It is also possible that the reverse has happened: the orthodoxy of Christianity has had an impact on the fa' 'aSamoa, making the traditional cultural emphasis on the belief in being Samoan, and upholding the cultural values, stronger. After living in Samoa for more than a year, I have seen the major emphasis on living and believing in the fa' 'aSamoa. However, as this research is not about the fa' 'aSamoa, I cannot prove that there is any correlation between these things when reversed in this way. To understand this, you would also need to gauge if fa'aSamoa was ever just orthopraxic (as I am deducing), you would then need to prove that it does emphasise belief now and that the spread of Christianity influenced that change.

The theory that $f a$ 'aSamoa has influenced Christianity solidifies the above analysis of the unavoidable saturation of religion in Samoa but takes this one step further. If we can accept that Christianity in Samoa has become orthopraxic through the influence of the fa'aSamoa then we should not view Christianity as being pervasive from a western framework. Instead, Christianity in Samoa has taken on a, unique form, 'Samoan Christianity,' and not in the way we might view Christianity in Australia or New Zealand. This form of Samoan Christianity allows business owners to fulfil the practical expectations of Samoan Christianity to meet the expectations of their society without needing to prioritise their own beliefs orthodoxically.

In presenting this theory, I will share Helsin's work again. Though a comment primarily on Catholicism, I believe it can be applied to all Christianity in Samoa:

"As we set out to tell the story of the growth of Catholicism within the fa'aSamoa, we can only narrate its historical beginning amidst a culture which was beginning to change colours under the influence of outside forces. Some of these outside forces were beginning to affect the traditional culture... Gradually the customs, habits and ways of life would disappear and be forgotten and be replaced by a Samoan interpretation of the "papalagi culture" for now by other cultures were being integrated by marriage, family influence and occupational opportunities, but most of all, by the influence of religion which entered into the very core of their way of life" (p. 1).

Heslin's writings from the mid-1990s are similar to what I have presented here. The intersection of the fa'aSamoa and the church has taken on a unique form making it 
impossible to talk about one without the other. Within business, this is also true. The business owners are observing their culture, which includes the requirements of Samoan Christianity as accepted practice and the cultural norm.

\subsection{Power}

As described in the literature Samoa has a structured hierarchy that exists in several different spheres; the fa'aMatai, the government and as described by the participants, the faife 'au and the church (Huffer and So'o, 2005; Thornton, Kerslake and Binns, 2010). The business owners described a power dynamic that oftentimes created conflict between these different silos of power and hierarchy. The role and scope of growth of these business owners rest heavily in their social setting. The government directly told one business that they could not intervene in the conflict with the village matai and another owner saying they had to take a faifa'eu to court for attempting to kick the village matai, including himself, from the village. These concrete examples show the delicate balance of power between the different institutions in the nation. Contending with these issues, especially for foreign owners, will make the growth of business increasingly difficult.

While the fa'Matai system is still very much intact, the church wields increasing soft power. Businesses find it very difficult to deny loans to their staff when they are needed for church payments; staff requiring them at any time results in a response from the business. This dynamic of unspoken soft power over the private sector is somewhat unexpected and shows the religiosity of the country and subsequently, the private sector. The approach to this is primarily negative but helping your family and community is an accepted norm and a source of pride, so this practice will likely continue for the foreseeable future. This notion ties heavily in Azmat's (2009) theory of small to medium enterprises (SMEs) in the developing world, where the impact of how they are perceived is influential on a business owner's behaviour. Where some of these business owners may refuse to give loans because of their own beliefs, others find it is more important to give the loans and fit within society than it is to act in accordance with their own beliefs.

The rising private sector is still in many ways, not the key player in their society. While they are subject to the power of the fa'aMatai and in this case, the church, they are 
also still at the whim of the government. The authority of the faife'au and the matai could have serious power over business, should they choose to wield it. Currently, the business owners interviewed reported a primarily enabling environment, with a few exceptions of specific cases. However, there is the ability of these sources of authority to change this environment.

\subsection{Conclusion}

The discussion shows a group of people who do not hold the primary view of the general population of Samoa when it comes to discussing religion. This population are not as religious as might be expected but go through the motions of organised religion in Samoa. This comes down to the development of "Samoan Christianity," an orthopraxic emphasis on Christianity as emphasised by the fa' 'aSamoa. The business owners demonstrate a high level of bonding, bridging and linking capital, but their spiritual capital does not insulate them from problems with theft from their religious staff members. The most widely demonstrated theory is that of Azmat (2009), who discussed how in developing economies business owners are heavily reliant on the perception of their communities. This theory explores the notion that a "not very religious' community of business owners felt pressured to create ample space for religion in their businesses to be perceived positively by the wider community who make up their customer base.

Overall, the business owners were not upset about the need to fulfil these practices. They felt that there were a number of positive things that came from the emphasis on religious and cultural practices. The business owners act as a safeguard against the growing pressure of capitalism and globalisation. They actively decided to prioritise Sundays and family over profit, which is unexpected for people who make their livelihood through business. 


\section{Conclusion}

\subsection{Summary of Research}

This thesis is a study of the role of religion in the formal private sector of Apia, Samoa. The research aimed to understand how religion impacts or affects business by understanding the perspectives of business owners. The study targeted formal businesses in the Apia Urban area. Thirty surveys and seven interviews were taken to inform the research. During the entire year of research and writing, I lived in Apia, which enabled a more holistic understanding of the topic and engagement with the research participants.

The research primarily looked at perceptions surrounding the role of religion. The questions sought insight regarding the participants own religiosity as well as that of those around them. It included questions about how positive or negative this role is, and the amount of input family and community have in the business. The study also 
asked more practical questions; about opening on Sundays, financial giving, where participants were born and if they had spent a significant portion of their lives outside of Samoa.

The case study of religion and business in Samoa fit mostly within the framework and previous research presented in the literature. However, the business owners themselves dissented more than Huffer and So'o (2005) suggested, but did fit within the frameworks of entrepreneurship in Azmat (2009) study of responsible entrepreneurship in developing countries.

Overall, the research presented participants who were generally practising Christians but with a lower rate of religiosity than the general population. There was a higher rate of Catholicism and a majority giving financial contributions to the church from their pockets and their businesses. The participants felt anger towards organised religion in Samoa, primarily due to the pressure being put on their staff members and therefore their businesses to make the financial contributions expected of them.

From a growth perspective, the financial expectation of the church in Samoa was detrimental to a business, as business owners either struggled to give loans or faced repercussion such as theft for not doing so. However, religion had a positive influence on business in Samoa as it provided a framework that allowed business owners to engage in their religious practices. But, more importantly, to spend time with their families and loved ones.

\subsection{Key Outcomes}

\section{2 a) Dominance Catholics in the Private Sector}

One of the main findings of the study was that Catholics dominate the formal private sector. $56 \%$ of respondents were Catholic, with the next closest denomination representing only $8 \%$ of the survey. In the general population, Catholics make up only $18 \%$ (Samoa Bureau of Statistics, 2016).

The domination of Catholics in the private sector is due to historical privileges that have existed since the arrival of the Marist Missionary Brothers. Those who were part of the Marist Church were given education, access to Credit Trade Unions and support from the government once they were alumni. At some points of history, it is estimated 
by Joseph Heslin (1995) that Marist Brothers educated up to $30 \%$ of the population. It is likely that this privilege has been handed down through families and that business owners today are the product of family capital accumulation, privileged knowledge networks and excellent bonding, bridging and linking social capital.

\section{2 b) Low Religiosity and Dissent towards Organised Religion}

The research population demonstrated rates of religion that were noticeably lesser than the rest of the population, $80 \%$ in contrast to $98 \%$. The participants also perceived themselves to be 'not very' religious and significantly less religious than their communities. The perception seemed to be that everyone was more religious than the participant, which led to a lack of discussion about religion in the business community.

There was a large amount of dissent against institutional religion, which came across as anger directed towards 'the church' and the faife 'au. This dissent was due to the large financial expectations of the church. In turn, they were flowing into the businesses through the demands of the staff members. Business owners felt particularly frustrated at staff members who would ask for numerous loans to meet their financial expectations. When denied these loans, staff members would often resort to stealing. The business owners felt that this was not how Christians should behave, and the demands were neither how a priest should behave, resulting in dissatisfaction with organised religion in Samoa. The criticisms being shared were those faced by society in general, such as generalised poverty which the participants felt could be pointed towards the financial expectations of the community and the church.

\section{2 c) Opening on Sundays}

Opening on Sundays was the most concrete intersection of religion and business, although it was also heavily cultural. The majority of business owners did not open on Sundays; those that did were primarily engaged in the tourism industry. Therefore, being unable to close in the case of hotels and resorts.

Business owners reported being generally positive about the general acceptance of closing on Sundays. Thus, they and their staff could have a day off to rest, go to church 
and spend time with their families. The business owners acknowledged that they would make more money if they opened on Sundays but felt that in this case, this was not a priority for them. The support for family time and the ability, primarily for staff, to attend church was important. It demonstrated the participant's prioritisation of Samoan culture and religion over the outside influences of capitalism and globalisation.

\section{2 d) 'Samoan Christianity'}

The findings through the behaviour, perceptions and discussions of the business owners suggested that Christianity in Samoa has taken on a unique form. In reference to the orthopraxic/orthodoxic theories of religion, Christianity has taken on a form of religiosity that is orthopraxic instead of the usual orthodoxy of Christianity. The research suggests that this is because the fa'aSamoa is orthopraxic and therefore, has influenced the way Christianity operates. The traditions of fa'aSamoa; to'ona' $i$ on Sundays and duty and care for you family have been fully integrated into Christian rituals. Meaning, Sundays are of utmost importance to Christianity and society as a whole.

Applying this lens allows for Christianity in Samoa to be viewed through the contextspecific idea of 'Samoan Christianity,' allowing space for what was demonstrated by the business owners as low identification of religiosity yet high participation in religious activities such as attending church or making financial contributions. This lens also provides the framework for the business owners to perceive low rates of religiosity while feeling that religion is generally positive in their lives. The practice being something that allows them to engage with their families and communities and having a positive role in their lives.

The idea 'Samoan Christianity' can also provide a future framework for any research conduction about religion in Samoa.

\subsection{Limitations}

\section{3 a) Gender}


Missing from this study was a focus on gender. A question on gender was not included for two reasons. The first was that due to the delicate nature of the research, questions regarding the business owners' personal attributes were avoided. Very few personal or identifying questions were asked to protect business owners from scrutiny and judgement. The second was that the unconscious bias of the research informed the idea that within a patriarchal society, business owners would overwhelmingly be men. In hindsight, and after the very welcome reception that I received by many business owners, this question would not have been controversial or invasive but was absent from the survey for these reasons.

Including gender in the research could have provided an interesting perspective on the role of business and the engagement in the church as women do not typically become faife 'au (with denominational differences) and are not largely represented in political or traditional positions of authority. The wider representation in the private sector is, therefore, quite interesting. This representation could be because the private sector has no traditional or cultural exclusion of women, within the private sphere individuals are not limited in their engagement.

\section{3 b) The Role of Chinese and Foreign Business Ownership in the Research}

In this survey, the population of people who refused to participate in the survey were the Chinese Business owners. Partially, because many of them do not speak English, the language of the survey, or because they refused to participate when approached. While this is means that the study does not provide a full snapshot of business in Samoa, it did mean that the results focused on the Samoan business owners and their perceptions. Which, allowed the study to engage in topics of culture and daily life more broadly, giving the study a richer, more holistic element.

However, in the future, as foreign and particularly Asian business grows in the Pacific, it would be important to make sure that this population is part of further research. Understanding and engaging with this community is important as their influence continues to grow and will likely shape the economic landscape of Pacific Island nations in the years to come.

\subsection{Directions for Future Research}




\section{4 a) Further Power Dynamics and Cultural Hierarchies in Business}

The underlying tone of the research is the presentation of a society that has three interconnected factors pulling and pushing throughout daily life and more broadly, the progress of the nation. The business owners could not talk about religion or their lives without talking about the fa' aMatai and the fa' 'aSamoa.

This research presents only one side. The other stakeholders, like the faife 'au, government representatives, and the community, need to be asked for their opinions. The setting of anonymous interviews with only business owners made it easy for the private sector to criticise the faife 'au. While there is pervasive disdain for the amount of money the faife 'au take from their congregations, the business owners still pay their staff members very little. Is it that the staff members cannot meet the demands of the church, or is it that the staff members are not paid enough? It would be interesting to extend this question, not only to the faife'au but to the government and general population. The measure could also be put to an economist to understand the broader implications of this financial giving to measures such as GDP and happiness indexes.

Further research could be done into the role of the matai titles within the businessowning communities. Some of the business owners did discuss their matai titles, but not all of them, especially as many of the business owners were women. What role does holding a matai title play in business in Samoa? Is it less significant in Apia than in more traditional villages? If you are a matai are you able to use your tradition source of authority for the benefit of your business?

\section{4 b) Quantification}

This research purposely did not include direct questions about the cost of religious activities on the business. Therefore, there is much scope to research the actual cost of staff loans and financial giving from business owners and their businesses. This additional research would inform a more direct study of the economic impact of religion on businesses in Apia. These studies would provide the cost to the business and explain the lack of business investment capital, particularly if the research can further explain the denominational differences in donation and tithing requirements. This study may also provide more explanation to the dominance of 
Catholics in the private sector, providing a snapshot into capital accumulation and give evidence to prove they are making fewer or smaller donations to the church.

\subsection{Development of Business in Apia}

Firstly, it is important for all stakeholders to realise that as the business owners are generally satisfied working within this intersecting framework of religion, culture and business, then development work, in particular, international organisations with differing perspectives should step back and allow for the private sector to grow naturally within this context.

However, the business owners of this research voiced serious complaints regarding the implications of the loans requested by their staff members. In answer to the final research question, the business owners felt that what needed to change, or the 'way forward' was to change the way that staff members interacted with money, their paychecks, the need for loans and the excessive financial giving.

These findings demonstrate that for business development in Apia, there should be financial literacy training. There is scope for development agencies to work alongside the private sector in funding and implementing financial literacy training for their staff members. While unexpected deaths in the family, damages to vehicles and other unfortunate surprises do happen, and frequently, if staff members are still asking for loans on an allegedly weekly basis, there is room for financial literacy training. Ensuring staff members understand loan policies and expectations, especially when they turn to loan sharks or banks with large interest rates, could reduce the actual amount of money leaving their pockets. Coupled with or even pre-empting a rise in the minimum wage, employers could ensure that increased wages are received by financially literate staff.

Businesses could provide support to this training through including the time taken in their weekly pay, providing work hours or venues for training. The impact of this could be measured through recorded loan requests or by noting the establishment of new bank accounts.

This project would also need to be teamed with a broader, cross-denominational, cross socio-economic move towards churches and families, reducing the financial demands 
of each other, including the churches and anyone who hosts weddings and funerals. This change requires far more significant attitude changes, and in my perspective, is not the work of development institutions. It involves community and society pulling together, to move towards a more equitable and manageable system. Which, encourages both financial stability and the maintenance of tradition. It would also involve the individuals who dissent against the church to engage in discussions about what a more equitable or 'moral' church might look like and then help create that environment for everyone.

On a broader level for all development projects, international governments and agencies which intend to offer to fund projects could spend more time to understand how best to engage with the church and the private sector as complicated, intersecting forces. James (2011), Ahdar (2013) and Thornton et al. (2012) discuss how the best way to reach the people is through the church, as the centre of grassroots development. Projects regarding the private sector and economic growth should consider the role of the church in possible projects as bridging capital, and community outreach can be a powerful tool for successful development.

\subsection{Conclusion}

This research has provided a baseline for understanding the role of religion in business in Apia. The business owners are a population of semi-religious Christians who support the active practice of religion within their businesses, and they support the continuation of cultural practices over the emphasis on capital accumulation. They are predominantly catholic due to historical factors that have allowed for the Catholic community to exist in a place of privilege in Samoan society. The business owners are unsupportive of formalised religion as it currently stands in Samoa and they hope that there will be change to a system that places crippling demands on their staff members which results in the expectations they will provide loans regularly. The business owners are concerned with morality and hope to own businesses are supportive of their staff members and community.

This research fits within broader literature surrounding religion, business and development and provides a working understanding of how to engage with businesses in Apia, Samoa. The business owners are happy to continue in a situation that allows 
them to engage in their spiritual side, which keeps them positive and engaged with their community. This research encourages development to engage with these ideas to understand a religious people who are willing to make economic compromises for spiritual gains.

\section{Reference List}

Ahdar, R. T. (2013). Samoa and the Christian State Ideal. International Journal for the Study of the Christian Church, 13(1), 59-72.

Ali, A. J. (2016). Global Capitalism and Developing Countries. Journal of Competitiveness Studies, 24(3), 102-106.

Alford, H., Clark, C. M. A., Cortright, S. A., \& Naughton, M. J. (2008). Rediscovering Adbundance; Interdisciplinary Essays on Wealth, Income, and Their Distribution in the Catholic Social Tradition. Religious Studies Review, 34(3), 181-182.

Antonio, R. J. (2013). Plundering the Commons: The Growth Imperative in Neoliberal Times. The Sociological Review, 61(2), 18-42. 
Australian Bureau of Statistics. (2016). Media Release, 2016 State Census. Retrieved from

http://www.abs.gov.au/AUSSTATS/abs@.nsf/mediareleasesbyReleaseDate/7E65A1 44540551D7CA258148000E2B85

Autiero, G. V., \& Paolo, C. (2016). Religion, Human Capital and Growth. International Journal of Social Economics, 43(1), 39-50.

Azmat, F., \& Samaratunge, R. (2009). Responsible Entrepreneurship in Developing Countries: Understanding the Realities and Complexities. Journal of Business Ethics, 90(3), 437-452.

Babb, S. (2013). The Washington Consensus as Transnational Policy Paradigm: Its Origins, Trajectory and Likely Successor, Review of International Political Economy, 20:2, 268-297.

Baker, B. (2015). Entrepreneurship as a Sign of Common Grace. Journal of Markets and Morality, 18(1), 81-98.

Bassiouny, N., Seoudi, I., Darrag, M., \& Zahran, N. (2015). CSR and Religiosity in a Developing Country Context: A Comparative Case Study Approach. African Journal of business and Economic Research, 10(2-3), 7-45.

Bayliss, K., Fine, B., \& Van aeyenberge, E. (2010) The Political Economy of Development: The World Bank, Neoliberalism and Development Research. London: Pulto Press.

Bull, B., \& Bøås, M. (2012) Between Ruptures and Continuity: Modernisation, Dependency and the Evolution of Development Theory, Forum for Development Studies, 39(3), 319-336.

Cahn, M. (2008). Indigenous entrepreneurship, culture and micro-enterprise in the Pacific Islands: Case Studies from Samoa. Entrepreneurship and Regional Development, 20(1), 1-18.

Central Bank of Samoa. (2018). Gross Private Remittances. Retrieved from https://www.cbs.gov.ws/index.php/statistics/tourism-earnings-and-remittance/

Chan, A. (2012). Contribution of Yazaki (Samoa) Ltd. to Samoan Economy. International Journal of Entrepreneurship and Small Business, 16(2), 189 - 198. 
Chari, M. D.R., \& Dixit, J. (2015). Business and entrepreneurship in developing countries after reforms. Journal of Business Research, 68, 1359-1366.

Choi, H. (2010). Religious Institutions and Ethnic Entrepreneurship: The Korean Ethnic Church as a Small Business Incubator. Economic Development Quarterly, 24(4), 372-383.

Cooper, A., Gimeno-Gascon, F., \& Woo, C.Y., (1994). Initial Human and Financial Capital as Predictors of New Venture Performance. Journal of Private Equity, 1(2), 13-30.

Dana, L. P. (1993) Environment for Entrepreneurship: A Model of Public Policy and Economic Development. Journal of Entrepreneurship, 2(1) 73-86.

Deneulin, S., \& Rakodi, C. (2011) Revisiting Religion: Development Studies Thirty Years On. World Development, 39(1) 45-54.

Douglas, E. J., \& Sherperd, D. A. (2002). Self-Employment as a Career Choice: Attitudes, Entrepreneurial Intentions, and Utility Maximization. Entrepreneurship Theory and Practice, 26(3), 81-90.

Elasrag, H. (2011). Principals of the Islamic Finance: A Focus on Project Finance. St. Louis: Federal Reserve Bank of St Louis.

Elliot, S., \& Yusuf, I. (2014). 'Yes, we can; but together': social capital and refugee resettlement. Kotuitui: New Zealand Journal of Social Sciences Online, 9(2), 101-110.

Erceg, N., Galić, Z., \& Bubić, A. (2018). The Psychology of Economic Attitudes Moral Foundations Predict Economic Attitudes beyond Socio-Demographic Variables. Croatian Economic Survey, 20(1), 7-70.

Fairbain, T. I. J. (1988). Island Entrepreneurs: Problems and Performances in the Pacific. Hawaii, University of Hawaii Press.

Farrelly, T., \& Nabobo-Baba, U. (2014). Talanoa as emphatic apprenticeship. Asia Pacific View Point, 55(3), 319-330.

Feagaimaali'i-Luamanu, J. (2017). Samoa bids farewell to Yazaki. Samoa Observer. Retrieved from http://www.samoaobserver.ws/en/26_08_2017/local/23599/Samoabids-farewell-to-Yazaki.htm . 
Feagaimaali'i-Luamanu, J. (2018). Taxing of church ministers to go ahead. Samoa Observer. Retrieved from http://www.samoaobserver.ws/en/01_08_2018/local/35517/Taxing-of-churchministers-to-go-ahead.htm

Fedotova, V A. (2017). Age-related difference in values and economic attitudes among Russians. Pyschology in Russia, 10(1), 105-116.

Gnegy, A. M., Wilson, A. J., Sementa, A., McWilliams, A., \& Helmer, C. (2011). Education and Entrepreneurship: Implications for Contemporary Microfinance. American Journal of Business Education, 4(11), 1-11.

Gore, C. (2000). The Rise and Fall of the Washington Consensus as a Paradigm for Developing Countries. World Development, 28(5), 789-804.

Guiso, L., Sapienza, P., \& Zingales, L. (2003). Peoples Opium? Religion and Economic Attitudes. Journal of Monetary Economics, 50(1), 225-282.

Halman, L., \& Müller, H. (2006) Contemporary Work Values in Africa and Europe: Comparing Orientations to Work in African and European Societies. International Journal of Comparative Sociology, 47(2), 117-143.

Hanushek, E. A. (2013). Economic Growth in Developing Countries: The Role of Human Capital. Economics of Education Review, 37, 204-212.

Hardin, J. (2016). Challenging Authority, Averting Risk, Creating Futures: Intersectionality in Interpreting Christian Ritual in Samoa. Journal of Contemporary Religion, 31(3), 379-391.

Hassan, R. (2017) Religion in the Global South. New York, Cham: Springer International Publishing.

Hopper, T., Lassou, P., \& Soobaroyen, T. (2017). Globalisation, accounting and developing countries. Critical Perspectives on Accounting, 43, 124-148.

Huffer, E., \& So’o, A. (2003). Consensus Versus Dissent: Democracy, Pluralism and Governance in Samoa. Asia Pacific Viewpoint, 44(3), 281-304. 
Hussain, M. (2018). Dichotomy of development aid's ambition and neoliberal imperatives: a case-study of private sector development in Bangladesh. Development Policy Review, 36, 803-814.

Isabel, A., \& Almeida, S. (2017). On the work values of entrepreneurs and nonentrepreneurs: a European Longitudinal Study. Journal of Developmental Entrepreneurship, 22(2), 1750010 - 1750039.

James, R. (2011). Handle with care: engaging with faith-based organisations in development. Development in Practice, 21(1), 109-117.

Khan, M. A. (2015). Putting 'Good Society' Ahead of Growth and/or 'Development': Overcoming Neoliberalism's Growth Trap and its Costly Consequences. Sustainable Development, 23(2), 65-73.

Khan, M. S., \& Reinhard, C. M. (1990) Private investment and economic growth in developing countries. World Development, 18(1), 19-27.

Kirchmaier, I., Prüfer, J., \& Trautmanna, S. T. (2018). Religion, moral attitudes and economic behavior. Journal of Economic Behavior and Organization, 148, 282-300.

Kristiansen, S. (2002). Individual perception of business contexts: The case of smallscale entrepreneurs in Tanzania. Journal of Developmental Entrepreneurship, 7(3), 283-304.

Larsen, L., Harlan, S. L., Bolin, B., Hackett, E. J., Hope, D., Kirby, A., Nelson, A., Rex, T. R., \& Wolf, S. (2004). Bonding and Bridging. Understanding the relationship between social capital and civic action. Journal of Planning Education and Research, 24(1), 64-77.

Laurin, K., \& Plaks, J. E. (2014). Religion and Punishment: Opposing Influences of Orthopraxy and Orthodoxy on Reactions to Unintentional Acts. Social Psychological and Personality Science, 5(7), 835-843.

Light, I., \& Dana, L., (2013) Boundaries of Social Capital in Entrepreneurship. Entrepreneurship Theory and Practice, 37, 603-624.

Ling, C., \& Dale, A. (2014). Agency and social capital: characteristics and dynamics. Community Development Journal, 49(1), 4-20. 
Macpherson, C., \& Macpherson, L. (2011). Churches and the Economy of Samoa. The Contemporary Pacific, 23(2), 304-337.

McBride, M. (2007). Club Mormon: Free-Riders, Monitoring, and Exclusion in the LDS Church. Rationality and Society, 19(4), 395-424. https://doi.org/10.1177/1043463107083736

McGuire, S. T., Omer, T. C., \& Sharp, N. Y. (2012). The Impact of religion on financial reporting irregularities. Accounting review, 87(2), 645-673.

Mele, D., \& Fontrodona, J. (2017). Christian Ethics and Spirituality in leading business organisations: Editorial Introduction. Journal of Business Ethics, 671-679.

Meleisea, M. (1987). The making of modern Samoa: Traditional authority and colonial administration in the history of Western Samoa. Fiji, University of the South Pacific.

Ministry of Finance. (2016). Strategy for the Development of Samoa 2016/172019/20. Samoa, Government of Samoa.

Naughton, M. J., \& Cornwall, J. R. (2006). The Virtue of courage in entrepreneurship: engaging the Catholic social Tradition and the life-cycle of the business. Business ethics Quarterly, 16(1), 69-94.

Neubert, M. J., Bradley, S. W. Ardianti, R., \& Simiyu, E. M. (2017). The Role of Spiritual Capital in Innovation and Performance: Evidence from Developing Economies. Entrepreneurship and Practice, 41(4), 621-640.

Pancorbo, A. (2012). Illustrating the need for dialogue between political Economy and Catholic Social Teaching. Journal of Markets \& Morality, 15(2), 329-346.

Peterson, M. J., \& Moigne, J. L. (2016). Donor Engagement with Religion and Faithbased organizations in Development Cooperation. The Ecumenical Review, 68(1), 387-397.

Radio New Zealand. (2002). Catholic Church in Samoa seeks more money from Parishioners. Radio New Zealand. Retrieved from 
https://www.radionz.co.nz/international/pacific-news/141071/catholic-church-insamoa-seeks-more-money-from-parishoners

Radio New Zealand. (2018). Liquor Board extends alcohol sales hours. Radio New $\begin{array}{lll}\text { Zealand. } & \text { Retrieved } & \text { from }\end{array}$ http://www.sobserver.ws/en/28_10_2018/local/37979/Liquor-Board-extendsalcohol-sales-hours.htm

Radio New Zealand. (2018). More Samoa Church ministers face charges over tax. Radio New Zealand. Retrieved from https://www.radionz.co.nz/international/pacificnews/376778/more-samoa-church-ministers-face-charges-over-tax.

Radio New Zealand. (2018). Samoa church body angry over tax on ministers. Radio New Zealand. Retrieved from https://www.radionz.co.nz/international/pacificnews/357938/samoa-church-body-angry-over-tax-on-ministers.

Ratten, V. (2014). Encouraging Collaborative Entrepreneurship in developing countries; the current challenges and a research agenda. Journal of Entrepreneurship in Emerging Economies, 6(3), 298-308.

Ravulo, J. (2016). Pacific epistemologies in professional social work, practice, policy and research. Asia Pacific Journal of Social Work and Development, 26(4), 191-202.

Renzulli, L. A., Aldrich, H. \& Moody, J. (2000). Family Matters: Gender Networks, and Entrepreneurial Outcomes. Social Forces, 79(2), 523-546.

Samoa Bureau of Statistics. (2016). Population and Housing Census. Retrieved from http://www.sbs.gov.ws/ .

Sangar, R. \& Rangnekar, S. (2014). Role Satisfaction and entrepreneurship. Journal of Entrepreneurship and Emerging Economies, 6(2), 122-139.

Sawrey, R., Waldegrave, C., Tamasese, T. K. \& Bush, A. (2011). After the earthquakes: immediate post-disaster work with children and families. New Zealand Journal of Psychology, 40(4), 48-60. 
Statistics New Zealand. (2013). 2013 State Census. Retrieved from http://nzdotstat.stats.govt.nz/wbos/Index.aspx?_ga=2.234478040.791300017.154620 2770-1093680707.1546202770\#

Sedgewick, P. (2013). Snowball Sampling. British Medical Journal (Online), 347, 12.

Siker, L. V. W. (1989). Christ and Business: A Typology for Christian Business Ethics. Journal of Business Ethics, 8(11), 883-888.

So'o, A. (2006). More Than 20 Years of Political Stability in Samoa under the Human Rights Protection Party. In Globalisation and Governance in the Pacific Islands, Australia: Australia National University, 2006.

Standifer, R. L., Evans, K. R., \& Dong, B. (2010). The Influence of Spirituality on Buyer Perception Within Business-to-Business Marketing Relationships: A CrossCultural Exploration and Comparison. Journal of Relationship Marketing, 9, 132-160.

Stokes, P., Baker, C., \& Lichy, J. (2016). The Role of Embedded Individual Values, Belief and Attitudes and Spiritual Capital in Shaping Everyday Post Secular Organizational Culture. European Management Review, 13, 37-51.

Taua'a, S. (2014). The Samoan Fa'amatai System: Social Protection and Governance Issues. The Journal of Pacific Studies, 34, 59-76.

Tecun, D. H. A., Hafoka, ‘i., 'ulu'ave, L., \& 'ulu’ave-Hafoka, M. (2018). Talanoa: Tongan Epistemology and Indigenous research method. AlterNative: An International Journal of Indigenous Peoples, 14(2), 156-163.

Theriault, S. M. (2014). The American Catholic Church as a Political Institution. The Forum, 11(4), 603-621.

Thornton, A., Binns, T., \& Kerslake, M. T. (2013). Hard times in Apia? Urban Landlessness and the church in Samoa." Singapore Journal of Tropical Geography, 34, 357-372.

Thornton, A., Kerslake, M. T., \& Binns, T. (2010). Alienation and Obligation: Religion and Social Change in Samoa. Asia Pacific Viewpoint, 51(1), 1-16. 
Thornton, A., Sakai, M., \& Hassall, G. (2012). Givers and Governance: The potential of faith-based development in the Asia Pacific. Development in Practice, 22(5), 779791.

The United Nations. (1990). Revitalizing Economic Growth in the Developing Countries. Population and Development Review, 16(2), 379-384.

The United Nations. (2014). Small Island Developing States Accelerated Modalities of Action Pathway. Samoa.

Vaioleti, T. (2014). Talanoa: Differentiating the Talanoa Research Methodology from Phenomenology, Narrative, Kaupapa Maori and Feminist Methodologies. Te Reo, 5657, 191-212.

Vaka, S., Brannelly, T., \& Huntington, A. (2016). Getting to the Heart of the Story: Using Talanoa to Explore Pacific Mental Health. Issues in Mental Health Nursing, $37(8), 537-544$.

Ver Beek, K. A. (2000). Spirituality: A Development Taboo. Development in Practice, 10(1), 31-43.

Yan, J., \& Sorenson, R. (2003). Collective Entrepreneurship in Family Firms: The Influence of Leader Attitudes and Behaviours. New England Journal of Entrepreneurship, 6(2), 37-51.

Zafar, S., \& Khan, I. (2014). A Study to Entrepreneurial Success with Respect to Gender, Education, Family Background, Self-Perceived Reasons for Success, and Culture. Journal of Asia Entrepreneurship and Sustainability, 10(2), 38-80. 


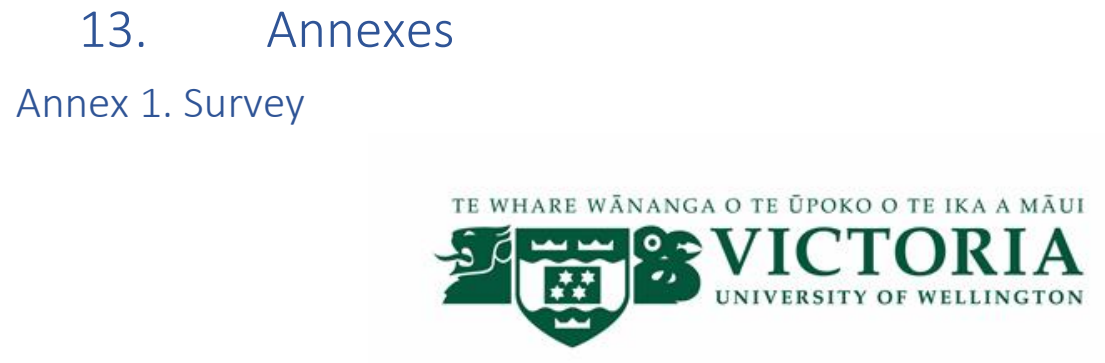

Business with God: The Role of Religion in Business in Apia, Samoa

Anonymous Survey

Please Circle

What is your business?

Bar/Club Restaurant Supermarket Shop Café Resort Import/Export Distribution Other

Do you have a religion?

Yes No

Are you a Christian? 
Yes No

What denomination do you belong to?

If no, what is your religion?

Were you born in Samoa?

Yes No

Have you spent more than 5 years of your life outside of Samoa?

Yes No

Do you open on Sundays?

Yes No

What are your opening hours?

I.e. Monday 10-6

Monday Tuesday Wednesday Thursday Friday Saturday Sunday

How many people does your business employ?

If you open on Sundays, do you allow staff members to opt out due to religious affiliation?

Yes No

Do you give money to the church?

Yes No

Does your business give money to the church?

Yes No

Do you give your staff loans/IOUs for religiously affiliated activities?

Yes No

Please Circle: 1 is not religious, 5 is very religious

How religious are you?

$\begin{array}{lllll}1 & 2 & 3 & 4 & 5\end{array}$

How religious is your family?

$\begin{array}{lllll}1 & 2 & 3 & 4 & 5\end{array}$ 
How religious is your community?

$\begin{array}{lllll}1 & 2 & 3 & 4 & 5\end{array}$

How religious do you think your business is?

$\begin{array}{lllll}1 & 2 & 3 & 4 & 5\end{array}$

How religious do you think business in Samoa generally?

$\begin{array}{lllll}1 & 2 & 3 & 4 & 5\end{array}$

How much influence does your family have over your business?

(A little) $1223 \quad 4 \quad 5$ (A lot)

How much influence does your community have over your business?

(A little) $1223 \quad 4 \quad 5$ (A lot)

If 1 negative and 5 is positive

What would you say the role of religion is in your life?

(Negative) $1223 \quad 4 \quad 5$ (Positive)

What would you say the role of religion is in your business?

(Negative) $12 \begin{array}{llll}3 & 4 & 5 \text { (Positive) }\end{array}$

What would you say the role of religion is in business in Samoa?

(Negative) $1223 \quad 45$ (Positive) 


\section{Business with God: The Role of Religion in Business in Apia, Samoa}

\section{Questions for semi structured interviews}

1. Tell me about your business?

2. Tell me about your relationship with the church?

3. Tell me about your relationship with religion?

4. In your life do you think church membership has had a positive impact? How/how not?

5. What about in your business? How/how not?

6. How do you think religious policies in Samoa interact or work with business?

7. What do you think the role of family has been in your business?

8. What do you think the role of community has been in your business?

9. What is the role of family in church?

10. What is the role of community in church? 
11. How does work and religion interact for your staff?

12. As a business owner does the religion of your staff have an impact? How so?

13. What ways do you think religion and business could interact differently?

14. How does religion work in Samoa generally?

15. How does business work in Samoa generally?

16. As business owner how do you view religion?

17. What are the commonly held views of religion from business owners generally?

18. Is there a law that relates to religion and business that you think could be amended or improved?

19. What role does religion play in Fa'aSamoa?

20. What role does Fa'aSamoa play in business?

21. What role does Fa'aSamoa play in your life? 
Annex 3. Samoa Bureau of Statistics Samoan Citizenship by Political District

Table 16: Percentage of Samoa citizenship by Political district, 2016

\begin{tabular}{|c|c|c|c|}
\hline Political District & Total & Samoa & $\%$ Samoa citizens \\
\hline Total & 195979 & 189035 & 96.5 \\
\hline Vaimauga West & 23527 & 21604 & 91.8 \\
\hline Faleata East & 13864 & 12888 & 93.0 \\
\hline Vaimauga East & 8151 & 7837 & 96.1 \\
\hline Faleata West & 22989 & 21691 & 94.4 \\
\hline Sagaga le Falefa & 12760 & 12174 & 95.4 \\
\hline Sagaga le Usoga & 6005 & 5896 & 98.2 \\
\hline Aana Alofi 1 & 6548 & 6456 & 98.6 \\
\hline Aana Alofi 2 & 3239 & 3154 & 97.4 \\
\hline Aana Alofi 3 & 6227 & 6109 & 98.1 \\
\hline Gagaemauga(part1) & 3457 & 3423 & 99.0 \\
\hline Safata & 6269 & 6190 & 98.7 \\
\hline Siumu & 2342 & 2280 & 97.4 \\
\hline Falelatai \& Samatau & 3192 & 3134 & 98.2 \\
\hline Lefaga \& Faleseela & 4059 & 3969 & 97.8 \\
\hline Aiga i le Tai & 5029 & 4964 & 98.7 \\
\hline Falealili & 4784 & 4705 & 98.3 \\
\hline Lotofaga & 1841 & 1820 & 98.9 \\
\hline Lepa & 1521 & 1484 & 97.6 \\
\hline Aleipata itupa i Luga & 1246 & 1213 & 97.4 \\
\hline Aleipata itupa i Lalo & 4188 & 4137 & 98.8 \\
\hline Anoamaa East & 4196 & 4085 & 97.4 \\
\hline Anoamaa West & 4993 & 4933 & 98.8 \\
\hline Vaa o Fonoti & 1621 & 1596 & 98.5 \\
\hline Gagaemauga(part2) & 371 & 357 & 96.2 \\
\hline Faasaleleaga 1 & 6328 & 6231 & 98.5 \\
\hline Faasaleleaga 2 & 2910 & 2839 & 97.6 \\
\hline Faasaleleaga 3 & 2787 & 2725 & 97.8 \\
\hline Faasaleleaga 4 & 1541 & 1511 & 98.1 \\
\hline Gagaemauga 1 & 1717 & 1698 & 98.9 \\
\hline Gagaemauga 2 & 600 & 593 & 98.8 \\
\hline Gagaemauga 3 & 1695 & 1675 & 98.8 \\
\hline Gagaifomauga 1 & 1387 & 1371 & 98.8 \\
\hline Gagaifomauga 2 & 2043 & 2018 & 98.8 \\
\hline Gagaifomauga 3 & 1448 & 1431 & 98.8 \\
\hline Vaisigano East & 2102 & 2079 & 98.9 \\
\hline Vaisigano West & 1599 & 1571 & 98.2 \\
\hline Falealupo & 1092 & 1066 & 97.6 \\
\hline Alataua West & 1750 & 1732 & 99.0 \\
\hline Salega & 3323 & 3285 & 98.9 \\
\hline Palauli West & 3334 & 3284 & 98.5 \\
\hline Palauli le Falefa & 3567 & 3535 & 99.1 \\
\hline Satupaitea & 1938 & 1930 & 99.6 \\
\hline Palauli East & 2399 & 2362 & 98.5 \\
\hline
\end{tabular}


Annex 4. Samoa Bureau of Statistics 2016 State Census

Table 17: Percentage of 6 denomination of churches by Political district, 2016

\begin{tabular}{|c|c|c|c|c|c|c|c|c|c|}
\hline Political District & Total & $\begin{array}{c}\text { EFKS/ } \\
\text { Congregation cCS }\end{array}$ & Methodist & $\begin{array}{l}\text { Roman Catholic } \\
\text { Church }\end{array}$ & $\begin{array}{l}\text { Latter Day } \\
\text { Saints }\end{array}$ & $\begin{array}{l}\text { Assembly of } \\
\text { God }\end{array}$ & $\begin{array}{l}\text { Seventh Day Adventist } \\
\text { (SDA \& SISDAC) }\end{array}$ & $\begin{array}{c}\text { Total of } 6 \\
\text { denomination }\end{array}$ & $\% 6$ denomination \\
\hline Total & 195979 & 56818 & 24228 & 36766 & 33077 & 13399 & 8534 & 172822 & 88 \\
\hline Vaimauga West & 23527 & 8755 & 1688 & 4715 & 2469 & 882 & 923 & 19432 & 83 \\
\hline Faleata East & 13864 & 2298 & 1384 & 4668 & 2683 & 498 & 471 & 12002 & \\
\hline Vaimauga East & 8151 & 3000 & 186 & 1517 & 1519 & 408 & 589 & 7219 & 89 \\
\hline Faleata West & 22989 & 5277 & 2783 & 4699 & 2683 & 2067 & 930 & 18439 & 80 \\
\hline Sagaga le Falefa & 12760 & 2753 & 1819 & 2570 & 2127 & 987 & 715 & 10971 & 86 \\
\hline Sagaga le Usoga & 6005 & 1754 & 500 & 1071 & 953 & 279 & 529 & 5086 & 85 \\
\hline Aana Alofi 1 & 6548 & 1120 & 630 & 567 & 1426 & 1184 & 361 & 5288 & 81 \\
\hline Aana Alofi 2 & 3239 & 916 & 209 & 1034 & 619 & 133 & 18 & 2929 & 90 \\
\hline Aana Alofi 3 & 6227 & 1748 & 946 & 664 & 934 & 696 & 552 & 5540 & 89 \\
\hline Gagaemauga(part1) & 3457 & 260 & 159 & 2206 & 275 & 14 & 162 & 3076 & 89 \\
\hline Safata & 6269 & 2386 & 940 & 810 & 1361 & 527 & 160 & 6184 & 99 \\
\hline Siumu & 2342 & 423 & 200 & 307 & 707 & 192 & 115 & 1944 & 83 \\
\hline Falelatai \& Samatau & 3192 & 1231 & 53 & 700 & 281 & 185 & 184 & 2634 & 83 \\
\hline $\begin{array}{l}\text { Lefaga \& Faleseela } \\
\text { Aiga ile Tai }\end{array}$ & $\begin{array}{l}4059 \\
5529\end{array}$ & 1578 & ${ }^{223}$ & 722 & 685 & 258 & 93 & 3559 & 88 \\
\hline $\begin{array}{l}\text { |ligaile Tai } \\
\text { Falealiti }\end{array}$ & 5029 & 1966 & 899 & 885 & 939 & $\begin{array}{r}48 \\
339\end{array}$ & 38 & 4775 & 95 \\
\hline Lotofaga & 1841 & ${ }_{786}^{1997}$ & $\begin{array}{l}445 \\
17\end{array}$ & $\begin{aligned} 257 \\
520\end{aligned}$ & 1290 & 392 & 191 & 4542 & 95 \\
\hline Lepa & 1521 & 824 & 2 & $\begin{array}{l}520 \\
95\end{array}$ & 297 & 199 & 48 & $181{ }^{10}$ & 99 \\
\hline Aleipata itupa i Luga & 1246 & 794 & 293 & ${ }_{20}-10-1$ & 44 & 35 & $\begin{array}{l}108 \\
59\end{array}$ & 1438 & 95 \\
\hline Aleipata itupa i Lalo & 4188 & 602 & 401 & 1423 & 906 & 679 & 43 & ${ }_{4054}^{1245}$ & $\begin{array}{l}100 \\
97-3 x\end{array}$ \\
\hline Anoamaa East & 4196 & 1561 & 481 & 875 & 784 & 155 & 126 & 3982 & 95 \\
\hline Anoamaa West & 4993 & 1720 & 328 & 882 & 1046 & 222 & 283 & 4481 & 90 \\
\hline Vaa o Fonoti & 1621 & 560 & 84 & 410 & 403 & 109 & 14 & 1580 & 97 \\
\hline Gagaemauga(part2) & 371 & 0 & 295 & 0 & 0 & 54 & 0 & 349 & 94 \\
\hline Faasaleleaga 1 & 6328 & 1439 & 1539 & 713 & 996 & 722 & 380 & 5789 & 91 \\
\hline Faasaleleaga 2 & 2910 & 1288 & 8 & 367 & 785 & 213 & 46 & 2707 & 93 \\
\hline Faasaleleaga 3 & 2787 & 1098 & 16 & 143 & 797 & 54 & 280 & 2388 & 86 \\
\hline Faasaleleaga 4 & 1541 & 420 & 57 & 300 & 399 & 162 & 118 & 1456 & 94 \\
\hline Gagaemauga 1 & 1717 & 346 & 11 & 588 & 432 & 117 & 119 & 1613 & 94 \\
\hline Gagaemauga 2 & 600 & 168 & 182 & 33 & 143 & 59 & 0 & 585 & 98 \\
\hline Gagaemauga 3 & 1695 & 700 & 175 & 115 & 312 & 76 & 77 & 1455 & 86 \\
\hline Gagaiffomauga 1 & 1387 & 224 & 370 & 641 & 148 & 0 & 0 & 1383 & 100 \\
\hline Gagaifomauga 2 & 2043 & 1002 & 274 & 201 & 291 & 200 & 61 & 2029 & 99 \\
\hline Gagaifomauga 3 & 1448 & 747 & 289 & 57 & 29 & 205 & 41 & 1368 & 94 \\
\hline Vaisigano East & 2102 & 744 & 527 & 217 & 299 & 48 & 162 & 1997 & 95 \\
\hline Vaisigano West & 1599 & 467 & 163 & 458 & 241 & 127 & 6 & 1462 & 91 \\
\hline Falealupo & 1092 & 245 & 3 & 400 & 111 & 8 & 27 & 794 & 73 \\
\hline Alataua West & 1750 & 89 & 740 & 89 & 553 & 94 & 2 & 1567 & 90 \\
\hline salega & 3323 & 457 & 1311 & 41 & 731 & 365 & 103 & 3008 & 91 \\
\hline Palauli West & 3334 & 925 & 1110 & 255 & 387 & 329 & 207 & 3213 & 96 \\
\hline Palauli le Falefa & 3567 & 1148 & 1288 & 101 & 683 & 107 & 114 & 3441 & 96 \\
\hline satupaitea & 1938 & 3 & 1212 & 7 & 384 & 82 & 78 & 1766 & 91 \\
\hline Palauli East & & & & 423 & 678 & 116 & & 2235 & \\
\hline
\end{tabular}




\begin{tabular}{|c|c|c|c|c|c|c|c|c|c|c|c|c|c|c|c|c|c|c|c|c|}
\hline & Score & A & B & C & D & $E$ & $F$ & G & H & I & $\mathbf{J}$ & K & $\mathbf{L}$ & $\mathbf{M}$ & $\mathbf{N}$ & 0 & $\mathbf{P}$ & $\mathbf{Q}$ & $\mathbf{R}$ & s \\
\hline Yes & 1 & 24 & 23 & 17 & 29 & 8 & 7 & 20 & 16 & 20 & & & & & & & & & & \\
\hline No & 2 & 6 & 7 & 13 & 1 & 22 & 4 & 9 & 14 & 10 & & & & & & & & & & \\
\hline Low & 1 & & & & & & & & & & 5 & 6 & 2 & 10 & 0 & 9 & 8 & 5 & 3 & 2 \\
\hline Low/Medium & 2 & & & & & & & & & & 10 & 5 & 5 & 3 & 2 & 5 & 8 & 1 & 4 & 4 \\
\hline Medium & 3 & & & & & & & & & & 7 & 8 & 7 & 13 & 15 & 2 & 5 & 9 & 13 & 13 \\
\hline Medium/High & 4 & & & & & & & & & & 3 & 4 & 3 & 2 & 8 & 3 & 7 & 4 & 5 & 6 \\
\hline High & 5 & & & & & & & & & & 5 & 7 & 11 & 2 & 4 & 11 & 2 & 11 & 5 & 5 \\
\hline N/A & N/A & 0 & 0 & 0 & & 0 & & 1 & & & 0 & 0 & 2 & 0 & 1 & 0 & 0 & 0 & 0 & 0 \\
\hline Count Total & & 30 & 30 & 30 & 30 & 30 & 11 & 30 & 30 & 30 & 30 & 30 & 30 & 30 & 30 & 30 & 30 & 30 & 30 & 30 \\
\hline Yes & & $80 \%$ & $77 \%$ & $57 \%$ & $97 \%$ & $27 \%$ & $64 \%$ & $67 \%$ & $53 \%$ & $67 \%$ & & & & & & & & & & \\
\hline No & & $20 \%$ & $23 \%$ & $43 \%$ & $3 \%$ & $73 \%$ & $36 \%$ & $30 \%$ & $47 \%$ & $33 \%$ & & & & & & & & & & \\
\hline Average & & & & & & & & & & & 2.8 & 3.0 & 3.6 & 2.4 & 3.5 & 3.1 & 2.6 & 3.5 & 3.2 & 3.3 \\
\hline
\end{tabular}

A- Are you religious?

B- Are you Christian?

C- Were you born in Samoa?

D- Do you open on Sundays?

E- Do you give money to the church?

F- How religious are you?

G- How religious is your family?

$\mathrm{H}-$ How religious is your community?

I- How religious do you think your business is?

J- How religious do you think business in Samoa is generally?

K- How much influence does your family have over your business?

L- How much influence does your community have over you business?

M- What would you say the role of religion is in your life?

$\mathrm{N}$ - What would you say the role of religion is in your business?

O- What would you say the role of religion is in Samoa? 